\title{
Cross Talk: The Microbiota and Neurodevelopmental Disorders
}

\author{
John R. Kelly, ${ }^{1,2}$, Chiara Minuto ${ }^{1,2}$, John F. Cryan ${ }^{2,3}$, Gerard Clarke ${ }^{1,2}$ and \\ Timothy G. Dinan ${ }^{1,2 *}$
}

${ }^{1}$ Department of Psychiatry and Neurobehavioural Science, University College Cork, Cork, Ireland, ${ }^{2}$ APC Microbiome Institute, University College Cork, Cork, Ireland, ${ }^{3}$ Department of Anatomy and Neuroscience, University College Cork, Cork, Ireland

\section{OPEN ACCESS}

Edited by:

Antonio Benítez-Burraco, University of Huelva, Spain

Reviewed by:

Andreas Martin Grabrucker, University of Limerick, Ireland

Aaron Conrad Ericsson,

University of Missouri, United States

*Correspondence:

Timothy G. Dinan

t.dinan@ucc.ie

Specialty section:

This article was submitted to

Social and Evolutionary Neuroscience,

a section of the journal

Frontiers in Neuroscience

Received: 31 May 2017

Accepted: 17 August 2017

Published: 15 September 2017

Citation:

Kelly JR, Minuto C, Cryan JF, Clarke G and Dinan TG (2017) Cross Talk: The Microbiota and Neurodevelopmental Disorders. Front. Neurosci. 11:490. doi: 10.3389/fnins.2017.00490
Humans evolved within a microbial ecosystem resulting in an interlinked physiology. The gut microbiota can signal to the brain via the immune system, the vagus nerve or other host-microbe interactions facilitated by gut hormones, regulation of tryptophan metabolism and microbial metabolites such as short chain fatty acids (SCFA), to influence brain development, function and behavior. Emerging evidence suggests that the gut microbiota may play a role in shaping cognitive networks encompassing emotional and social domains in neurodevelopmental disorders. Drawing upon pre-clinical and clinical evidence, we review the potential role of the gut microbiota in the origins and development of social and emotional domains related to Autism spectrum disorders (ASD) and schizophrenia. Small preliminary clinical studies have demonstrated gut microbiota alterations in both ASD and schizophrenia compared to healthy controls. However, we await the further development of mechanistic insights, together with large scale longitudinal clinical trials, that encompass a systems level dimensional approach, to investigate whether promising pre-clinical and initial clinical findings lead to clinical relevance.

Keywords: microbiota, microbiome, gut-brain axis, immune system, social cognition, autism, schizophrenia, psychobiotics

\section{INTRODUCTION}

From an evolutionary-based perspective, the host and its microbiome evolved as a cooperative unit (Rosenberg et al., 2007; Zilber-Rosenberg and Rosenberg, 2008; Martin et al., 2015; Douglas and Werren, 2016). All stages in the evolution of the human brain occurred within this microbial ecosystem (McFall-Ngai et al., 2013; Bordenstein and Theis, 2015). The predominant theory to account for the evolution of the enlargement of the human brain implicates social interaction. Brain areas such as the prefrontal cortex and the amygdala have undergone pronounced changes in the evolution of social mammals (Kolb et al., 2012; Janak and Tye, 2015). Brains of social species exhibit a set of features that need to integrate for group living to become advantageous, and the development of the complex neural circuitry underlying social and emotional cognition is of fundamental importance to neurodevelopmental disorders, such as ASD and schizophrenia (Adolphs, 2001; Lederbogen et al., 2011; Janak and Tye, 2015; Averbeck and Costa, 2017).

Neurodevelopment requires the intricate interplay of genetic expression, influenced by pre-and post-natal environmental events. Critical periods or "windows" of brain development exist, during which time neural circuits are particularly sensitive to, and require, the influence of appropriate environmental inputs, in order to develop properly. Human brain development begins in the third gestational week (Stiles and Jernigan, 2010) and at time of birth approximately 86 billion neurons 
(Azevedo et al., 2009) with up to 100 trillion connections are produced. These connections form simple circuits, and when reinforced through repeated use, under the influence of environmental cues, form more complex interconnected circuits, leading to complex networks (Bassett and Sporns, 2017). The developmental trajectory of social, emotional and cognitive brain domains occur in parallel, though social cognition may be linked to certain specific subnetworks (Dunbar, 2012; Sliwa and Freiwald, 2017).

The development of this neural circuitry requires precise regulation from molecular signaling pathways. Hormones, such as oxytocin (Kirsch et al., 2005), neurotransmitters, such as serotonin (Whitaker-Azmitia, 2001), and the immune system (Bilbo et al., 2012), all play pivotal roles in sculpting the neural circuitry underlying social cognition, emotion and behavior. Many of the brain regions involved and the molecular substrates subserving relevant functions are also responsive to microbiome-gut-brain axis signaling (Clarke et al., 2013; Semple et al., 2013; Montiel et al., 2014; Dinan et al., 2015; Erny et al., 2015; Buffington et al., 2016; Vuong and Hsiao, 2017) Figure 1.

The trajectory of early post-natal brain development overlaps with the acquisition and reorganization of the gut microbiota (Borre et al., 2014; Chu et al., 2017). The gut microbiota in the initial days of life is unstable and of low diversity (Arrieta et al., 2014). By age three, a stage by which verbal communication and Theory of Mind develops (the ability to infer and reason about the intentions, emotions and thoughts of others) (Grosse Wiesmann et al., 2017), the gut microbiota composition stabilizes into a pattern that more resembles an adult-like profile (Voreades et al., 2014). These social, cognitive and emotional domains, and their neurodevelopment, are compromised in neurodevelopmental disorders, such as ASD and schizophrenia. Deciphering the gut microbiota compositional trajectories and profiles, corresponding metabolic output and precise signaling pathways that play a pertinent role in molding the neural circuitry underlying the social-communicative domains of the brain, is one of the great challenges of modern neuroscience (Chen et al., 2013; Mayer et al., 2014a; Dinan and Cryan, 2017; Sherwin et al., 2017).

\section{AUTISM SPECTRUM DISORDERS (ASD)}

ASD is a heterogeneous neurodevelopmental disorder, affecting approximately 1 in 68 children (Christensen et al., 2016). It is characterized by deficits in social communication, social interaction and restricted/repetitive behavioral patterns. The processing of emotional stimuli, be it language or facial expressions is impaired in individuals with ASD (Dalton et al., 2005; Preissler and Carey, 2005; Monk et al., 2010; Lartseva et al., 2014; Neuhaus et al., 2016; Wang and Adolphs, 2017). Therefore, deficits in social communication, together with emotional processing, and a lack of social interest in communication can result in language delay, and a proportion of children at the severe end of the spectrum will not develop language abilities (Landry and Loveland, 1988).
The heritability of ASD is estimated at between 64 and 91\% (Tick et al., 2016), and genes that encode proteins for synaptic formation, microglial function, transcriptional regulation and chromatin-remodeling pathways are implicated (De Rubeis et al., 2014; Parikshak et al., 2016). New mutations contribute to the risk, and a recent large scale study, showed that approximately one third of spontaneous, non-inherited genetic mutations found in people with ASD were also found in the general population (Kosmicki et al., 2017). A recent study suggests that those ASD children with de novo mutations show relative strengths in verbal and language abilities, including a smaller discrepancy between non-verbal and verbal IQ and a greater likelihood of having achieved fluent language, relative to those with no identified genetic abnormalities (Bishop et al., 2017). Taken together, these genetic studies in ASD highlight the neurodiversity of the disorder (Baron-Cohen, 2017; Vorstman et al., 2017; Yuen et al., 2017).

The origins of ASD are likely to occur during the prenatal timeframe, a time window during which important connections are formed (Willsey et al., 2013). A study, using a highresolution transcriptional atlas in primates, showed that many ASD-related genes are activated in new-born neurons during prenatal development, while schizophrenia related genes are activated from infancy through adulthood (Bakken et al., 2016). Maternal infections during pregnancy are associated with the development of neurodevelopmental disorders (Atladottir et al., 2010; Jiang et al., 2016; Careaga et al., 2017). Certain subtypes of ASD are associated with increased levels of maternal peripheral chemokines and cytokines during gestation (Goines et al., 2011; Jones et al., 2017; Graham et al., in press). Moreover, subgroups of children diagnosed with ASD have elevated levels of peripheral cytokines (Ashwood et al., 2011), and microglial activation in young adults with ASD has been demonstrated using positron emission tomography (PET) imaging (Suzuki et al., 2013). Progress is being made in diagnosing infants at high risk of developing ASD, by utilizing imaging techniques such as fMRI (Hazlett et al., 2017; Shen et al., 2017). A recent structural and diffusion MRI study of 3 year old infants diagnosed with Neurodevelopmental Disorders (32 ASD and 16 other developmental disorders, including intellectual disability and language disorder) reported an over-connectivity pattern in ASD in networks primarily involving the fronto-temporal nodes, known to be crucial for social-skill development (Conti et al., 2017).

Risk factors such as advanced parental age (Durkin et al., 2008; Sandin et al., 2016), low birth weight (Schendel and Bhasin, 2008) and multiple births (Croen et al., 2002) have been identified, while others such as mode of birth have been advanced. However, epidemiological data suggests that C-section mode of delivery, currently far in excess of WHO recommendations (WHO, 2015) and known to alter microbiome signatures (see below), is associated only with a slightly increased risk of ASD and that this may be due to familial confounds (Curran et al., 2014, 2015, 2016; O’Neill et al., 2015). Identifying additional modifiable environmental factors that play a causal role in ASD, particularly during the prenatal and early post-natal period, is of vital importance. 


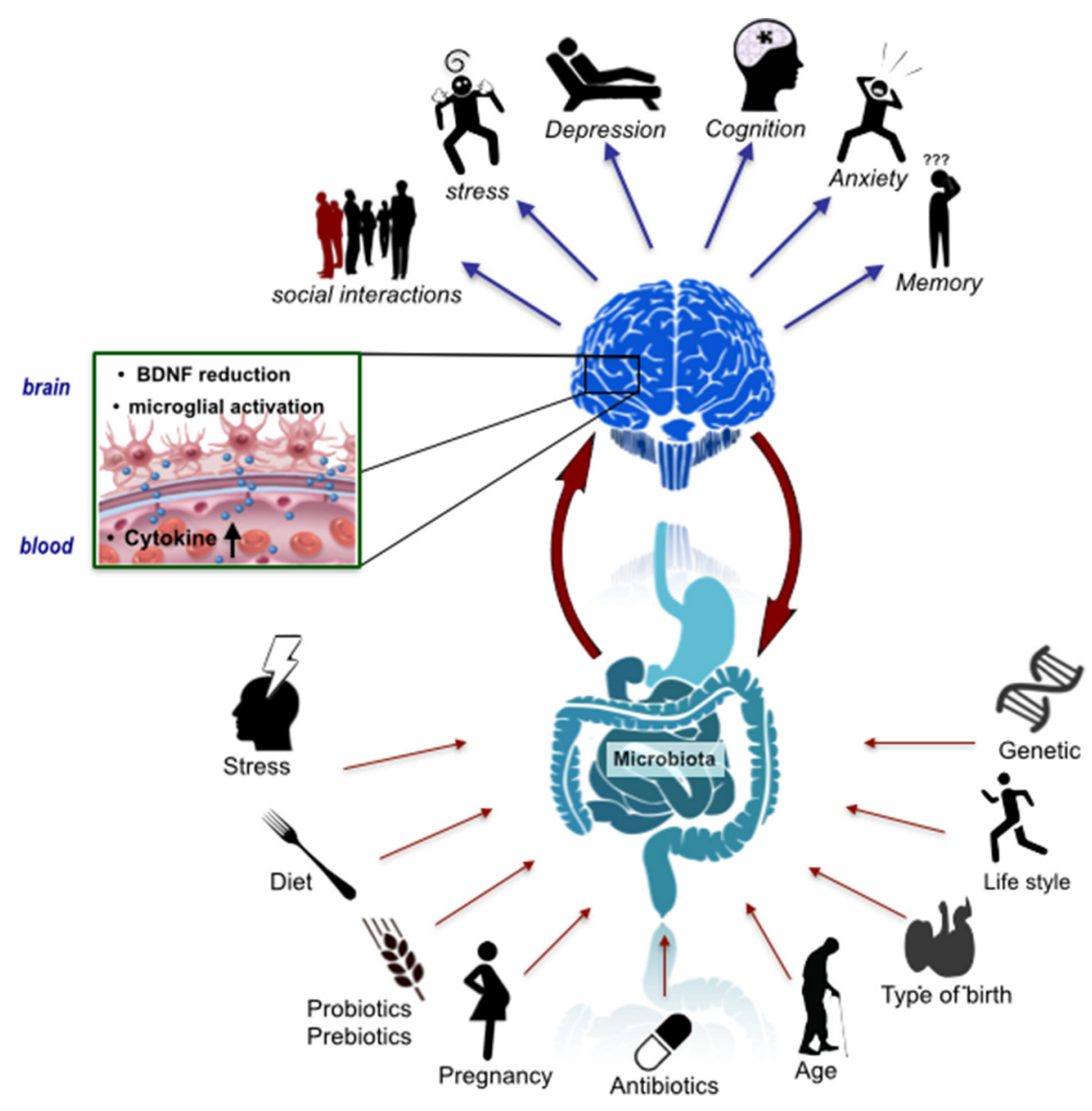

FIGURE 1 | The microbiome-gut-brain axis in psychiatry. A number of factors have an influence on the assembly, composition and stability of the gut microbiota including mode of birth, lifestyle factors such as diet and exercise, and stress. These factors could thus impact signaling along the microbiome-gut-brain axis, which has been implicated in a variety of behavioral features relevant to schizophrenia and autism including anxiety and cognition. This impact may be underpinned by microbial regulation of the host immune system, CNS BDNF expression and microglial activation states.

\section{SCHIZOPHRENIA SPECTRUM DISORDERS (SSD)}

Schizophrenia is a heterogeneous neurodevelopmental disorder, with a general population lifetime prevalence of approximately $0.87 \%$ (Perala et al., 2007), and an annual incidence of approximately 0.20/1,000/year (Messias et al., 2007). There is a slightly greater risk for males (Aleman et al., 2003) and psychotic symptoms usually manifest clinically during the adolescent period. This disorder can have a major detrimental impact on functioning, and is associated with a reduced life expectancy (Laursen et al., 2014; Schoenbaum et al., 2017; Strati et al., 2017) and a suicide rate of 5\% (Hor and Taylor, 2010). schizophrenia is classically characterized by positive (delusions, hallucinations), negative (affective flattening, alogia, and avolition), and cognitive symptoms (Aleman et al., 1999; Kahn and Keefe, 2013; Schaefer et al., 2013). Social interaction and communication deficiencies, including disorganized speech, can be prominent, even early in the course of this disorder
(Sullivan et al., 2003; Roche et al., 2016; Morgan et al., 2017).

Similar to ASD, the precise cause of schizophrenia is unknown. A complex and dynamic bidirectional interaction of genomic and environmental factors converge to shape the trajectory of schizophrenia (O'Tuathaigh et al., 2017). Prenatal and early post-natal environmental factors sensitize the vulnerable brain. Although psychotic symptoms usually manifest during the adolescent period, it has been established that schizophrenia is associated with poor premorbid functioning, cognitive impairment, and social deficits prior to the onset of psychotic symptoms (Schenkel and Silverstein, 2004). Indeed, previously considered distinct forms of psychopathology may in fact have characteristics in common, and exhibit age adjusted variations of common underlying dispositions (Casey et al., 2014; Hommer and Swedo, 2015).

The immune system is an important player in the pathophysiology of schizophrenia (Benros et al., 2012; Feigenson et al., 2014; Muller, 2014). At the genetic level, genes related to 
B-lymphocyte lineages involved in acquired immunity (CD19 and CD20 lines) and major histocompatibility complex locus have been linked to schizophrenia (Corvin and Morris, 2014; Schizophrenia Working Group of the Psychiatric Genomics Consortium., 2014). A recent translational study implicated excessive complement activity, particularly the role of $\mathrm{C} 4$ in mediating synapse elimination during post-natal development (Sekar et al., 2016). Neuro-immune signaling also changes during the adolescent period, regulating changes in synaptic pruning, neurite outgrowth, and neurotransmitter release via Blood Brain Barrier (BBB) dynamics and glial activity (Brenhouse and Schwarz, 2016). It is established that subgroups of patients with schizophrenia have elevated levels of peripheral cytokines, including subgroups of medication free first-episode psychosis individuals (Miller et al., 2011; Di Nicola et al., 2013; de Witte et al., 2014; Upthegrove et al., 2014). There is also some suggestion, though not well established, that schizophrenia is associated with altered intestinal (Severance et al., 2013) and blood brain barrier function (Pollak et al., 2017). This, taken together with altered microglial activation in psychosis patients (Bloomfield et al., 2016), highlights the key role of the immune system, in at least subgroups of individuals with psychosis (Al-Diwani et al., 2017).

Infections at different stages of brain development result in varying degrees of lifelong changes in behavior and cognition (Spencer and Meyer, 2017). Certain infections are known to increase the risk of schizophrenia (Meyer et al., 2009; Brown, 2012). A large epidemiological study ( $n=1,015,447)$, showed that treatment with anti-infective agents (primarily driven by infections treated with antibiotics), were associated with an increased risk of schizophrenia by a hazard rate ratio of 1.37 (Kohler et al., 2017). However, an earlier study found an increased risk for mood and anxiety disorders for antibiotic exposure, but no change in risk for psychosis with any antibiotic group (Lurie et al., 2015). An infection with a robust link to psychosis is the protozoan Toxoplasma gondii (Torrey and Yolken, 2003; Severance et al., 2016b). A meta-analysis of 16 studies demonstrated increased T. gondii IgM levels in patients with acute psychosis (Monroe et al., 2015). The mechanism is not completely understood, but a putative role of attenuated CD8 $\mathrm{T}$-cell response in $T$. gondii seropositive individuals has been suggested (Bhadra et al., 2013). It is known that T. gondii induces the production of a variety of cytokines by microglia, astrocytes, and neurons (Carruthers and Suzuki, 2007). Monocytes and dendritic cells are the most important candidates for the transport of T. gondii from the periphery to the immunologically privileged sites of the brain (Feustel et al., 2012).

Indeed, latent $T$. gondii infection is associated with an upregulation of cerebral complement factor $\mathrm{Clq}$ (Xiao et al., 2016). Furthermore, T. gondii infection can alter dopamine metabolism (Prandovszky et al., 2011) and latent T. gondii is associated with reduced psychomotor performance (Havlicek et al., 2001). More recently, T. gondii has been shown to lead to deficits in goal-directed behavior in healthy elderly individuals (Beste et al., 2014). Interestingly, acute T. gondii infection can affect the gut microbiota in mice (Molloy et al., 2013). Although only a minor subset of $T$. gondii seropositive individuals develop serious mental impairments, taken together, the example of $T$. gondii, suggests that microbial agents contribute to the vulnerability to the development of subgroups of schizophrenia (Yolken and Torrey, 2008). Although we have focussed on T. gondii, it is noteworthy that other infections, such as Human Herpesvirus 2, Borna Disease Virus Human Endogenous Retrovirus W, Chlamydophila pneumoniae, and Chlamydophila psittaci are also associated with the disorder (Arias et al., 2012). It remains an open question whether there is a common mechanism through which these microbes exert their influence, albeit, that one shared general feature in most examples cited is an intracellular life stage.

Interestingly, urbanicity, known to affect microbial diversity and impact the overall functionality of the gut microbiome (Mancabelli et al., 2017), is also a risk factor for the development of schizophrenia (Pedersen and Mortensen, 2001; Krabbendam and van Os, 2005; Peen et al., 2010; Vassos et al., 2012; Newbury et al., 2016). In healthy individuals, a negative correlation was found between early-life urbanicity and gray matter volume in the right dorsolateral prefrontal cortex in males and females, and in perigenual anterior cingulate cortex volumes, a key region for regulation of amygdala, in men only (Haddad et al., 2015). Using fMRI, city living was associated with increased amygdala activity (Lederbogen et al., 2011), known to be associated with schizophrenia (Aleman and Kahn, 2005; Rasetti et al., 2009). Stamper and colleagues postulate that differential exposure to microbes in the urban compared to the rural environment interact with differences in social stressors to alter social stress neural circuitry (Stamper et al., 2016).

\section{ASD AND MICROBIOTA}

GI symptoms are a common comorbidity in ASD (Molloy and Manning-Courtney, 2003; Buie et al., 2010; Berding and Donovan, 2016). However, the underlying mechanism is not fully known (Mayer et al., 2014b). The vast majority of human studies show that ASD is associated with altered microbial profiles (see Table 1). A systematic review of gut microbiota alterations in ASD, verified alterations in gut microbiota, but highlighted the heterogeneity of findings, and the limited quantity and quality of studies (Cao et al., 2013). Studies investigating ASD, the gut microbiota and SCFAs, showed significantly higher levels of Desulfovibrio species and Bacteroides vulgatus and higher levels of SCFA's in the stools of autistic children compared to controls (Finegold et al., 2010; Wang et al., 2012). Clostridium Bolteae, another species that is reported to be over-represented in the gut microbiota in ASD, and its capsular polysaccharide consisting of rhamnose and mannose units, has been proposed as a viable potential vaccine to reduce $C$. bolteae colonization of the intestinal tract in autistic patients (Pequegnat et al., 2013).

Most studies conducted in ASD are non-interventional, and many do not adequately record detailed dietary information or medication use. Indeed, it is well established that ASD is highly associated with atypical eating patterns (Cermak et al., 2010). The interventional studies are few, and of small sample size. An open labeled trial $(n=11)$, with no control group, 
TABLE 1 | Microbiota and ASD clinical studies.

\begin{tabular}{|c|c|c|c|c|}
\hline Design & Diagnosis, N, Age & Measures & Results & References \\
\hline $\begin{array}{l}\text { Antibiotic-12-week } \\
\text { trial of open label oral } \\
\text { vancomycin }\end{array}$ & $\begin{array}{l}\text { ASD, regressive-onset } \\
\text { autism }(n=11) \\
\text { Age ( } 43-84 \text { months) } \\
\text { No control group }\end{array}$ & $\begin{array}{l}\text { Childhood Autism Rating Scale } \\
\text { Developmental Profile II } \\
\text { Coded, paired videotapes scored by a clinical } \\
\text { psychologist blinded to treatment status }\end{array}$ & $\begin{array}{l}\text { Behavioral improvement } \\
\text { Improvement at follow-up (2-8 } \\
\text { months)-not sustained }\end{array}$ & Sandler et al., 2000 \\
\hline $\begin{array}{l}\text { FMT- } 18 \text { weeks in } \\
\text { total; } 10 \text { week open } \\
\text { label and } 8 \text { week } \\
\text { follow-up }\end{array}$ & $\begin{array}{l}\text { ASD }(n=18) \\
\text { Age }(7-16 \text { years }) \\
\text { Controls }(n=20) \\
\text { Age and Gender matched }\end{array}$ & $\begin{array}{l}\text { Gastrointestinal Symptom Rating Scale } \\
\text { Parent Global Impressions-III (PGI-II) } \\
\text { Childhood Autism Rating Scale (CARS) } \\
\text { Aberrant Behavior Checklist (ABC) } \\
\text { Social Responsiveness Scale (SRS) } \\
\text { Vineland Adaptive Behavior Scale II (VABS-II) }\end{array}$ & $\begin{array}{l}\text { ASD-related behavior improved } \\
\text { (PGI-II) (CARS) (SRS) (ABC) } \\
80 \% \text { reduction of Gl symptoms } \\
\text { (persisted for } 8 \text { weeks post-FMT) } \\
\text { Bifidobacterium, Prevotella, and } \\
\text { Desulfovibrio increased post-FMT } \\
\text { (persisted for } 8 \text { weeks post-FMT) }\end{array}$ & Kang et al., 2017 \\
\hline Cross-sectional & $\begin{array}{l}\text { ASD, regressive-onset } \\
\text { autism }(n=13) \\
\text { Controls }(n=8)\end{array}$ & $\begin{array}{l}\text { All ASD had Gl symptoms (diarrhea and } \\
\text { constipation) } \\
\text { Gastric and small-bowel specimens (7 ASD, } \\
4 \text { controls) } \\
\text { Limited dietary data: patients were on a } \\
\text { gluten-free (GF), casein-free (CF) diet }\end{array}$ & $\begin{array}{l}\text { ASD-more Clostridial species and } \\
\text { non-spore-forming anaerobes and } \\
\text { microaerophilic bacteria }\end{array}$ & Finegold et al., 2002 \\
\hline Cross-sectional & $\begin{array}{l}\text { ASD }(n=20) \\
\text { Age }(6.7 \pm 2.7 \text { years }) \\
20 \text { neurotypical children } \\
\text { Age ( } 8.3 \pm 4.4 \text { years })\end{array}$ & $\begin{array}{l}\text { Fecal samples } \\
\text { Autism Diagnostics Interview-Revised } \\
\text { (ADI-Revised) } \\
\text { Autism Diagnostics Observation Schedule } \\
\text { (ADOS) } \\
\text { Autism Treatment Evaluation Checklist (ATEC) } \\
\text { Pervasive Developmental Disorder Behavior } \\
\text { Inventory (PDD-BI) } \\
\text { Limited dietary data } \\
\text { Most ASD had Gl symptoms }\end{array}$ & $\begin{array}{l}\text { ASD-less diverse gut microbial } \\
\text { compositions with lower levels of } \\
\text { Prevotella, Coprococcus, and } \\
\text { unclassified Veillonellaceae } \\
\text { Autistic symptoms, rather than the } \\
\text { severity of Gl symptoms, was } \\
\text { associated with less diverse gut } \\
\text { microbiota }\end{array}$ & Kang et al., 2013 \\
\hline Cross-sectional & $\begin{array}{l}\text { ASD }(n=23) \\
\text { Age (123 } \pm 9 \text { months }) \\
\text { Controls }(n=31) \\
\text { Age (136 } \pm 9 \text { months })\end{array}$ & $\begin{array}{l}\text { SCFAs } \\
\text { Dietary intake of macro-nutrients }\end{array}$ & $\begin{array}{l}\text { ASD-fecal acetic, butyric, isobutyric, } \\
\text { valeric, and isovaleric acid were all } \\
\text { significantly higher compared with } \\
\text { controls }\end{array}$ & Wang et al., 2012 \\
\hline Cross-sectional & $\begin{array}{l}\text { ASD }(n=40) \\
\text { Age }(11.1 \pm 6.8 \text { years }) \\
\text { Neurotypical controls } \\
(n=40) \\
\text { Age }(9.2 \pm 7.9 \text { years })\end{array}$ & $\begin{array}{l}\text { Childhood Autism Rating Scale (CARS) } \\
\text { Autism Diagnostic Observation Schedule and } \\
\text { Autism Behavior Checklist } \\
\text { Constipation defined according to Rome III } \\
\text { criteria } \\
\text { All subjects of in this study were on a } \\
\text { Mediterranean-based diet, and no antibiotics, } \\
\text { probiotics, or prebiotics taken in the } 3 \\
\text { months prior to the sample collection }\end{array}$ & $\begin{array}{l}\text { ASD-increase in the } \\
\text { Firmicutes/Bacteroidetes ratio due to } \\
\text { a reduction of the Bacteroidetes } \\
\text { relative abundance } \\
\text { ASD-at the genus level-decrease } \\
\text { in Alistipes, Bilophila, Dialister, } \\
\text { Parabacteroides, and Veillonella, } \\
\text { while Collinsella, Corynebacterium, } \\
\text { Dorea, and } \\
\text { Lactobacillus were significantly } \\
\text { increased } \\
\text { Constipated ASD-high levels of } \\
\text { bacterial taxa belonging to } \\
\text { Escherichia/Shigella and Clostridium } \\
\text { cluster XVIII } \\
\text { ASD-fungal genus Candida } \\
\text { increased }\end{array}$ & Strati et al., 2017 \\
\hline
\end{tabular}


TABLE 1 | Continued

\begin{tabular}{|c|c|c|c|c|}
\hline Design & Diagnosis, N, Age & Measures & Results & References \\
\hline Cross-sectional & $\begin{array}{l}\text { ASD }(n=23 \text {, without Gl } \\
\text { symptoms) } \\
\text { ASD }(n=28 \text {, with Gl } \\
\text { symptoms) } \\
\text { Age range }(2-12 \text { years) } \\
\text { Neurotypical siblings }(n=53) \\
\text { Age range }(2-12 \text { years })\end{array}$ & $\begin{array}{l}\text { Childhood Autism Rating Scale (CARS) } \\
\text { Limited dietary data; Probiotics not excluded }\end{array}$ & $\begin{array}{l}\text { No significant differences in } \\
\text { microbiota }\end{array}$ & Gondalia et al., 2012 \\
\hline Cross-sectional & $\begin{array}{l}\text { ASD }(n=15 \text {, with } \mathrm{Gl} \\
\text { symptoms) } \\
\text { Age }(4.5 \pm 1.3 \text { years }) \\
\text { Controls }(n=7 \text {, with } \mathrm{Gl} \\
\text { symptoms }) \\
\text { Age }(4.0 \pm 1.1 \text { years })\end{array}$ & $\begin{array}{l}\text { Autism Diagnostic Interview-Revised (ADI-R) } \\
\text { Intestinal biopsies }\end{array}$ & $\begin{array}{l}\text { ASD with Gl symptoms had a } \\
\text { decrease in disaccharidases and } \\
\text { hexose transporters, and decreases } \\
\text { in Bacteroidetes, increase in } \\
\text { Firmicutes/Bacteroidetes ratio, and } \\
\text { increase in Betaproteobacteria } \\
\text { compared with controls with Gl } \\
\text { symptoms }\end{array}$ & Williams et al., 2011 \\
\hline Cross-sectional & $\begin{array}{l}\text { ASD }(n=58, \text { Gl symptoms }) \\
\text { Age ( } 6.91 \pm 3.4 \text { years }) \\
\text { Controls }(n=39) \\
\text { Age }(7.7 \pm 4.4 \text { years })\end{array}$ & $\begin{array}{l}\text { Gl symptoms (assessed by the six-item Gl } \\
\text { Severity Index (6-GSI) questionnaire) } \\
\text { Autism Treatment Evaluation Checklist } \\
\text { (ATEC) } \\
\text { Diet not recorded, ASD on probiotics }\end{array}$ & $\begin{array}{l}\text { ASD-decreased fecal SCFAs, } \\
\text { acetate, proprionate, and valerate } \\
\text { ASD-lower levels of Bifidobacterium } \\
\text { and higher levels of Lactobacillus } \\
\text { Gl symptoms were strongly } \\
\text { correlated with the severity of autism }\end{array}$ & Adams et al., 2011 \\
\hline $\begin{array}{l}\text { Meta-analysis of } 15 \\
\text { cross-sectional } \\
\text { studies }\end{array}$ & & & $\begin{array}{l}11 \text { studies }(n=562) \text { reported } \\
\text { significant gut microbiota differences } \\
\text { between ASD children and controls, } \\
\text { particularly in the Firmicutes, } \\
\text { Bacteroidetes and Proteobacteria } \\
\text { phyla } \\
\text { Substantial heterogeneity in } \\
\text { methodology and the often } \\
\text { contradictory results of different } \\
\text { studies - not possible to pool the } \\
\text { results into a meta-analysis }\end{array}$ & Cao et al., 2013 \\
\hline Cross-sectional & $\begin{array}{l}\text { ASD }(n=33 \text {, varying Gl } \\
\text { symptoms) } \\
\text { Controls ( } n=15) ; \\
7 \text { sibling controls } \\
8 \text { non-sibling controls } \\
\text { Age (all ASD and controls } \\
\text { between } 2 \text { and } 13 \text { years) }\end{array}$ & No diet & $\begin{array}{l}\text { Bacteroidetes was found at high } \\
\text { levels in the severely autistic group } \\
\text { Firmicutes were more predominant in } \\
\text { the control group } \\
\text { Smaller, but significant, differences } \\
\text { also in the Actinobacterium and } \\
\text { Proteobacterium phyla } \\
\text { Desulfovibrio species and } \\
\text { Bacteroides vulgatus present in } \\
\text { significantly higher numbers in stools } \\
\text { of severely autistic children than in } \\
\text { controls }\end{array}$ & Finegold et al., 2010 \\
\hline
\end{tabular}


TABLE 1 | Continued

\begin{tabular}{|c|c|c|c|c|}
\hline Design & Diagnosis, N, Age & Measures & Results & References \\
\hline $\begin{array}{l}\text { Probiotic } \\
\text { Intervention- } \\
\text { "Children Dophilus" } \\
\text { oral capsule } \\
\text { containing } 3 \text { strains } \\
\text { of Lactobacillus } \\
(60 \%), 2 \text { strains of } \\
\text { Bifidumbacteria } \\
(25 \%) \text { and one strain } \\
\text { of Streptococcus } \\
\text { (15\%), times a day for } \\
4 \text { months }\end{array}$ & $\begin{array}{l}\text { ASD }(n=10) \\
\text { Age }(2-9 \text { years }) \\
\text { Siblings }(n=9) \\
\text { Age }(5-17 \text { years }) \\
\text { Controls }(n=10) \\
\text { Age }(2-11 \text { years) }\end{array}$ & $\begin{array}{l}\text { Autism Diagnostic Interview (ADI) } \\
\text { Childhood Autism Rating Scale (CARS) }\end{array}$ & $\begin{array}{l}\text { ASD-decrease of the } \\
\text { Bacteroidetes/Firmicutes ratio and } \\
\text { elevation of the amount of } \\
\text { Lactobacillus } \\
\text { Desulfovibrio decreased postprobiotic } \\
\text { Desulfovibrio spp. associated with the } \\
\text { severity of autism (ADI) } \\
\text { restricted/repetitive behavior subscale } \\
\text { score } \\
\text { Probiotic significantly decreased fecal } \\
\text { TNFa levels in ASD } \\
\text { No correlation between plasma levels } \\
\text { of oxytocin, testosterone, DHEA-S } \\
\text { and fecal microbiota }\end{array}$ & Tomova et al., 2015 \\
\hline
\end{tabular}

Cross-sectional Healthy children $(n=77)$ Age (18-27 months)
Early Childhood Behavior Questionnaire (ECBQ)

(18 dimensions of temperament, three composite scales: Negative Affectivity,

Surgency/Extraversion, Effortful Control)
Greater surgency/extraversion was associated greater phylogenetic diversity

Boys only - subscales loading on this composite scale were associated with differences in phylogenetic diversity, the Shannon Diversity index (SDI), beta diversity, and differences in abundances of Dialister, Rikenellaceae, Ruminococcaceae, and Parabacteroides Higher effortful control was associated with a lower SDI score and differences in both beta diversity and Rikenellaceae were observed in relation to Fear Associations between temperament and dietary patterns were observed

\begin{tabular}{|c|c|c|c|c|}
\hline Cross-sectional & $\begin{array}{l}\text { ASD }(n=17) \\
\text { Asperger's syndrome }(n=6) \\
\text { Mean age ( } 123 \pm 9 \text { months) } \\
22 \text { typically developing } \\
\text { siblings } \\
\text { Age (144 } \pm 12 \text { months }) \\
\text { Community controls }(n=9) \\
\text { Age (114 } \pm 15 \text { months })\end{array}$ & $\begin{array}{l}\text { Functional gastrointestinal disorder (FGID) } \\
\text { questionnaire } \\
\text { Antibiotics/probiotics not excluded } \\
\text { Some on Gluten- and casein-free diet }\end{array}$ & $\begin{array}{l}\text { ASD-Low Relative Abundances of } \\
\text { the Mucolytic Bacterium and } \\
\text { Akkermansia muciniphila and } \\
\text { Bifidobacterium spp. in } \\
\text { Feces }\end{array}$ & Wang et al., 2011 \\
\hline Cross-sectional & $\begin{array}{l}\text { ASD ( } n=23,3 \text { without } \\
\text { siblings) } \\
22 \text { typically developing } \\
\text { siblings } \\
\text { Age ( } 144 \pm 12 \text { months }) \\
\text { Community controls }(n=9) \\
\text { Age ( } 114 \pm 15 \text { months })\end{array}$ & No diet & $\begin{array}{l}\text { ASD-Sutterella spp. elevated in } \\
\text { feces relative to controls and } \\
\text { Ruminococcus torques higher in the } \\
\text { children with ASD with a reported } \\
\text { functional gastrointestinal disorder } \\
\text { than those without such a disorder }\end{array}$ & Wang et al., 2013 \\
\hline Cross-sectional & $\begin{array}{l}\text { ASD }(n=10) \\
\text { Pervasive Developmental } \\
\text { Disorder Not Otherwise } \\
\text { Specified (PDD-NOS) } \\
(n=10) \\
\text { Healthy controls (HC) siblings } \\
(n=10) \\
\text { Age (all } 4-10 \text { years) }\end{array}$ & $\begin{array}{l}\text { Autism Diagnostic Interview-Revised (ADI-R) } \\
\text { Autistic Diagnostic Observation Schedule } \\
\text { (ADOS) } \\
\text { Childhood Autism Rating Scale (CARS) } \\
\text { Diet not recorded } \\
\text { No antibiotics, probiotics and prebiotics for at } \\
\text { least } 1 \text { month before sampling }\end{array}$ & $\begin{array}{l}\text { ASD-highest microbial diversity } \\
\text { Faecalibacterium and Ruminococcus } \\
\text { were present at the highest level in } \\
\text { fecal samples of PDD-NOS and HC } \\
\text { children. Caloramator, Sarcina and } \\
\text { Clostridium genera were the highest } \\
\text { in ASD children } \\
\text { Except for Eubacterium siraeum, the } \\
\text { lowest level of Eubacteriaceae was } \\
\text { found in fecal samples of ASD }\end{array}$ & De Angelis et al., 2013 \\
\hline
\end{tabular}

Christian et al., 2015

Chistian et al., 2015

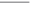

Bifidumbacteria

of Streptococcus

(Continued) 
TABLE 1 | Continued

\begin{tabular}{|c|c|c|c|c|}
\hline Design & Diagnosis, N, Age & Measures & Results & References \\
\hline & & & $\begin{array}{l}\text { Bifidobacterium species decreased in } \\
\text { AD-Compared to HC children } \\
\text { Altered levels of free amino acids and } \\
\text { volatile organic compounds of fecal } \\
\text { samples in ASD and PDD-NOS }\end{array}$ & \\
\hline Cross-sectional & $\begin{array}{l}\text { ASD probands }(n=66) \\
\text { Neurotypical }(\mathrm{NT}) \text { siblings } \\
(n=37) \\
\text { Age }(7-14 \text { years })\end{array}$ & $\begin{array}{l}\text { Parent-completed ROME III questionnaire for } \\
\text { pediatric Functional gastrointestinal disorders } \\
\text { (FGIDs) } \\
\text { Child Behavior Check List (CBCL) } \\
\text { Targeted quantitative polymerase chain } \\
\text { reaction (qPCR) assays were conducted on } \\
\text { selected taxa implicated in ASD, including } \\
\text { Sutterella spp., Bacteroidetes spp., and } \\
\text { Prevotella spp. }\end{array}$ & $\begin{array}{l}\text { No significant difference in } \\
\text { macronutrient intake between ASD } \\
\text { and NT siblings } \\
\text { There was no significant difference in } \\
\text { ASD severity scores between ASD } \\
\text { children with and without FGID } \\
\text { No significant difference in diversity or } \\
\text { overall microbial composition was } \\
\text { detected between ASD children with } \\
\text { NT siblings }\end{array}$ & Son et al., 2015 \\
\hline
\end{tabular}

using the poorly absorbed oral antibiotic, vancomycin for 12 weeks, reportedly resulted in a short-term improvement in ASD related behavioral symptomatology in a group of children with regressive-onset autism (Sandler et al., 2000). Follow-up which occurred between 2 and 8 months, showed that the improvement was not sustained. More recently, a small $(n=18)$ open label study of Fecal Microbiota Transfer (FMT) in children with ASD reported an improvement in both GI symptoms and behavioral symptoms after 8 weeks (Kang et al., 2017). In this study, the abundance of Bifidobacterium, Prevotella, and Desulfovibrio increased following the 8 weeks of FMT treatment (see Table 1). Interestingly, in a cross sectional study, in healthy prepubertal children $(n=65)$ dietary fiber was associated with a better performance on a task measuring attentional inhibition (Khan et al., 2015). Moreover, a study investigating microbial composition at 1 year of age showed that a higher alpha diversity was associated with lower scores on the Mullen scale, the visual reception scale, and the expressive language scale at 2 years of age (Carlson et al., in press).

\section{SCHIZOPHRENIA SPECTRUM DISORDER AND THE MICROBIOTA}

As discussed below, data from pre-clinical studies indicate that certain domains related to schizophrenia, such as social cognition, are under the partial influence of the gut microbiota (Dinan et al., 2014). However, pre-clinical models have many limitations and translating promising pre-clinical findings into discernible clinical benefits for patients can be challenging, particularly for complex disorders such as schizophrenia. Moreover, it is important to highlight that there are considerable interpersonal differences in the gut microbiota profiles of healthy individuals (Backhed et al., 2012; Falony et al., 2016; Zhernakova et al., 2016). Consequently, there are multiple possible configurations for a healthy gut microbiota and it is also likely that some stable configurations are associated with disorders (Relman, 2012). It is important also to appreciate that the functional output of multiple microbiota configurations may in fact be equivalent, given that concepts of redundancy and pleiotropy can also be applied to specific microbial members of the overall consortium (Falony et al., 2016).

Despite the significant challenges, several pilot clinical studies investigating the microbiome in schizophrenia have emerged (see Table 2). A recent study investigating the gut microbiota in schizophrenia was conducted in First Episode Psychosis (FEP) patients $(n=28)$ compared to healthy controls $(n=16)$ (Schwarz et al., in press). There were five significant differences between the groups at the family level; Lactobacillaceae, Halothiobacillaceae, Brucellaceae, and Micrococcineae were increased, whereas Veillonellaceae were decreased in FEP patients. At the genus level, Lactobacillus, Tropheryma, Halothiobacillus, Saccharophagus, Ochrobactrum, Deferribacter, and Halorubrum were increased, and Anabaena, Nitrosospira, and Gallionella were decreased in FEP. Lactobacillus group bacterial numbers correlated positively with severity of psychotic symptoms measured using the Brief Psychiatric Rating Scale, and negatively with global assessment of functioning (GAF) scale. A subgroup analysis of those classified as less physically active, confirmed significant increases in Lactobacillaceae and significant decreases in Veillonellaceae in FEP. It is noteworthy that the vast majority of FEP patients were prescribed antipsychotic medication, which can impact gut microbiota composition (Davey et al., 2012, 2013; Bahra et al., 2015; Bahr et al., 2015). A small study $(n=32)$ of the oropharyngeal microbiome in schizophrenia also showed an increased abundance of Lactobacillus in schizophrenia patients, in addition to, Bifidobacterium and Ascomycota, compared to healthy controls (Castro-Nallar et al., 2015). Another study of the oral pharynx of 41 individuals with schizophrenia and 33 controls demonstrated that one bacteriophage genome Lactobacillus phage phiadh, was significantly more abundant in schizophrenia patients than in controls after adjustment for multiple comparisons and demographic covariates (Yolken et al., 2015).

Studies investigating the fungal composition of the human gut-the Mycobiome-are also emerging (Suhr and Hallen-Adams, 2015). A case-control cohort study that included 
TABLE 2 | Microbiota and clinical schizophrenia (SCZ) studies.

\begin{tabular}{|c|c|c|c|c|}
\hline Design & Diagnosis, N, Years & Measures & Results & References \\
\hline Cross-sectional & $\begin{array}{l}\text { Schizophrenia }(n=16) \\
\text { Years }(34.7 \pm 4.8) \\
\text { Controls }(n=16) \\
\text { Years (34.3 } \pm 10.1) \\
\text { Differences in smoking and } \\
\text { BMl between groups }\end{array}$ & $\begin{array}{l}\text { Shotgun metagenomic analysis of the } \\
\text { oropharyngeal microbiome }\end{array}$ & $\begin{array}{l}\text { SCZ-higher proportions of } \\
\text { Firmicutes, Ascomycota, } \\
\text { Bifidobacterium and Lactobacilli } \\
\text { (largest effect was observed in } \\
\text { Lactobacillus gasseri) } \\
\text { SCZ-increase Candida and } \\
\text { Eubacterium and reduction of } \\
\text { Neisseria, Haemophilus and } \\
\text { Capnocytophaga } \\
\text { SCZ-increased number of metabolic } \\
\text { pathways related to metabolite } \\
\text { transport systems including } \\
\text { siderophores, glutamate and vitamin } \\
\text { B12 } \\
\text { Carbohydrate and lipid pathways and } \\
\text { energy metabolism were abundant in } \\
\text { controls }\end{array}$ & $\begin{array}{l}\text { Castro-Nallar et al., } \\
2015\end{array}$ \\
\hline $\begin{array}{l}\text { Two case-control } \\
\text { cohorts }(n=947)\end{array}$ & $\begin{array}{l}\text { Schizophrenia }(n=261) \text {, } \\
\text { including; } \\
\text { First-episode schizophrenia } \\
(n=139,78 \text { antipsychotic } \\
\text { naïve) } \\
\text { Years }(37.71 \pm 13.69) \\
\text { Bipolar }(n=270) \\
\text { Years (34.08 } \pm 13.15) \\
\text { Controls }(n=277) \\
\text { Years (32.02 } \pm 11.31)\end{array}$ & $\begin{array}{l}\text { Repeatable Battery for the Assessment of } \\
\text { Neuropsychological Status (RBANS) }\end{array}$ & $\begin{array}{l}\text { No differences in C. albicans } \\
\text { exposures were found until diagnostic } \\
\text { groups stratified by sex } \\
\text { SCZ-in males, C. albicans } \\
\text { seropositivity conferred increased } \\
\text { odds (OR 2.04-9.53) for a SCZ } \\
\text { diagnosis } \\
\text { SCZ-in females, C. albicans } \\
\text { seropositivity conferred increased } \\
\text { odds (OR 1.12) for lower cognitive } \\
\text { scores on RBANS with significant } \\
\text { decreases on memory modules } \\
\text { C. albicans IgG levels were not } \\
\text { impacted by antipsychotic } \\
\text { medications } \\
\text { Gastrointestinal (GI) disturbances } \\
\text { were associated with elevated } \\
\text { C. albicans in males with SCZ and } \\
\text { females with bipolar }\end{array}$ & Severance et al., $2016 a$ \\
\hline $\begin{array}{l}14 \text { week } \\
\text { double-blind, } \\
\text { placebo controlled } \\
\text {.Lactobacillus } \\
\text { rhamnosus strain GG } \\
\text { and Bifidobacterium } \\
\text { animalis subsp. lactis } \\
\text { Bb12 }\left(10^{9} \mathrm{cfu}\right)\end{array}$ & $\begin{array}{l}\text { Schizophrenia }(n=56) \\
\text { Probiotic }(n=30) \\
\text { Placebo }(n=26) \\
\text { Years }(44.66+11.4)\end{array}$ & $\begin{array}{l}\text { Biweekly Positive and Negative Syndrome } \\
\text { Scale (PANSS) } \\
\text { Self-reported-bowel score (scale of 1-4) }\end{array}$ & $\begin{array}{l}\text { SCZ-in males-reduced C. albicans } \\
\text { antibodies } \\
\text { S. cerevisiae were not altered } \\
\text { Trends toward improvement in } \\
\text { positive psychiatric symptoms in } \\
\text { males } \\
\text { treated with probiotics who were } \\
\text { seronegative for C. albicans }\end{array}$ & Severance et al., 2017 \\
\hline $\begin{array}{l}\text { Lactobacillus } \\
\text { rhamnosus strain GG } \\
\text { and Bifidobacterium } \\
\text { animalis subsp. lactis } \\
\left.\text { Bb12 ( } 10^{9} \mathrm{cfu}\right) 14 \\
\text { week double-blind, } \\
\text { placebo controlled }\end{array}$ & $\begin{array}{l}\text { Schizophrenia }(n=65) \\
33 \text { probiotic } \\
\text { Years }(44.4 \pm 11.0) \\
32 \text { placebo } \\
\text { Years }(48.1 \pm 9.4) \\
\text { All on antipsychotic } \\
\text { medication }\end{array}$ & $\begin{array}{l}\text { Positive and Negative Syndrome Scale } \\
\text { (PANSS) every } 2 \text { weeks } \\
\text { Self-reported-bowel score (scale of 1-4) }\end{array}$ & $\begin{array}{l}\text { No significant differences in the } \\
\text { PANSS } \\
\text { Probiotic group-significantly less } \\
\text { likely to develop severe bowel } \\
\text { difficulty }\end{array}$ & Dickerson et al., 2014 \\
\hline
\end{tabular}


TABLE 2 | Continued

\begin{tabular}{|c|c|c|c|c|}
\hline Design & Type, N, Years & Measures & Results & References \\
\hline $\begin{array}{l}\text { Longitudinal (12 } \\
\text { months) }\end{array}$ & $\begin{array}{l}\text { First Episode Psychosis } \\
\text { (FEP) }(n=28) \\
\text { Years }(25.9 \pm 5.5) \\
\text { Most on antipsychotics } \\
\text { Healthy controls }(n=16) \\
\text { Years }(27.8 \pm 6.0)\end{array}$ & $\begin{array}{l}\text { Brief Psychiatric Rating Scale (BPRS) Global } \\
\text { assessment of functioning (GAF) scale } \\
\text { Diet adapted from "Health Behavior and } \\
\text { Health among the Finnish Adult Population" } \\
\text { survey }\end{array}$ & $\begin{array}{l}\text { FEP_at family level; } \\
\text { Lactobacillaceae, } \\
\text { Halothiobacillaceae, Brucellaceae and } \\
\text { Micrococcineae were increased } \\
\text { whereas Veillonellaceae were } \\
\text { decreased } \\
\text { FEP-at genus level; Lactobacillus, } \\
\text { Tropheryma, Halothiobacillus, } \\
\text { Saccharophagus, Ochrobactrum, } \\
\text { Deferribacter and Halorubrum were } \\
\text { increased, and Anabaena, } \\
\text { Nitrosospira and Gallionella were } \\
\text { decreased } \\
\text { Lactobacillus group bacterial } \\
\text { numbers correlated positively with } \\
\text { severity of psychotic symptoms } \\
\text { measured using the BPRS and } \\
\text { negatively with GAF scale }\end{array}$ & Schwarz et al., in press \\
\hline
\end{tabular}

261 individuals with schizophrenia, 270 with bipolar disorder, and 277 non-psychiatric controls, found no differences in $C$. albicans exposure when analyzed at the group level. However, when stratified by sex, there was a reported increase in the odds for schizophrenia in males (Severance et al., 2016a). The same group conducted a randomized, double-blind, placebocontrolled, probiotic trial over a 14-week period, and showed that probiotic treatment significantly reduced C. albicans antibodies in males only, and a trend toward improvement in positive psychiatric symptoms in seronegative males (Severance et al., 2017). Both groups were prescribed antipsychotic medication, but antipsychotic regimes were not different between probiotic and placebo groups.

\section{COMMUNICATION PATHWAYS OF BRAIN-GUT-MICROBIOTA AXIS}

The human body contains as many bacterial cells as human cells (Sender and Fuchs, 2016), the majority of which reside in the gut, with bacterial concentrations ranging from $10^{1}$ to $10^{3}$ cells per gram in the upper intestines to $10^{11}-10^{12}$ bacteria per gram in the colon (O'Hara and Shanahan, 2006; Derrien and van Hylckama Vlieg, 2015). With over 1,000 species and 7,000 strains the microbiota is an ecosystem dominated by bacteria, mainly strict anaerobes, but also includes viruses and bacteriophages, protozoa, archaea and fungi (Lankelma et al., 2015). In terms of bacterial phyla found in the gut, Firmicutes (species such as Lactobacillus, Clostridium, Enterococcus) and Bacteroidetes (species such as Bacteroides) account for the majority (Dethlefsen et al., 2007), though the other phyla such as Actinobacteria (Bifidobacteria), Proteobacteria (Escherichia coli), Fusobacteria, Verrucomicrobia, and Cyanobacteria are also present in relatively low abundance (Eckburg et al., 2005; Qin et al., 2010; Lankelma et al., 2015).

Although the functional significance of the gut microbiota has yet to be fully determined (Franzosa et al., 2014; Cani, 2017), it is clear that an intricate and interlinked symbiotic relationship exists between host and microbe (Ley et al., 2008), and there are a number of bidirectional signaling pathways by which the gut microbiota, acting via the brain-gut axis, can impact the brain. A key signaling pathway involves modulation of the immune system (Erny et al., 2015), though other pathways include the hypothalamic-pituitary-adrenal (HPA) axis (Sudo et al., 2004; Mudd et al., 2017), tryptophan metabolism (O'Mahony et al., 2015), the production of bacterial metabolites, such as SCFA (Tan et al., 2014) and via the vagus nerve (Bravo et al., 2011). Although much progress has been made, the precise signaling pathways mediating the influence of microbial products derived from gut microbiota on the brain remain largely unknown. Epigenetic factors may also play a role (Dalton et al., 2014; Stilling et al., 2014a,b; Thaiss et al., 2016). Recently, a novel signaling pathway has been advanced, that involves bacterial peptidoglycan (PGN) derived from the commensal gut microbiota (Arentsen et al., 2017). PGN was shown to translocate into the brain to activate specific pattern-recognition receptors (PRRs) of the innate immune system, and this could occur in both physiological and pathological conditions (Arentsen et al., 2017).

In addition, pre-clinical evidence from germ-free (GF) mice suggests that the microbiota can modulate the Blood Brain Barrier (BBB). Exposure of GF adult mice to the fecal microbiota from pathogen-free donors decreased $\mathrm{BBB}$ permeability (Braniste et al., 2014). Moreover, monocolonization of the intestine of GF adult mice with SCFA-producing bacterial strains normalized BBB permeability, whilst sodium butyrate was associated with increased expression of the tight junction protein occludin in the frontal cortex and hippocampus (Braniste et al., 2014). Together with a study that showed antibiotic-induced gut dysbiosis reduced the expression of tight junction proteins (claudin and occludin) mRNA in the hippocampus, and increased the expression of tight junction protein 1 and occludin mRNA in the amygdala (Frohlich et al., 2016), suggests that the BBB may be partially modulated by changes in the gut microbiota. 


\section{MICROBIOTA AND THE IMMUNE SYSTEM}

A bidirectional communication system exists between the immune system and the CNS. Neuroimmune signaling during the prenatal or early post-natal developmental stages can have long lasting effects on the brain, and is an important determinant of cognitive function and emotional behavior (Dantzer et al., 2008; Bilbo et al., 2012; Filiano et al., 2017; Freytag et al., 2017). Peripheral cytokine signaling can modulate astrocytes, microglia and neurons in the CNS (Kohman and Rhodes, 2013). This occurs through leaky regions in the BBB such as circumventricular organs, active transport through transport molecules, activation of cells lining the cerebral vasculature (endothelial cells and perivascular macrophages), binding to cytokine receptors associated with the vagus nerve, stimulating the HPA axis at the anterior pituitary or hypothalamus and recruitment of activated cells such as monocytes/macrophages from the periphery to the brain (Haroon et al., 2012). In addition, functional lymphatic vessels lining the dural sinuses have been discovered, which serve as a route by which immune cells can communicate with the CNS (Louveau et al., 2015). Consequently, peripheral cytokines can modulate neurogenesis, synapse formation and plasticity (Hodes et al., 2015). It is established that cytokines can impact cognition and mood (Dowlati et al., 2010; Udina et al., 2012; Valkanova et al., 2013; Khandaker et al., 2014). Brain regions affected by administration of inflammatory stimuli include the basal ganglia and the dorsal anterior cingulate cortex (dACC), part of the limbic system, involved in cognitive and emotional processing (Harrison et al., 2009; Slavich et al., 2010; Capuron et al., 2012; Felger and Miller, 2012; Felger et al., 2013; Miller et al., 2013).

A critical function of the gut microbiota is to prime the development of the neuroimmune system (Round and Mazmanian, 2009; Olszak et al., 2012; Chistiakov et al., 2014; Francino, 2014). Alterations in the gut microbiota signature early in life can predispose to immune disorders (Penders et al., 2007; Fujimura et al., 2016) and the luminal surface of the gut is a key interface in this process (O'Hara and Shanahan, 2006). Indeed, the hygiene hypothesis first proposed in the late 1980's (Strachan, 1989; Patel and Gruchalla, 2017) and reconceptualized as the "old friends hypothesis" (Rook et al., 2003; Williamson et al., 2015) proposes that encountering less microbial biodiversity may contribute to the increase in chronic inflammatory disorders (Klerman and Weissman, 1989; Guarner et al., 2006; Rook and Lowry, 2008; Turnbaugh et al., 2009; Hidaka, 2012; Rook et al., 2013, 2014; Kostic et al., 2015; Stein et al., 2016). An intriguing strategy of "reintroducing" old friends has been suggested by a pre-clinical study using heat-killed Mycobacterium vaccae, an immunoregulatory environmental microorganism. Mice given this vaccine exhibited reduced subordinate, flight, and avoiding behavioral responses to a dominant aggressor in a murine model of chronic psychosocial stress when tested 1-2 weeks following the final immunization, compared to the control group (Reber et al., 2016). Depletion of regulatory T cells negated the protective effects of immunization with $M$. vaccae on anxiety-like or fear behaviors.

\section{MECHANISTIC INFLUENCES OF MICROBIOTA ON BRAIN FUNCTION AND DEVELOPMENT}

\section{Toll-Like Receptors (TLRs)}

Structural components of bacteria interact with the immune system via TLRs (McCusker and Kelley, 2013). Different TLRs recognize specific bacterial structures, for example; TLR2 recognizes structures from Gram positive bacteria whereas TLR4 mediates responses to structures such as lipopolysaccharide (LPS) primarily from Gram negative bacteria (Marteau and Shanahan, 2003). In the CNS, neurons and glial cells can express various TLRs (Bsibsi et al., 2002; Kielian, 2006; Trudler et al., 2010). Activation of TLRs trigger the induction of pro and anti-inflammatory cytokines (Takeda and Akira, 2005) and, as mentioned above, there are a number of routes by which peripheral cytokines can impact the brain (Haroon et al., 2012; Miller et al., 2013; Louveau et al., 2015). Dysregulation of this process, or excessive TLR activation, can result in chronic inflammatory and over-exuberant repair responses. Consequently, TLRs may serve as molecular communication channels between gut microbiota alterations and immune system homeostasis (Rogier et al., 2015). Indeed, TLR2 and TLR4 knockout mice showed subtle impairments in behavior and cognitive functions (Park et al., 2015; Too et al., 2016). A clinical study in subjects diagnosed with psychotic disorders showed specific alterations in TLR agonist-mediated cytokine release compared to healthy controls (McKernan et al., 2011), and more recently it has been shown that abnormal expression of TLRs can be modulated by antipsychotics (Kéri et al., 2017). Moreover, in post-mortem prefrontal cortex samples from subjects diagnosed with psychosis, alterations in TLR4 have been shown, which were dependent on antipsychotic treatment status at time of death (García-Bueno et al., 2016).

\section{Microbiota and Microglia}

Microglia, central to the inflammatory process (Facci et al., 2014) are emerging as playing key roles in brain development, plasticity and cognition (Tay et al., 2017). These phagocytic innate immune cells account for approximately $10 \%$ of cells in the brain (Prinz et al., 2014), contribute to the plasticity of neural circuits by modulating synaptic architecture and function (Graeber and Streit, 2010) and can be modulated by glutamatergic and GABAergic neurotransmission (Fontainhas et al., 2011). Preclinical studies have shown that acute stress results in microglia activation and increased levels of proinflammatory cytokines in areas such as the hippocampus (Frank et al., 2007) and hypothalamus (Blandino et al., 2009; Sugama et al., 2011). Most studies show increases in activated microglia in response to chronic stress (Tynan et al., 2010; Hinwood et al., 2011, 2012; Bollinger et al., 2016).

Preliminary changes in the microenvironment of the microglia may result in a susceptibility to a secondary inflammatory stimulus (Perry and Holmes, 2014). This concept of microglia priming may be of relevance to neurodevelopmental disorders, such as ASD and schizophrenia, which often require multiple environmental "hits" (Feigenson et al., 2014; Fenn et al., 
2014). In an environmental two-hit rodent model in which the first experimental manipulation targeted pregnant dams, and the second manipulation was given to the resulting offspring, exposure to prenatal immune challenge and peripubertal stress synergistically induced pathological effects on adult behavioral functions and neurochemistry (Giovanoli et al., 2013, 2015). Thus, early-life stress may prime microglia, leading to a potentiated response to subsequent stress (Calcia et al., 2016).

In human studies, microglial dysregulation has been demonstrated in several psychiatric disorders. In medication free depressed patients, microglial activation has been demonstrated in the prefrontal cortex, ACC, and insula, using translocator protein density measured by distribution volume in a PET study positron emission tomography (PET) study (Setiawan et al., 2015). Using a different tracer, (11)[C]PBR28, subjects at high risk of psychosis, and those with schizophrenia also showed evidence of altered microglial activation compared to healthy controls (van Berckel et al., 2008; Bloomfield et al., 2016). However, not all studies are consistent and no clear consensus exists (Holmes et al., 2016; Narendran and Frankle, 2016; Collste et al., 2017; Notter and Meyer, 2017).

The gut microbiota, emerging as an important neuroimmunomodulator (Foster, 2016; Rea et al., 2016), is also involved in the maturation and activation of microglia (Cryan and Dinan, 2015; Erny et al., 2015). Interestingly, GF mice display underdeveloped and immature microglia in the cortex, corpus callosum, hippocampus, olfactory bulb, and cerebellum (Erny et al., 2015). There was an upregulation of microglia transcription and survival factors, and downregulation of cell activation genes and genes for type 1 IFN receptor signaling compared with those isolated from conventionally colonized control mice. These defects were partially restored by recolonization with a complex microbiota, and SCFAs reversed the defective microglia in the absence of complex microbiota (Erny et al., 2015). Collectively, these studies suggest that subtle alterations in gut microbiota acquisition and development, by regulating neuro-inflammatory processes, may act as additional vulnerability factors that predispose to neurodevelopmental disorders such as ASD and schizophrenia.

\section{MICROBIOTA AND NEUROCHEMISTRY}

At the cellular level, brain development and function requires a complex and coordinated birth, migration and differentiation of both neurons and glia, followed by synaptic integration and neural circuit formation. Both ASD and schizophrenia are associated with dysregulation of synaptic function and structure (McGlashan and Hoffman, 2000; Faludi and Mirnics, 2011; Spooren et al., 2012; Habela et al., 2016). The gut microbiota plays a role in developmental programming of the brain, specifically, synapse maturation and synaptogenesis (Diaz Heijtz et al., 2011) Figure 2. Synaptophysin, a marker of synaptogenesis, and PSD 95, a marker of excitatory synapse maturation, were decreased in the striatum in GF animals compared to specific-pathogen-free (SPF) animals. This suggests that the gut microbiota may programme certain brain circuits when colonized by maternal microbiota. However, the authors point out that exposure to gut microbiota metabolites during embryogenesis may also be a possible mechanism. Interestingly, reduced levels of synaptophysin have been demonstrated in the cerebral cortex of post-mortem samples from schizophrenia subjects (Hu et al., 2015).

\section{Brain-Derived Neurotrophic Factor (BDNF)}

A key regulator of synaptic plasticity and neurogenesis in the brain, throughout life, is the neurotrophin, BDNF (Monteggia et al., 2004). Given the role of BDNF in the regulation of synaptic strengthening and pruning, maintaining appropriate levels of BDNF and other neurotrophins, especially during critical neurodevelopmental windows is vital for both ASD and schizophrenia (Nieto et al., 2013). Meta-analysis showed reduced blood levels in both medication naïve and medicated adult individuals diagnosed with schizophrenia (Green et al., 2011). Conversely, children with ASD have increased levels of blood BDNF (Qin et al., 2016; Saghazadeh and Rezaei, 2017). In GF rodents, levels of BDNF were reduced in the cortex and hippocampus in GF mice (Sudo et al., 2004). In a study by Clarke et al. this finding was replicated, but in male mice only (Clarke et al., 2013). However, not all studies are consistent; Neufeld et al. (2011) confirmed a decreased level of anxiety like behavior in GF animals, but found an increase in BDNF mRNA in the hippocampus in female mice. Prebiotics can alter BDNF levels (Savignac et al., 2013) and increase BDNF gene expression in the hippocampus (Burokas et al., in press). Collectively, these pre-clinical studies suggest that certain neurotransmitters and neuromodulators of relevance to the pathophysiology of ASD and schizophrenia are under the influence of the gut microbiota Figure 2.

\section{$\gamma$-Aminobutyric Acid (GABA) and Glutamate}

At the neurotransmitter level, several signaling pathways have been shown to be dysfunctional in ASD and schizophrenia. Glutamatergic and GABAergic dysfunction and the consequences on excitatory to inhibitory cortical activity is one hypothesis to account for the similarities in the social and cognitive disturbances in ASD and schizophrenia (Canitano and Pallagrosi, 2017). GABA is an important inhibitory neurotransmitter in the brain, and GABA dysfunction has been implicated in ASD and schizophrenia (Schmidt and Mirnics, 2015). Although not a central source, it is interesting to note that certain bacteria can produce neuroactive metabolites (Wikoff et al., 2009; Lyte, 2011, 2013), for example specific strains of Lactobacillus and Bifidobacteria can produce GABA by metabolizing dietary glutamate (Barrett et al., 2012). Indeed, $L$. rhamnosus (JB-1) was shown to reduce anxiety and depression related behavior in mice and increase GABA receptor levels in the hippocampus (Bravo et al., 2011). Interestingly, in vagotomized mice, these effects were not found, further supporting the concept that the vagus nerve is an important neural signaling pathway between the microbiota and brain. A pre-clinical magnetic resonance spectroscopy study adds further evidence to support the concept that oral L. rhamnosus can increase central 


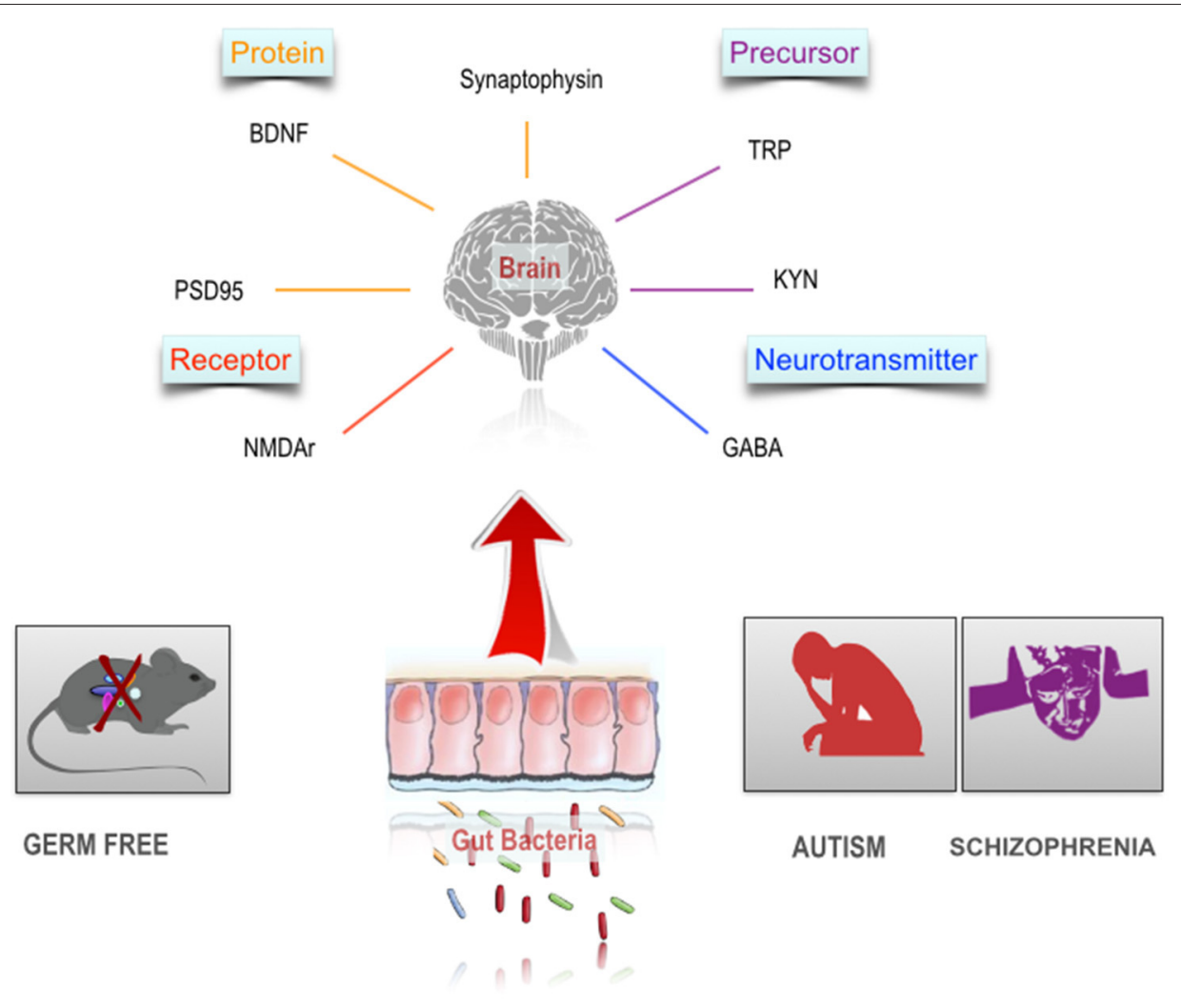

FIGURE 2 | The gut microbiome and the neurobiology of schizophrenia and autism. Autism and schizophrenia are associated with a number of alterations in the CNS including altered availability of neuroactive precursors. Studies in germ free animals indicate a substantial overlap between these neurobiological characteristics and the scope of influence of the gut microbiome in the CNS.

GABA levels (Janik et al., 2016). In a recent study, prebiotics, fructo-oligosaccharide (FOS) and galacto-oligosaccharide (GOS), increased GABA-B1 and GABA-B2 receptor gene expression in the hippocampus (Burokas et al., in press).

The glutamate hypothesis of schizophrenia, has suggested that hypofunction of signaling through NMDA receptors (NMDARs) plays a causal role in schizophrenia (Gonzalez-Burgos and Lewis, 2012). The glutamatergic system appears to contribute to certain cognitive deficits in schizophrenia (Thomas et al., 2017). Similarly, glutamatergic dysfunction has been implicated in ASD (Rojas, 2014). In GF mice Neufeld and colleagues demonstrated a decrease in the NMDAR subunit NR2B mRNA expression in the amygdala (Neufeld et al., 2011) Figure 2. Although a review of post-mortem studies of subjects with schizophrenia found consistent evidence of morphological alterations of dendrites of glutamatergic neurons in the cerebral cortex, there were no consistent alterations of mRNA expression of glutamate receptors (Hu et al., 2015).

\section{Serotonin}

Serotonin (5-HT) has a wide range of physiological functions, and is involved in the modulation of anxiety, conditioned fear, stress responses, reward, and social behavior (Lucki, 1998; Dayan and Huys, 2008; Asan et al., 2013). A meta-analysis of post-mortem studies found an elevation in prefrontal 5-HT1A receptors and a reduction in prefrontal 5-HT2A receptors in schizophrenia (Selvaraj et al., 2014). Serotonin, and its pre-cursor tryptophan, are critical signaling molecules in the brain-gutmicrobiota axis (O’Mahony et al., 2015). In GF mice decreased 5-HT1A in hippocampus has been shown (Neufeld et al., 2011). In the gastrointestinal tract (GI), 5-HT plays an important role in secretion, sensing and signaling (Mawe and Hoffman, 2013). The largest reserve of 5-HT is located in enterochromaffin cells (Berger et al., 2009). Emerging evidence also suggests that the serotonergic system may be under the influence of gut microbiota, especially, but not limited to, periods prior to the emergence of a stable adult-like gut microbiota (Desbonnet et al., 2008; El Aidy et al., 2012; Clarke et al., 2013). A metabolomics study demonstrated that the gut microbiota has a significant impact on blood metabolites and showed an almost three-fold increase in plasma serotonin levels when GF mice are colonized by gut microbiota (Wikoff et al., 2009). The gut microbiota itself is also an important regulator of 5-HT synthesis and secretion. For example, colonic tryptophan hydroxylase 1 (Tph1) mRNA and protein were increased in humanized GF and conventionally raised mice. Bacterial metabolites have also been demonstrated to influence Tph1 transcription in a human enterochromaffin cell model (Reigstad et al., 2015). Others have demonstrated 
that distinct microbial metabolites produced by spore forming bacteria increase colonic and blood 5-HT in chromaffin cell cultures (Yano et al., 2015).

\section{Kynurenine}

The regulation of circulating tryptophan availability, and the distribution and subsequent kynurenine pathway metabolism, in the periphery and CNS, is tightly regulated during all stages of life (Ruddick et al., 2006; Badawy, 2017). The enzyme indoleamine 2,3-dioxygenase (IDO) found in macrophages and microglia cells is the first and rate limiting step in the kynurenine pathway of tryptophan catabolism. The expression of tryptophan-2,3dioxygenase (TDO) can be induced by circulating glucocorticoids (O'Connor et al., 2009) and has been reported to be regulated by the gut microbiota during colonization (El Aidy et al., 2014). Under normal physiological conditions, approximately $99 \%$ of tryptophan is metabolized to kynurenine in the liver by TDO. However, proinflammatory cytokines such as IFN- $\gamma$, CRP, IL-1, IL- 6 , and TNF- $\alpha$ can induce IDO resulting in the metabolism of tryptophan along the kynurenine pathway (Schwarcz et al., 2012). Kynurenine, tryptophan and 3-hydroxykynurenine (3-HK) can cross the $\mathrm{BBB}$ and tryptophan's conversion to kynurenine and 3 -HK in the peripheral circulation can therefore contribute to CNS levels (Schwarcz et al., 2012; Myint and Kim, 2014). In the brain, kynurenine metabolism occurs in all cells, though the two kynurenine pathway branches are physically segregated into distinct cell types. Astrocytes contain kynurenine aminotransferases (KATs), not kynurenine 3-monooxygenase (KMO) and therefore cannot produce 3-hydroxykynurenine (3HK) from Kynurenine (Guidetti et al., 2007). The end result of the metabolic pathway in astrocytes is the neuroprotective Kynurenic acid (KYNA) (Gramsbergen et al., 1997), whereas, in microglia, it is the neurotoxic metabolite quinolinic acid (Alberati-Giani et al., 1996).

As mentioned above, regulation of the kynurenine pathway is important throughout life, but especially during sensitive periods of early neurodevelopment. KYNA is an NMDA and alpha7 nicotinic $(\alpha 7 \mathrm{nACh})$ receptor antagonist, both important in modulating brain development (Myint and Kim, 2014). Administration of kynurenine, starting during embryogenesis, reduced the expression of $\alpha 7 \mathrm{nACh}$ receptor and mGluR2 expression, and induced deficits in prefrontal cortex mediated cognition in adult rats (Pershing et al., 2015). Indeed, prenatal, but not adolescent, kynurenine treatment caused significant impairments in hippocampal-mediated behavioral tasks (Pocivavsek et al., 2014). Combining perinatal cholinesupplementation, with embryonic kynurenine manipulation, to potentially increase activation of $\alpha 7 \mathrm{nACh}$ receptors during development, can attenuate cognitive impairments in adult rat offspring (Notarangelo and Pocivavsek, 2017). Furthermore, prenatal kynurenine induces age-dependent changes in NMDA receptor expression (NR2A, NR1) (Pershing et al., 2016). This study also showed that juvenile rats that were given kynurenine performed better in a trace fear conditioning task, whereas the adults showed deficits. Prenatal inhibition of kynurenine pathway, using the kynurenine-3-monoxygenase inhibitor (Ro61-8048), results in altered synaptic transmission and protein expression in the brains of adult offspring (Forrest et al., 2013; Khalil et al., 2014; Pisar et al., 2014), and also changes hippocampal plasticity (Forrest et al., 2015). Using a kynurenine 3 -monooxygenase knockout mouse model $(\mathrm{Kmo}-/-)$, which increased brain KYNA levels, showed impairments in contextual memory, social behavior, and increased anxiety-like behavior (Erhardt et al., in press). Interestingly, administering Damphetamine to Kmo-/- mice showed potentiated horizontal activity in the open field paradigm.

In schizophrenia, increased KYNA levels in CSF, including in drug naïve patients (Nilsson et al., 2005), and in post-mortem brain samples have been shown (Erhardt et al., 2001; Plitman et al., 2017). In a clinical study, patients with schizophrenia ( $n=64)$ were more intolerant to a psychological stress challenge than healthy controls, and while salivary KYNA levels increased significantly between baseline and 20 min following the stressor in both patients and controls, patients who were unable to tolerate the stressful tasks showed significantly higher levels of KYNA than patients who tolerated the psychological stressor or healthy controls (Chiappelli et al., 2014). A recent pre-clinical study showed that restraint stress in pregnant mice caused significant elevations of KYNA levels in the maternal plasma, placenta, and fetal brain (Notarangelo and Schwarcz, 2017). Furthermore, the kynurenine/tryptophan ratio was significantly higher in patients diagnosed with psychotic disorder (Barry et al., 2009). Collectively, these pre-clinical and clinical studies highlight the importance of the kynurenine pathway during neurodevelopment, and there is a growing appreciation that integrating these important insights with the emerging importance of microbial regulation of this pathway will be an important research objective (Kennedy et al., 2017).

\section{Zinc Signaling}

The essential micronutrient Zinc plays an important role in immune function and GI development and function (Kau et al., 2011; Vela et al., 2015). Multiple independent factors affect Zinc status, including diet, prenatal and early life stress, immune system dysregulation, and impaired GI function (Vela et al., 2015). Zinc deficiency, particularly during the prenatal phase, has been proposed as an environmental risk factor for ASD. Indeed, in rats, acute Zinc deficiency can result in hyperactivity and over-responsivity, whereas prenatal deficiency can impair vocalizations and social behavior (Grabrucker et al., 2014). It has been suggested that the post-synaptic protein Shank3, which is localized at synapses in the brain and is associated with neuro-developmental disorders such as ASD and schizophrenia, is an important component of zinc-sensitive signaling system that regulates excitatory synaptic transmission, and may lead to cognitive and behavioral abnormalities in infants with ASD (Grabrucker et al., 2014; Arons and Lee, 2016). In clinical studies, Zinc deficiency has been reported in infants with ASD (Yorbik et al., 2004; Yasuda et al., 2011; Li et al., 2014). However, studies investigating Zinc levels in schizophrenia have yielded inconsistent results (Cai et al., 2015). The impact of micronutrient imbalances on the gut microbiota are beginning to emerge (Hibberd et al., 2017). In a study using chicks, Zinc deficiency induced gut microbiota alterations and decreased 
species richness and diversity (Reed et al., 2015). Excess dietary Zinc significantly altered the gut microbiota and in turn reduced the threshold of antibiotics needed to confer susceptibility to $C$. difficile infection in mice (Zackular et al., 2016).

\section{Epigenetic Influences}

Dietary factors can result in epigenetic alterations that lead to disease susceptibility (Jirtle and Skinner, 2007). It has been established that prenatal malnutrition increases the risk of schizophrenia (Susser and Lin, 1992; St Clair et al., 2005; Xu et al., 2009). Furthermore, it has been suggested that the microbiota is an important mediator of gene-environment interactions (Stilling et al., 2014b). SCFAs (butyrate, acetate and propionate) are neurohormonal signaling molecules produced by certain classes of bacteria such as Bacteroides, Bifidobacterium, Propionibacterium, Eubacterium, Lactobacillus, Clostridium, Roseburia, and Prevotella (Macfarlane and Macfarlane, 2012). SCFAs are transported by monocarboxylate transporters, which notably are expressed at the BBB (Steele, 1986; Vijay and Morris, 2014). A pre-clinical imaging study demonstrated that microbiota-derived acetate can cross the $\mathrm{BBB}$ where it can subsequently alter hypothalamic gene expression (Frost et al., 2014). Butyrate has been shown to be associated with increased expression of the tight junction protein occludin in the frontal cortex and hippocampus (Braniste et al., 2014). Butyrate, which acts as a potent inhibitor of Histone deacetylase (HDAC), is also a ligand for a subset of $G$ protein-coupled receptors (Bourassa et al., 2016). It is clear that supra-physiological levels do have marked behavioral consequences (MacFabe et al., 2007; Macfabe, 2012; Thomas et al., 2012). However, the ability of physiological levels of SCFAs to substantially effect behavior via central mechanism are likely to be subtle, though cumulative chronic delivery may produce long-lasting stable effects on gene expression.

\section{Microbiota and Social Behavior and Cognition}

Neuronal activity in the amygdala is altered in GF mice (Stilling et al., 2015). In these mice, expression of immediate early response genes such as Fos, Fosb, Egr2, or Nr4a1 were increased in the amygdala, in conjunction with increased signaling of the transcription factor CREB (Stilling et al., 2015). Differential expression and recoding of several genes involved in fundamental brain processes ranging from neuronal plasticity, metabolism, neurotransmission and morphology were identified and a significant downregulation was noted for immune systemrelated genes (Stilling et al., 2015). In addition to an altered transcriptional profile in the amygdala, GF mice have recently been shown to exhibit reduced freezing behavior during a cued memory retention test, while colonized GF mice were behaviorally comparable to conventionally raised mice during the retention test (Hoban et al., 2017). Furthermore, adult GF mice have distinct dendritic morphological changes in the amygdala and hippocampus (Luczynski et al., 2016) and myelination of the prefrontal cortex has also been shown to be under the influence of the gut microbiota (Hoban et al., 2016b). Using GF mice, Desbonnet et al. (2014) showed that the microbiota is crucial for the development of normal social behaviors, including social motivation and preference for social novelty, while also being an important regulator of repetitive behaviors (Arentsen et al., 2015; Buffington et al., 2016). This decreased sociability has also been demonstrated in rats (Crumeyrolle-Arias et al., 2014). Interestingly, the peptidoglycan (PGN)-sensing molecule, Pglyrp2, has been shown to modulate the development of social behavior in mice and alterations in the expression of the ASD risk gene c-Met (Arentsen et al., 2017).

Oxytocin, a neuropeptide produced in the paraventricular nucleus (PVN) of the hypothalamus, is important for sociability (Teng et al., 2013). Offspring of mothers fed a high-fat diet showed reduced levels of oxytocin PVN neurons, in addition to behavioral and gut microbiota alterations (Buffington et al., 2016). L. reuteri treatment restored oxytocin levels and social behaviors. A recent study, using low dose penicillin, administered to dams in late pregnancy and early post-natal life showed that this antibiotic induced gut microbiota alterations, increased cytokine expression in frontal cortex, modified BBB integrity and decreased anxiety-like and social behaviors, in offspring (Leclercq et al., 2017). Interestingly, concurrent supplementation with $L$. rhamnosus (JB-1) attenuated the penicillin induced decrease in social novelty.

The maternal immune activation (MIA) model serves as a useful model for neurodevelopmental disorders such as ASD and schizophrenia, and it is well established that prenatal infection can act as "neurodevelopmental disease primer," the consequences of which are dependent on precise timing of MIA (Meyer et al., 2006; Smith et al., 2007; Knuesel et al., 2014; Meyer, 2014; Coiro et al., 2015; Meehan et al., 2016; Pendyala et al., 2017). MIA rodents display all three of the core features of human ASD, including limited social interactions, a tendency toward repetitive behavior and reduced communication (Patterson, 2011). A recent study showed that MIA induces dysregulation of fetal brain transcriptome by downregulating genes related to ASD (Lombardo et al., 2017). MIA has been associated with altered gut microbiota. Furthermore, the commensal Bacteroides fragilis reversed the deficits in communicative, stereotypic, anxiety-like and sensorimotor behaviors (Hsiao et al., 2013).

Autistic like behavior and neurochemical alterations have also been demonstrated in a mouse model of food allergy (de Theije et al., 2014b). The same author showed an altered gut microbiota profile in an autism model, using valproic acid (VPA) (de Theije et al., 2014a). Interestingly, VPA, a medication used as a mood stabilizer in bipolar affective disorder and as an antiepileptic, functions as a HDAC inhibitor and has a similar structure to the SCFA propionic acid. It is well established that VPA acid use during pregnancy increases the risk of autism (Jacob et al., 2013), and propionic acid can also modulate mitochondrial function in autism and control cell lines (Frye et al., 2016).

As indicated above, multiple cognitive domains are impacted in ASD and schizophrenia and the gut microbiota has been implicated in a number of relevant cognitive functions. The combination of acute stress and infection can impact cognition. Citrobacter rodentium infected C57BL/6 mice that were exposed to acute stress exhibited memory dysfunction (Gareau et al., 2011). Moreover, GF Swiss-Webster mice displayed memory 
impairment at baseline, in the absence of acute stress (Gareau et al., 2011). In male C57BL/6 mice, higher percentages of Clostridiales and lower levels of Bacteroidales in high-energy diets were related to poorer cognitive flexibility (Magnusson et al., 2015). In BALB/c mice, treatment with B. Longum resulted in an improvement in stress related behavior and cognition (Savignac et al., 2015). Hippocampal neurogenesis, a pivotal process in learning and memory consolidation (Deng et al., 2010; Levone et al., 2015; Anacker and Hen, 2017; Hueston et al., 2017) has been shown to be regulated by the gut microbiota. GF mice exhibit increased adult hippocampal neurogenesis in the dorsal hippocampus, and post-weaning microbial colonization failed to reverse the changes in adult hippocampal neurogenesis (Ogbonnaya et al., 2015). Furthermore, exercise or probiotics were able to ameliorate deficits in neurogenesis and behavior in antibiotic-treated mice (Mohle et al., 2016). A recent study showed that L. johnsonii CJLJ103 attenuated colitis and memory impairment in mice by inhibiting gut microbiota lipopolysaccharide production and NF- $\kappa$ B activation (Lim et al., 2017).

Using an antibiotic (ampicillin, metronidazole, vancomycin, ciprofloxacin, imipenem) treated rat model, gut microbiota depletion during adulthood resulted in deficits in spatial memory as measured by Morris water maze (Hoban et al., 2016a). In another pre-clinical study, that used ampicillin, bacitracin, meropenem, neomycin, and vancomycin, novel object recognition, but not spatial memory, was impaired in antibiotictreated mice and this cognitive deficit was associated with brain region-specific changes in the expression of cognitionrelevant signaling molecules, notably BDNF, N-methyl-Daspartate receptor subunit $2 \mathrm{~B}$, serotonin transporter and neuropeptide Y system. The authors concluded that circulating metabolites and the cerebral neuropeptide $\mathrm{Y}$ system play an important role in the cognitive impairment and dysregulation of cerebral signaling molecules due to antibiotic-induced gut alterations (Frohlich et al., 2016). Furthermore, in a pre-clinical rodent model of diabetes, $L$. acidophilus, B. lactis, and $L$. fermentum, improved diabetes-induced impairment of cognitive function in the Morris water maze and synaptic activity in rats (Davari et al., 2013). The N-methyl-D-aspartate (NMDA) receptor antagonist, phencyclidine causes hyperlocomotion, social withdrawal, and cognitive impairment in rodents, and serves as a useful pharmacological rodent model of schizophrenia (Jones et al., 2011). A study investigating the effect of subchronic phencyclidine (subPCP) treatment on cognition and gut microbiota, found that the microbiota altered immediately after subPCP washout. Administration of ampicillin abolished the subPCP-induced memory deficit (Pyndt Jorgensen et al., 2015).

\section{Microbiota and Stress}

The brain interprets perceived stressors to determine physiological and behavioral responses. This process can promote adaptation (allostasis), but when responses are exaggerated or overused (allostatic overload), pathology can ensue (McEwen, 2017). The immune system and HPA axis are pivotal to the stress response and act as mediators to alter neural circuitry and function, particularly in the hippocampus, amygdala, and prefrontal cortex (McEwen et al., 2016). Stressful life events can precipitate psychotic symptoms (Day et al., 1987), and increased sensitivity to minor stressful events are associated with more intense psychotic experiences in first episode psychosis (FEP) (Reininghaus et al., 2016b). In addition early life event stressors, such as childhood trauma (Varese et al., 2012) and social adversity/defeat stressors, such as migration/ethnic minority status can increase the risk of psychosis (Elizabeth Cantor-Graae and Jean-Paul Selten, 2005; Selten and CantorGraae, 2005; Fusar-Poli et al., 2017). As mentioned above, schizophrenia is a highly heterogenous disorder, and commonly co-morbid with anxiety and depressive disorders (Buckley et al., 2009; Achim et al., 2011). Similarly, approximately 40\% of young people with ASD have at least one comorbid DSM-IV anxiety disorder (van Steensel et al., 2011) and there are higher levels of depression (Ghaziuddin et al., 2002; Magnuson and Constantino, 2011; Strang et al., 2012).

Stress can reshape gut microbiota composition (Wang and Wu, 2005; O’Mahony et al., 2009; Galley et al., 2014a,b; Golubeva et al., 2015; Frohlich et al., 2016). For example, early life maternal separation resulted in a significant decrease in fecal Lactobacillus numbers on day 3 post-separation which was correlated with stress related behaviors in rhesus monkeys (Bailey and Coe, 1999). In a mouse model of social disruption, stress altered the gut microbial profile and increased the levels of the proinflammatory cytokine IL-6 (Bailey et al., 2011). Interestingly, it was possible to transfer an anxious behavioral phenotype between two strains of mice via fecal microbiota transfer (Bercik et al., 2011). More recently, it has been shown that mice that received an obesity associated microbiota exhibit more anxiety-like behaviors associated with increased evidence of neuroinflammation compared to controls (Bruce-Keller et al., 2015).

As previously mentioned, the developmental trajectory of the gut microbiota is compatible with concepts of the earlylife period as a vulnerable phase for the subsequent emergence of neurodevelopmental disorders (O’Mahony et al., 2009, 2017; Borre et al., 2014). Pre-clinical evidence suggests that the gut microbiota signature acquired and maintained during these pivotal stages may also affect stress reactivity. GF rodents demonstrate abnormal behavioral and neuroendocrine responses to stress (Sudo et al., 2004; Nishino et al., 2013; CrumeyrolleArias et al., 2014; Moloney et al., 2014) and the normal development of the HPA axis is contingent on microbiota colonization at specific neurodevelopmental time points (Sudo et al., 2004).

Furthermore, the expression of anxiety like behavior in a mouse model of early life stress is partially dependent on the gut microbiota (De Palma et al., 2015). Evidence suggests that prenatal stress also impacts the gut microbiota with implications for physiological outcomes in the offspring (Golubeva et al., 2015). In a mouse model of prenatal stress, maternal stress decreased the abundance of vaginal Lactobacillus, resulting in decreased transmission of this bacterium to offspring, which corresponded with changes in metabolite profiles involved in energy balance, and with disruptions of amino acid profiles in 
the developing brain (Jasarevic et al., 2015). Human infants of mothers with high self-reported stress and high salivary cortisol concentrations during pregnancy had significantly higher relative abundances of Proteobacterial groups known to contain pathogens and lower relative abundances of lactic acid bacteria (Lactobacillus) and Bifidobacteria (Zijlmans et al., 2015). In addition, those infants with altered microbiota composition exhibited a higher level of maternally reported infant GI symptoms and allergic reactions, highlighting the functional consequences of aberrant colonization patterns.

The stress related disorder, depression, commonly co-morbid with ASD and schizophrenia, has been associated with alterations in gut microbiota profiles (Naseribafrouei et al., 2014; Jiang et al., 2015) and altered metabolomic output (Yu et al., 2017). Fecal Microbiota Transfer (FMT) from depressed patients to GF mice (Zheng et al., 2016) and antibiotic treated rats (Kelly, 2016; Kelly et al., 2016a) resulted in the transfer of certain depressive and anxiety like behaviors in the recipient rodents. The first study investigating the gut microbiota in bipolar affective disorder patients $(n=115)$, showed levels of Faecalibacterium were decreased, after adjusting for age, sex, and BMI, compared to healthy control subjects $(n=64)$. Moreover, Faecalibacterium was associated with better self-reported health outcomes based on the Short Form Health Survey, the Patient Health Questionnaire, the Pittsburg Sleep Quality Index, the Generalized Anxiety Disorder scale, and the Altman Mania Rating Scale (Evans et al., 2017). Interestingly, reduced levels of Faecalibacterium were reported in the study by Jiang and colleagues, which negatively correlated with severity of depressive symptoms (Jiang et al., 2015).

Fecal microbiota signatures in patients with diarrheapredominant Irritable Bowel Syndrome (IBS), a stress related GI disorder, were shown to be similar to those patients with depression (Liu et al., 2016). Moreover, FMT from IBS patients to rats, induced anxiety related behaviors in the rats (De Palma and Lynch, 2017). In a double blind RCT of IBS patients, 6 weeks of $B$. longum NCC3001 reduced depression scores as measured by the Hospital Anxiety and Depression scale, and responses to negative emotional stimuli in amygdala and fronto-limbic regions, using fMRI, compared to placebo (Pinto-Sanchez et al., 2017). A recent study, using structural MRI, showed that gut microbial composition correlated with sensory and salience-related brain regions (Labus et al., 2017).

\section{Translational Approaches}

In pre-clinical studies, both prebiotic (Burokas et al., in press) and probiotic treatment can reduce stress related behaviors (Abildgaard et al., 2017; Moya-Pérez et al., 2017). In a recent study, $L$. reuteri was reported to reduce despair like behavior in mice by inhibition of intestinal Indoleamine 2,3-dioxygenase (IDO1) and decrease peripheral levels of kynurenine (Marin et al., 2017). The profusion of pre-clinical data indicating a role for the brain-gut-microbiota axis in brain development, function and behavior, prompted the growing need to translate these findings into human populations (Kelly et al., 2015). "Psychobiotics," originally defined as live bacteria that when ingested in adequate amounts could produce a positive mental health benefit, in terms of anxiety, mood and cognition (Dinan et al., 2013), has more recently been expanded to encompass "any substance that exerts a microbiome-mediated psychological effect" (Sarkar et al., 2016; Allen et al., 2017).

The process of translating psychobiotics from bench to bedside is not without significant challenges (Arrieta et al., 2016; Kelly, 2016; Kelly et al., 2016b; Cani, 2017), but a growing number of small studies with healthy individuals suggest that prolonged pre- and probiotic consumption can positively affect aspects of mood and anxiety in healthy controls (Messaoudi et al., 2011; Mohammadi et al., 2015; Steenbergen et al., 2015; Allen et al., 2016) and modulate HPA axis function (Messaoudi et al., 2011; Schmidt et al., 2015; Allen et al., 2016). Importantly, a fermented milk containing $B$. animalis, Streptococcus thermophiles, $L$. bulgaricus, and $L$. lactis, administered for 4 weeks to healthy women, reduced the task-related response of a distributed functional network containing affective, viscerosensory and somatosensory cortices, independent of self-reposted GI symptoms (Tillisch et al., 2013).

In humans, studies investigating the potential cognitive enhancing effects of microbial based therapies are starting to emerge (Allen et al., 2016). In this study, 4 weeks of treatment with the probiotic B. longum 1714 modestly improved performance in a hippocampal dependent memory task in healthy volunteers. However, this effect is likely strain specific since this subtle cognitive enhancing effect was not evident following administration of L. rhamnosus (JB-1) (Kelly et al., 2017a). In a randomized, double-blind, placebo-controlled trial involving healthy human participants $(n=76)$, the tetracycline antibiotic doxycycline $(200 \mathrm{mg})$, a matrix metalloproteinase inhibitor, resulted in reduced fear memory retention, measured with fear-potentiated startle, 7 days post-acquisition compared to participants that received placebo (Bach et al., 2017). Doxycycline can alter the composition of the gut microbiota and its metabolomic output (Angelakis et al., 2014; Behr et al., 2017). Considering the recent pre-clinical data suggesting a role for the gut microbiota in the behavioral response during amygdala-dependent memory retention (Hoban et al., 2017), it would be a compelling prospect to ascertain if alterations in gut microbiota played a physiological role in this antibiotic human study. A cross sectional MRI study comparing 20 obese individuals to 19 age and sex matched non-obese controls, reported that the relative abundance of Actinobacteria phylum was associated with magnetic diffusion tensor imaging variables in the thalamus, hypothalamus, and amygdala and also with to cognitive test scores related to speed, attention, and cognitive flexibility (Fernandez-Real et al., 2015). Although preliminary, these studies, and others (Pinto-Sanchez et al., 2017), are beginning to merge microbiome research with neuroimaging to further delineate the role of the gut microbiota on cognition and neural circuitry.

To date, there are two interventional studies investigating potential psychobiotics in clinical depression, with conflicting results. In the first study, 8 weeks of a multispecies probiotic containing L. acidophilus, L. casei, and B. bifidum, added to an SSRI, reportedly reduced depressive symptoms in moderately depressed patients compared to placebo (Akkasheh et al., 2016). 
The other study, conducted in antidepressant free depressed subjects, failed to show superiority of L. helveticus and B. longum over placebo, in an 8-week double blind randomized controlled trial (Romijn et al., 2017). A Mediterranean diet, suggested as protective for depression, has been associated with beneficial microbiome-related metabolomic profiles (De Filippis et al., 2015) and there is increasing awareness of the role of a healthy diet in reducing the risk of depression (Jacka et al., 2010, 2017; Opie et al., 2017). Collectively, these studies suggest that the gut microbiota may play a pathophysiological role in stressrelated disorders. However, given the small sample sizes and lack of a standardized approach in these studies, a robust and consistent gut microbiota signature in stress-related disorders, remains elusive. Moreover, a systematic review found very limited evidence for the efficacy of psychobiotics in psychological outcomes (Romijn and Rucklidge, 2015). Similarly, even in GI disorders, gut microbiota analysis as a diagnostic or prognostic tool has not transitioned into routine clinical practice (Quigley, 2017).

There has been one clinical interventional study investigating probiotics in patients diagnosed with schizophrenia. This randomized, double-blind, placebo-controlled trial $(n=65)$, used Lactobacillus rhamnosus strain GG and Bifidobacterium animalis subsp. lactis strain $\mathrm{Bb} 12$, improved GI symptoms, but failed to impact positive or negative symptoms (Dickerson et al., 2014). A number of small studies have shown that the antibiotic minocycline, notwithstanding a complex mechanism of action, is known to modulate the brain-gut-microbiota axis, (Wong et al., 2016), and may improve negative and cognitive symptoms in schizophrenia (Miyaoka et al., 2008; Levkovitz et al., 2010; Jhamnani et al., 2013; Khodaie-Ardakani et al., 2014). This raises the question of whether microbiome based therapies could play a role in the amelioration of cognitive or negative symptoms in subgroups of psychosis spectrum disorder.

\section{Schizophrenia Spectrum Disorder and Stratified Psychiatry}

The full neuropsychiatric implications of specific aberrations in the gut microbiota at early developmental stages or during adolescence have not been fully explored. It is an intriguing prospect that these aberrations may serve as additional risk factors or mediators for the development of psychotic disorders. It remains an unanswered question whether the gut microbiota is a state or trait marker and whether it plays a role, in conjunction with for example, stress, as a trigger factor for a psychotic relapse. The role of psychobiotics in schizophrenia remains under investigated (see Table 2). It would be interesting to explore whether a microbial based therapy could be a useful preventative strategy, or as an adjunctive agent in subgroups or whether it could reduce conversion to psychosis in subgroups at risk of developing the disorder. Well powered, longitudinal studies, encompassing neuroimaging markers would be required to definitively answer these questions.

In recent years, the categorical diagnostic system in clinical psychiatry has been challenged. Even the term schizophrenia has been disputed (van Os, 2016), with evidence showing that renaming the disorder can reduce stigma and benefit communication between clinicians, patients and families (George and Klijn, 2013; Lasalvia et al., 2015). There is growing momentum toward a more precise, dimensional approach, designed to uncover the biological mechanisms of these complex disorders. Functional dimensional constructs grouped into domains such as negative valance (acute threat (fear), potential threat (anxiety), sustained threat, loss, frustrative non-reward), positive valence (approach motivation, initial responsiveness to reward attainment, sustained/longer term responsiveness to reward attainment, reward learning, habit), cognitive (attention, perception, declarative memory, language, cognitive control, working memory), social processing (affiliation and attachment, social communication, perception, and understanding of self/others), and arousal/regulatory systems (arousal, circadian rhythms, sleep-wakefulness) examined across units of analysis from genes, molecules, cells, circuits, physiology, neuroimaging, behavior and self-report have been proposed (Insel et al., 2010). This dimensional approach is more difficult in disorders such as psychosis, compared to mood disorders, but this exciting process has begun (Reininghaus et al., 2016a; Cohen et al., 2017; Joyce et al., 2017). By deconstructing heterogenous systemsdisorders (Öngür, 2017; Silbersweig and Loscalzo, 2017), such as schizophrenia into transdiagnostic constructs, and stratifying subgroups of patients based on similar pathophysiology, such as microbiome alterations and related signaling pathways, this opens up the possibility to advance personalized and precision treatments options (Kaiser and Feng, 2015).

Additionally, by removing the constraints of classical psychiatric disease diagnosis it has the potential to better align pre-clinical and clinical studies to build a common framework of comparable neurobiological abnormalities. Clearly, it is impossible to fully mimic a complex neuropsychiatric disorder such as schizophrenia or ASD in non-human animals. Hallucinations, delusions, thought disorder, and language impairments cannot be modeled. Thus, rather than modeling an entire disorder, the focus should be aimed at more precise constructs such those mentioned above, with the addition of the gut microbiota. Most currently used behavioral models do not include the gut microbiota as a factor. Clearly demonstrating causality in microbiome research is challenging (Hanage, 2014; Cani, 2017). The humanized FMT model is an integral component to demonstrate cause and effect in gut microbiota studies involving neurodevelopmental disorders such as schizophrenia, and provided a reliable and reproducible model can be developed, the precise temporal dynamics of the emergence and possible persistence of the behavioral alterations post FMT could be further delineated.

Furthermore, whether different human donor symptom profiles can be transferred via FMT may further disentangle the contribution of the gut microbiota to the pathophysiology of aspects of psychosis, by attempting to transfer sub-categories of psychotic subjects, including medication free subjects, with different constructs such as negative valance, positive valence, cognitive, social processing and arousal/regulatory systems. While it must be acknowledged that significant neuroscientific 
advances have frequently been lost in translation and not had appreciable benefits for psychiatric patients as yet, an evolving dimensional framework, consolidating multiple disciplines, and encompassing the gut microbiota as an additional environmental construct linked to other constructs, offers potential to identify sub-groups of patients that may be more likely to respond to a microbiome-based therapeutic approach at specific neurodevelopmental time points (Kelly, 2016; Severance et al., 2016c; Kelly et al., 2017b).

\section{CONCLUSIONS AND PERSPECTIVES}

Highly complex neurodevelopmental disorders such as ASD and schizophrenia require a systems level approach. The human brain develops and functions within the context of a complex network of lifelong microbial signaling pathways from gut to brain. Pre-clinical studies are beginning to provide mechanistic insights into these signaling pathways as they relate to the social, emotional and cognitive domains of the brain. Furthermore, they suggest that psychobiotics can ameliorate certain defects. However, translating these promising pre-clinical benefits to human neurodevelopment disorders is challenging. The majority of clinical studies investigating the gut microbiota in ASD are cross sectional and underpowered, and there is insufficient evidence of solid clinical relevance. In schizophrenia, there is emerging preliminary evidence of an altered gut microbiota. An intriguing prospect would be to focus on different neurodevelopmental time points, for example during adolescence, in subgroups at risk of developing neuropsychiatric symptoms, and to encompass a dimensional construct approach. Larger prospective interventional clinical studies, with central markers of brain function, utilizing therapeutic modulation of the gut microbiota or its metabolites are required. Furthermore,

\section{REFERENCES}

Abildgaard, A., Elfving, B., Hokland, M., Wegener, G., and Lund, S. (2017). Probiotic treatment reduces depressive-like behaviour in rats independently of diet. Psychoneuroendocrinology 79, 40-48. doi: 10.1016/j.psyneuen.2017.02.014 Achim, A. M., Maziade, M., Raymond, É., Olivier, D., Mérette, C., and Roy, M.-A. (2011). How prevalent are anxiety disorders in schizophrenia? A meta-analysis and critical review on a significant association. Schizophr. Bull. 37, 811-821. doi: $10.1093 /$ schbul/sbp148

Adams, J. B., Johansen, L. J., Powell, L. D., Quig, D., and Rubin, R. A. (2011). Gastrointestinal flora and gastrointestinal status in children with autismcomparisons to typical children and correlation with autism severity. BMC Gastroenterol. 11:22. doi: 10.1186/1471-230X-11-22

Adolphs, R. (2001). The neurobiology of social cognition. Curr. Opin. Neurobiol. 11, 231-239. doi: 10.1016/S0959-4388(00)00202-6

Akkasheh, G., Kashani-Poor, Z., Tajabadi-Ebrahimi, M., Jafari, P., Akbari, H., Taghizadeh, M., et al. (2016). Clinical and metabolic response to probiotic administration in patients with major depressive disorder: a randomized, double-blind, placebo-controlled trial. Nutrition 32, 315-320. doi: $10.1016 /$ j.nut.2015.09.003

Alberati-Giani, D., Ricciardi-Castagnoli, P., Kohler, C., and Cesura, A. M. (1996). Regulation of the kynurenine metabolic pathway by interferon-gamma in murine cloned macrophages and microglial cells. J. Neurochem. 66, 996-1004. doi: 10.1046/j.1471-4159.1996.66030996.x exploration of the interaction of the gut microbiota and nutritional modification, at different neurodevelopmental stages, including pre-conception, warrants exploration as a preventative strategy for neurodevelopmental disorders in addition to stress-related disorders (Jacka, 2017). Although it is premature to draw firm conclusions about the clinical utility of microbiome based treatment strategies in neurodevelopmental disorders at this point, it is an exciting frontier in psychiatry research.

\section{AUTHOR CONTRIBUTIONS}

JK wrote the manuscript. CM created the figures. GC, JC, and TD critiqued and edited the manuscript drafts.

\section{ACKNOWLEDGMENTS}

The APC Microbiome Institute is funded by Science Foundation Ireland (SFI). This publication has emanated from research conducted with the financial support of Science Foundation Ireland (SFI) under Grant Number SFI/12/RC/2273. The authors and their work were also supported by the Health Research Board (HRB) through Health Research Awards (grants no HRA_POR/2011/23; TD, JC, and GC, HRA_POR/2012/32; JC, TD, and HRA-POR-2-14-647: GC, TD) and through EUGRANT613979(MYNEWGUTFP7-KBBE-2013-7). The Centre has conducted studies in collaboration with several companies including GSK, Pfizer, Wyeth and Mead Johnson. GC is supported by a NARSAD Young Investigator Grant from the Brain and Behavior Research Foundation (Grant Number 20771). We would like to acknowledge work conducted as part of a PhD thesis; JK (2016). The gut microbiota in depression (PhD Thesis), University College Cork.
Al-Diwani, A. A. J., Pollak, T. A., Irani, S. R., and Lennox, B. R. (2017). Psychosis: an autoimmune disease? Immunology. doi: 10.1111/imm.12795. [Epub ahead of print].

Aleman, A., Hijman, R., de Haan, E. H., and Kahn, R. S. (1999). Memory impairment in schizophrenia: a meta-analysis. Am. J. Psychiatry 156, 1358-1366.

Aleman, A., and Kahn, R. S. (2005). Strange feelings: do amygdala abnormalities dysregulate the emotional brain in schizophrenia? Prog. Neurobiol. 77, 283-298. doi: 10.1016/j.pneurobio.2005.11.005

Aleman, A., Kahn, R. S., and Selten, J. (2003). Sex differences in the risk of schizophrenia: evidence from meta-analysis. Arch. Gen. Psychiatry 60, 565-571. doi: 10.1001/archpsyc.60.6.565

Allen, A. P., Dinan, T. G., Clarke, G., and Cryan, J. F. (2017). A psychology of the human brain-gut-microbiome axis. Soc. Pers. Psychol. Compass 11, e12309. doi: $10.1111 / \mathrm{spc} 3.12309$

Allen, A. P., Hutch, W., Borre, Y. E., Kennedy, P. J., Temko, A., Boylan, G., et al. (2016). Bifidobacterium longum 1714 as a translational psychobiotic: modulation of stress, electrophysiology and neurocognition in healthy volunteers. Transl. Psychiatry 6:e939. doi: 10.1038/tp.2016.191

Anacker, C., and Hen, R. (2017). Adult hippocampal neurogenesis and cognitive flexibility [mdash] linking memory and mood. Nat. Rev. Neurosci. 18, 335-346. doi: $10.1038 / \mathrm{nrn} .2017 .45$

Angelakis, E., Million, M., Kankoe, S., Lagier, J. C., Armougom, F., Giorgi, R., et al. (2014). Abnormal weight gain and gut microbiota modifications 
are side effects of long-term doxycycline and hydroxychloroquine treatment. Antimicrob. Agents Chemother. 58, 3342-3347. doi: 10.1128/AAC.02437-14

Arentsen, T., Qian, Y., Gkotzis, S., Femenia, T., Wang, T., Udekwu, K., et al. (2017). The bacterial peptidoglycan-sensing molecule Pglyrp2 modulates brain development and behavior. Mol. Psychiatry 22, 257-266. doi: 10.1038/mp.2016.182

Arentsen, T., Raith, H., Qian, Y., Forssberg, H., and Heijtz, R. D. (2015). Host microbiota modulates development of social preference in mice. Microb. Ecol. Health Dis. 26:29719. doi: 10.3402/mehd.v26.29719

Arias, I., Sorlozano, A., Villegas, E., Luna, J. D. D., McKenney, K., Cervilla, J., et al. (2012). Infectious agents associated with schizophrenia: a meta-analysis. Schizophr. Res. 136, 128-136. doi: 10.1016/j.schres.2011.10.026

Arons, M. H., and Lee, K. (2016). Shank3 is part of a zinc-sensitive signaling system that regulates excitatory synaptic strength. J. Neurosci. 36, 9124-9134. doi: 10.1523/JNEUROSCI.0116-16.2016

Arrieta, M.-C., Stiemsma, L. T., Amenyogbe, N., Brown, E. M., and Finlay, B. (2014). The intestinal microbiome in early life: health and disease. Front. Immunol. 5:427. doi: 10.3389/fimmu.2014.00427

Arrieta, M. C., Walter, J., and Finlay, B. B. (2016). Human microbiotaassociated mice: a model with challenges. Cell Host Microbe 19, 575-578. doi: 10.1016/j.chom.2016.04.014

Asan, E., Steinke, M., and Lesch, K. P. (2013). Serotonergic innervation of the amygdala: targets, receptors, and implications for stress and anxiety. Histochem. Cell Biol. 139, 785-813. doi: 10.1007/s00418-013-1081-1

Ashwood, P., Krakowiak, P., Hertz-Picciotto, I., Hansen, R., Pessah, I., and Van de Water, J. (2011). Elevated plasma cytokines in autism spectrum disorders provide evidence of immune dysfunction and are associated with impaired behavioral outcome. Brain Behav. Immun. 25, 40-45. doi: 10.1016/j.bbi.2010.08.003

Atladottir, H. O., Thorsen, P., Ostergaard, L., Schendel, D. E., Lemcke, S., Abdallah, M., et al. (2010). Maternal infection requiring hospitalization during pregnancy and autism spectrum disorders. J. Autism Dev. Disord. 40, 1423-1430. doi: $10.1007 /$ s10803-010-1006-y

Averbeck, B. B., and Costa, V. D. (2017). Motivational neural circuits underlying reinforcement learning. Nat. Neurosci. 20, 505-512. doi: 10.1038/nn.4506

Azevedo, F. A., Carvalho, L. R., Grinberg, L. T., Farfel, J. M., Ferretti, R. E., Leite, R. E., et al. (2009). Equal numbers of neuronal and nonneuronal cells make the human brain an isometrically scaled-up primate brain. J. Comp. Neurol. 513, 532-541. doi: 10.1002/cne.21974

Bach, D. R., Tzovara, A., and Vunder, J. (2017). Blocking human fear memory with the matrix metalloproteinase inhibitor doxycycline. Mol. Psychiatry. doi: 10.1038/mp.2017.65. [Epub ahead of print].

Backhed, F., Fraser, C. M., Ringel, Y., Sanders, M. E., Sartor, R. B., Sherman, P. M., et al. (2012). Defining a healthy human gut microbiome: current concepts, future directions, and clinical applications. Cell Host Microbe 12, 611-622. doi: 10.1016/j.chom.2012.10.012

Badawy, A. A. B. (2017). Tryptophan availability for kynurenine pathway metabolism across the life span: control mechanisms and focus on aging, exercise, diet and nutritional supplements. Neuropharmacology 112(Pt B), 248-263. doi: 10.1016/j.neuropharm.2015.11.015

Bahr, S. M., Tyler, B. C., Wooldridge, N., Butcher, B. D., Burns, T. L., Teesch, L. M., et al. (2015). Use of the second-generation antipsychotic, risperidone, and secondary weight gain are associated with an altered gut microbiota in children. Transl. Psychiatry 5:e652. doi: 10.1038/tp.2015.135

Bahra, S. M., Weidemann, B. J., Castro, A. N., Walsh, J. W., deLeon, O., Burnett, C. M., et al. (2015). Risperidone-induced weight gain is mediated through shifts in the gut microbiome and suppression of energy expenditure. EBioMedicine 2, 1725-1734. doi: 10.1016/j.ebiom.2015.10.018

Bailey, M. T., and Coe, C. L. (1999). Maternal separation disrupts the integrity of the intestinal microflora in infant rhesus monkeys. Dev. Psychobiol. 35, 146-155.

Bailey, M. T., Dowd, S. E., Galley, J. D., Hufnagle, A. R., Allen, R. G., and Lyte, M. (2011). Exposure to a social stressor alters the structure of the intestinal microbiota: implications for stressor-induced immunomodulation. Brain Behav. Immun. 25, 397-407. doi: 10.1016/j.bbi.2010.10.023

Bakken, T. E., Miller, J. A., Ding, S. L., Sunkin, S. M., Smith, K. A., Ng, L., et al. (2016). A comprehensive transcriptional map of primate brain development. Nature 535, 367-375. doi: 10.1038/nature18637
Baron-Cohen, S. (2017). Editorial perspective: neurodiversity - a revolutionary concept for autism and psychiatry. J. Child Psychol. Psychiatry 58, 744-747. doi: $10.1111 /$ jcpp. 12703

Barrett, E., Ross, R. P., O’Toole, P. W., Fitzgerald, G. F., and Stanton, C. (2012). gamma-Aminobutyric acid production by culturable bacteria from the human intestine. J. Appl. Microbiol. 113, 411-417. doi: 10.1111/j.1365-2672.2012.05344.x

Barry, S., Clarke, G., Scully, P., and Dinan, T. (2009). Kynurenine pathway in psychosis: evidence of increased tryptophan degradation. J. Psychopharmacol. 23, 287-294. doi: $10.1177 / 0269881108089583$

Bassett, D. S., and Sporns, O. (2017). Network neuroscience. Nat. Neurosci. 20, 353-364. doi: 10.1038/nn.4502

Behr, C., Kamp, H., Fabian, E., Krennrich, G., Mellert, W., Peter, E., et al. (2017). Gut microbiome-related metabolic changes in plasma of antibiotic-treated rats. Arch. Toxicol. doi: 10.1007/s00204-017-1949-2. [Epub ahead of print].

Benros, M. E., Mortensen, P. B., and Eaton, W. W. (2012). Autoimmune diseases and infections as risk factors for schizophrenia. Ann. N.Y. Acad. Sci. 1262, 56-66. doi: 10.1111/j.1749-6632.2012.06638.x

Bercik, P., Denou, E., Collins, J., Jackson, W., Lu, J., Jury, J., et al. (2011). The intestinal microbiota affect central levels of brain-derived neurotropic factor and behavior in mice. Gastroenterology 141, 599-609, 609.e1-3. doi: 10.1053/j.gastro.2011.04.052

Berding, K., and Donovan, S. M. (2016). Microbiome and nutrition in autism spectrum disorder: current knowledge and research needs. Nutr. Rev. 74, 723-736. doi: 10.1093/nutrit/nuw048

Berger, M., Gray, J. A., and Roth, B. L. (2009). The expanded biology of serotonin. Annu. Rev. Med. 60, 355-366. doi: 10.1146/annurev.med.60.042307.110802

Beste, C., Getzmann, S., Gajewski, P. D., Golka, K., and Falkenstein, M. (2014). Latent Toxoplasma gondii infection leads to deficits in goaldirected behavior in healthy elderly. Neurobiol. Aging 35, 1037-1044. doi: 10.1016/j.neurobiolaging.2013.11.012

Bhadra, R., Cobb, D. A., Weiss, L. M., and Khan, I. A. (2013). Psychiatric disorders in toxoplasma seropositive patients-the CD8 connection. Schizophr. Bull. 39, 485-489. doi: 10.1093/schbul/sbt006

Bilbo, S. D., Smith, S. H., and Schwarz, J. M. (2012). A lifespan approach to neuroinflammatory and cognitive disorders: a critical role for glia. $J$. Neuroimmun. Pharmacol. 7, 24-41. doi: 10.1007/s11481-011-9299-y

Bishop, S. L., Farmer, C., Bal, V., Robinson, E. B., Willsey, A. J., Werling, D. M., et al. (2017). Identification of developmental and behavioral markers associated with genetic abnormalities in autism spectrum disorder. Am. J. Psychiatry 174, 576-585. doi: 10.1176/appi.ajp.2017.16101115

Blandino, P. Jr., Barnum, C. J., Solomon, L. G., Larish, Y., Lankow, B. S., and Deak, T. (2009). Gene expression changes in the hypothalamus provide evidence for regionally-selective changes in IL-1 and microglial markers after acute stress. Brain Behav. Immun. 23, 958-968. doi: 10.1016/j.bbi.2009.0 4.013

Bloomfield, P. S., Selvaraj, S., Veronese, M., Rizzo, G., Bertoldo, A., Owen, D. R et al. (2016). Microglial activity in people at ultra high risk of psychosis and in schizophrenia: an [(11)C]PBR28 PET brain imaging study. Am. J. Psychiatry 173, 44-52. doi: 10.1176/appi.ajp.2015.14101358

Bollinger, J. L., Bergeon Burns, C. M., and Wellman, C. L. (2016). Differential effects of stress on microglial cell activation in male and female medial prefrontal cortex. Brain Behav. Immun. 52, 88-97. doi: 10.1016/j.bbi.2015.10.003

Bordenstein, S. R., and Theis, K. R. (2015). Host biology in light of the microbiome: ten principles of holobionts and hologenomes. PLOS Biol. 13:e1002226. doi: 10.1371/journal.pbio.1002226

Borre, Y. E., O'Keeffe, G. W., Clarke, G., Stanton, C., Dinan, T. G., and Cryan, J. F. (2014). Microbiota and neurodevelopmental windows: implications for brain disorders. Trends Mol. Med. 20, 509-518. doi: 10.1016/j.molmed.2014.05.002

Bourassa, M. W., Alim, I., Bultman, S. J., and Ratan, R. R. (2016). Butyrate, neuroepigenetics and the gut microbiome: can a high fiber diet improve brain health? Neurosci. Lett. 625, 56-63. doi: 10.1016/j.neulet.2016.02.009

Braniste, V., Al-Asmakh, M., Kowal, C., Anuar, F., Abbaspour, A., Toth, M., et al. (2014). The gut microbiota influences blood-brain barrier permeability in mice. Sci. Transl. Med. 6:263ra158. doi: 10.1126/scitranslmed.3009759

Bravo, J. A., Forsythe, P., Chew, M. V., Escaravage, E., Savignac, H. M., Dinan, T. G., et al. (2011). Ingestion of Lactobacillus strain regulates emotional 
behavior and central GABA receptor expression in a mouse via the vagus nerve. Proc. Natl. Acad. Sci. U.S.A. 108, 16050-16055. doi: 10.1073/pnas.11029 99108

Brenhouse, H. C., and Schwarz, J. M. (2016). Immunoadolescence: neuroimmune development and adolescent behavior. Neurosci. Biobehav. Rev. 70, 288-299. doi: 10.1016/j.neubiorev.2016.05.035

Brown, A. S. (2012). Epidemiologic studies of exposure to prenatal infection and risk of schizophrenia and autism. Dev. Neurobiol. 72, 1272-1276. doi: 10.1002/dneu.22024

Bruce-Keller, A. J., Salbaum, J. M., Luo, M., Blanchard, E. T., Taylor, C. M., Welsh, D. A., et al. (2015). Obese-type gut microbiota induce neurobehavioral changes in the absence of obesity. Biol. Psychiatry 77, 607-615. doi: 10.1016/j.biopsych.2014.07.012

Bsibsi, M., Ravid, R., Gveric, D., and van Noort, J. M. (2002). Broad expression of Toll-like receptors in the human central nervous system. J. Neuropathol. Exp. Neurol. 61, 1013-1021. doi: 10.1093/jnen/61.11.1013

Buckley, P. F., Miller, B. J., Lehrer, D. S., and Castle, D. J. (2009). Psychiatric Comorbidities and Schizophrenia. Schizophr. Bull. 35, 383-402. doi: 10.1093/schbul/sbn135

Buffington, S. A., Di Prisco, G. V., Auchtung, T. A., Ajami, N. J., Petrosino, J. F., and Costa-Mattioli, M. (2016). Microbial reconstitution reverses maternal diet-induced social and synaptic deficits in offspring. Cell 165, 1762-1775. doi: 10.1016/j.cell.2016.06.001

Buie, T., Fuchs, G. J. III., Furuta, G. T., Kooros, K., Levy, J., Lewis, J. D., et al. (2010). Recommendations for evaluation and treatment of common gastrointestinal problems in children with ASDs. Pediatrics 125(Suppl. 1), S19-29. doi: 10.1542/peds.2009-1878D

Burokas, A., Arboleya, S., Moloney, R. D., Peterson, V. L., Murphy, K., Clarke, G., et al. (in press). Targeting the microbiota-gut-brain axis: prebiotics have anxiolytic and antidepressant-like effects and reverse the impact of chronic stress in mice. Biol. Psychiatry. doi: 10.1016/j.biopsych.2016.12.031

Cai, L., Chen, T., Yang, J., Zhou, K., Yan, X., Chen, W., et al. (2015). Serum trace element differences between Schizophrenia patients and controls in the Han Chinese population. Sci. Rep. 5:15013. doi: 10.1038/srep15013

Calcia, M. A., Bonsall, D. R., Bloomfield, P. S., Selvaraj, S., Barichello, T., and Howes, O. D. (2016). Stress and neuroinflammation: a systematic review of the effects of stress on microglia and the implications for mental illness. Psychopharmacology 233, 1637-1650. doi: 10.1007/s00213-016-4218-9

Cani, P. D. (2017). Gut microbiota-at the intersection of everything? Nat. Rev. Gastroenterol. Hepatol. 14, 321-322. doi: 10.1038/nrgastro.2017.54

Canitano, R., and Pallagrosi, M. (2017). Autism spectrum disorders and schizophrenia spectrum disorders: excitation/inhibition imbalance and developmental trajectories. Front. Psychiatry 8:69. doi: 10.3389/fpsyt.2017.00069

Cao, X., Lin, P., Jiang, P., and Li, C. (2013). Characteristics of the gastrointestinal microbiome in children with autism spectrum disorder: a systematic review. Shanghai Arch. Psychiatry 25, 342-353. doi: 10.3969/j.issn.1002-0829.2013.06.003

Capuron, L., Pagnoni, G., Drake, D. F., Woolwine, B. J., Spivey, J. R., Crowe, R. J., et al. (2012). Dopaminergic mechanisms of reduced basal ganglia responses to hedonic reward during interferon alfa administration. Arch. Gen. Psychiatry 69, 1044-1053. doi: 10.1001/archgenpsychiatry.2011.2094

Careaga, M., Murai, T., and Bauman, M. D. (2017). Maternal immune activation and autism spectrum disorder: from rodents to nonhuman and human primates. Biol. Psychiatry 81, 391-401. doi: 10.1016/j.biopsych.2016. 10.020

Carlson, A. L., Xia, K., Azcarate-Peril, M. A., Goldman, B. D., Ahn, M., Styner, M. A., et al. (in press). Infant gut microbiome associated with cognitive development. Biol. Psychiatry. doi: 10.1016/j.biopsych.2017.06.021

Carruthers, V. B., and Suzuki, Y. (2007). Effects of Toxoplasma gondii infection on the brain. Schizophr. Bull. 33, 745-751. doi: 10.1093/schbul/sbm008

Casey, B. J., Oliveri, M. E., and Insel, T. (2014). A neurodevelopmental perspective on the research domain criteria (RDoC) framework. Biol. Psychiatry 76, 350-353. doi: 10.1016/j.biopsych.2014.01.006

Castro-Nallar, E., Bendall, M. L., Perez-Losada, M., Sabuncyan, S., Severance, E. G., Dickerson, F. B., et al. (2015). Composition, taxonomy and functional diversity of the oropharynx microbiome in individuals with schizophrenia and controls. PeerJ 3:e1140. doi: 10.7717/peerj.1140
Cermak, S. A., Curtin, C., and Bandini, L. G. (2010). Food selectivity and sensory sensitivity in children with autism spectrum disorders. J. Am. Diet. Assoc. 110, 238-246. doi: 10.1016/j.jada.2009.10.032

Chen, X., D'Souza, R., and Hong, S. T. (2013). The role of gut microbiota in the gut-brain axis: current challenges and perspectives. Protein Cell 4, 403-414. doi: 10.1007/s13238-013-3017-x

Chiappelli, J., Pocivavsek, A., Nugent, K. L., Notarangelo, F. M., Kochunov, P., Rowland, L. M., et al. (2014). Stress-induced increase in kynurenic acid as a potential biomarker for patients with schizophrenia and distress intolerance. JAMA Psychiatry 71, 761-768. doi: 10.1001/jamapsychiatry.2014.243

Chistiakov, D. A., Bobryshev, Y. V., Kozarov, E., Sobenin, I. A., and Orekhov, A. N. (2014). Intestinal mucosal tolerance and impact of gut microbiota to mucosal tolerance. Front. Microbiol. 5:781. doi: 10.3389/fmicb.2014.00781

Christensen, D. L., Baio, J., Van Naarden Braun, K., Bilder, D., Charles, J., Constantino, J. N., et al. (2016). Prevalence and characteristics of autism spectrum disorder among children aged 8 years-autism and developmental disabilities monitoring network, 11 sites, United States, 2012. MMWR. Surveill. Summ. 65, 1-23. doi: 10.15585/mmwr.ss6503al

Christian, L. M., Galley, J. D., Hade, E. M., Schoppe-Sullivan, S., Kamp Dush, C., and Bailey, M. T. (2015). Gut microbiome composition is associated with temperament during early childhood. Brain Behav. Immun. 45, 118-127. doi: $10.1016 /$ j.bbi.2014.10.018

Chu, D. M., Ma, J., Prince, A. L., Antony, K. M., Seferovic, M. D., and Aagaard, K. M. (2017). Maturation of the infant microbiome community structure and function across multiple body sites and in relation to mode of delivery. Nat. Med. 23, 314-326. doi: 10.1038/nm.4272

Clarke, G., Grenham, S., Scully, P., Fitzgerald, P., Moloney, R. D., Shanahan, F., et al. (2013). The microbiome-gut-brain axis during early life regulates the hippocampal serotonergic system in a sex-dependent manner. Mol. Psychiatry 18, 666-673. doi: 10.1038/mp.2012.77

Cohen, A. S., Le, T. P., Fedechko, T. L., and Elvevag, B. (2017). Can RDoC help find order in thought disorder? Schizophr. Bull. 43, 503-508. doi: $10.1093 / \mathrm{schbul} / \mathrm{sbx} 030$

Coiro, P., Padmashri, R., Suresh, A., Spartz, E., Pendyala, G., Chou, S., et al. (2015). Impaired synaptic development in a maternal immune activation mouse model of neurodevelopmental disorders. Brain Behav. Immun. 50, 249-258. doi: 10.1016/j.bbi.2015.07.022

Collste, K., Plaven-Sigray, P., Fatouros-Bergman, H., Victorsson, P., Schain, M., Forsberg, A., et al. (2017). Lower levels of the glial cell marker TSPO in drug-naive first-episode psychosis patients as measured using PET and [lsqb]11C[rsqb]PBR28. Mol. Psychiatry 22, 850-856. doi: 10.1038/mp.2016.247

Conti, E., Mitra, J., Calderoni, S., Pannek, K., Shen, K. K., Pagnozzi, A., et al. (2017). Network over-connectivity differentiates autism spectrum disorder from other developmental disorders in toddlers: a diffusion MRI study. Hum. Brain Mapp. 38, 2333-2344. doi: 10.1002/hbm.23520

Corvin, A., and Morris, D. W. (2014). Genome-wide association studies: findings at the major histocompatibility complex locus in psychosis. Biol. Psychiatry 75, 276-283. doi: 10.1016/j.biopsych.2013.09.018

Croen, L. A., Grether, J. K., and Selvin, S. (2002). Descriptive epidemiology of autism in a California population: who is at risk? J. Autism Dev. Disord. 32, 217-224. doi: 10.1023/A:1015405914950

Crumeyrolle-Arias, M., Jaglin, M., Bruneau, A., Vancassel, S., Cardona, A., Dauge, V., et al. (2014). Absence of the gut microbiota enhances anxiety-like behavior and neuroendocrine response to acute stress in rats. Psychoneuroendocrinology 42, 207-217. doi: 10.1016/j.psyneuen.2014.01.014

Cryan, J. F., and Dinan, T. G. (2015). Gut microbiota: microbiota and neuroimmune signalling-Metchnikoff to microglia. Nat. Rev. Gastroenterol. Hepatol. 12, 494-496. doi: 10.1038/nrgastro.2015.127

Curran, E. A., Cryan, J. F., Kenny, L. C., Dinan, T. G., Kearney, P. M., and Khashan, A. S. (2016). Obstetrical mode of delivery and childhood behavior and psychological development in a British Cohort. J. Autism Dev. Disord. 46, 603-614. doi: 10.1007/s10803-015-2616-1

Curran, E. A., Dalman, C., Kearney, P. M., Kenny, L. C., Cryan, J. F., Dinan, T. G., et al. (2015). Association Between obstetric mode of delivery and autism spectrum disorder: a population-based sibling design study. JAMA Psychiatry 72, 935-942. doi: 10.1001/jamapsychiatry.2015.0846

Curran, E. A., O’Neill, S. M., Cryan, J. F., Kenny, L. C., Dinan, T. G., Khashan, A. S., et al. (2014). Research Review: birth by caesarean section and development 
of autism spectrum disorder and attention-deficit/hyperactivity disorder: a systematic review and meta-analysis. J Child Psychol Psychiatry. 56, 500-508. doi: $10.1111 /$ jcpp. 12351

Dalton, K. M., Nacewicz, B. M., Johnstone, T., Schaefer, H. S., Gernsbacher, M. A., Goldsmith, H. H., et al. (2005). Gaze fixation and the neural circuitry of face processing in autism. Nat. Neurosci. 8, 519-526. doi: 10.1038/nn1421

Dalton, V. S., Kolshus, E., and McLoughlin, D. M. (2014). Epigenetics and depression: return of the repressed. J. Affect. Disord. 155, 1-12. doi: 10.1016/j.jad.2013.10.028

Dantzer, R., O’Connor, J. C., Freund, G. G., Johnson, R. W., and Kelley, K. W. (2008). From inflammation to sickness and depression: when the immune system subjugates the brain. Nat. Rev. Neurosci. 9, 46-56. doi: 10.1038/nrn2297

Davari, S., Talaei, S. A., Alaei, H., and Salami, M. (2013). Probiotics treatment improves diabetes-induced impairment of synaptic activity and cognitive function: behavioral and electrophysiological proofs for microbiome-gut-brain axis. Neuroscience 240, 287-296. doi: 10.1016/j.neuroscience.2013.02.055

Davey, K. J., Cotter, P. D., O’Sullivan, O., Crispie, F., Dinan, T. G., Cryan, J. F., et al. (2013). Antipsychotics and the gut microbiome: olanzapine-induced metabolic dysfunction is attenuated by antibiotic administration in the rat. Transl. Psychiatry 3:e309. doi: 10.1038/tp.2013.83

Davey, K. J., O’Mahony, S. M., Schellekens, H., O’Sullivan, O., Bienenstock, J., Cotter, P. D., et al. (2012). Gender-dependent consequences of chronic olanzapine in the rat: effects on body weight, inflammatory, metabolic and microbiota parameters. Psychopharmacology 221, 155-169. doi: 10.1007/s00213-011-2555-2

Day, R., Nielsen, J. A., Korten, A., Ernberg, G., Dube, K. C., Gebhart, J., et al. (1987). Stressful life events preceding the acute onset of schizophrenia: a cross-national study from the World Health Organization. Cult. Med. Psychiatry 11, 123-205. doi: $10.1007 / \mathrm{BF} 00122563$

Dayan, P., and Huys, Q. J. (2008). Serotonin, inhibition, and negative mood. PLoS Comput. Biol. 4:e4. doi: 10.1371/journal.pcbi.0040004

De Angelis, M., Piccolo, M., Vannini, L., Siragusa, S., De Giacomo, A., Serrazzanetti, D. I., et al. (2013). Fecal microbiota and metabolome of children with autism and pervasive developmental disorder not otherwise specified. PLoS ONE 8:e76993. doi: 10.1371/journal.pone.0076993

De Filippis, F., Pellegrini, N., Vannini, L., Jeffery, I. B., La Storia, A., Laghi, L., et al. (2015). High-level adherence to a Mediterranean diet beneficially impacts the gut microbiota and associated metabolome. Gut 65, 1812-1821. doi: 10.1136/gutjnl-2015-309957

Deng, W., Aimone, J. B., and Gage, F. H. (2010). New neurons and new memories: how does adult hippocampal neurogenesis affect learning and memory? Nat. Rev. Neurosci. 11, 339-350. doi: 10.1038/nrn2822

De Palma, G., Blennerhassett, P., Lu, J., Deng, Y., Park, A. J., Green, W., et al. (2015). Microbiota and host determinants of behavioural phenotype in maternally separated mice. Nat. Commun. 6:7735. doi: 10.1038/ncomms8735

De Palma, G., and Lynch, M. D. (2017). Transplantation of fecal microbiota from patients with irritable bowel syndrome alters gut function and behavior in recipient mice. Sci. Transl. Med. 9:eaaf6397 9. doi: 10.1126/scitranslmed.aaf6397

Derrien, M., and van Hylckama Vlieg, J. E. (2015). Fate, activity, and impact of ingested bacteria within the human gut microbiota. Trends Microbiol. 23, 354-366. doi: 10.1016/j.tim.2015.03.002

De Rubeis, S., He, X., Goldberg, A. P., Poultney, C. S., Samocha, K., Cicek, A. E., et al. (2014). Synaptic, transcriptional and chromatin genes disrupted in autism. Nature 515, 209-215. doi: 10.1038/nature13772

Desbonnet, L., Clarke, G., Shanahan, F., Dinan, T. G., and Cryan, J. F. (2014). Microbiota is essential for social development in the mouse. Mol. Psychiatry 19, 146-148. doi: 10.1038/mp.2013.65

Desbonnet, L., Garrett, L., Clarke, G., Bienenstock, J., and Dinan, T. G. (2008). The probiotic Bifidobacteria infantis: an assessment of potential antidepressant properties in the rat. J. Psychiatr. Res. 43, 164-174. doi: 10.1016/j.jpsychires.2008.03.009

de Theije, C. G., Wopereis, H., Ramadan, M., van Eijndthoven, T., Lambert, J., Knol, J., et al. (2014a). Altered gut microbiota and activity in a murine model of autism spectrum disorders. Brain Behav. Immun. 37, 197-206. doi: 10.1016/j.bbi.2013.12.005

de Theije, C. G., Wu, J., Koelink, P. J., Korte-Bouws, G. A., Borre, Y., Kas, M. J., et al. (2014b). Autistic-like behavioural and neurochemical changes in a mouse model of food allergy. Behav. Brain Res. 261, 265-274. doi: 10.1016/j.bbr.2013.12.008

Dethlefsen, L., McFall-Ngai, M., and Relman, D. A. (2007). An ecological and evolutionary perspective on human-microbe mutualism and disease. Nature 449, 811-818. doi: 10.1038/nature06245

de Witte, L., Tomasik, J., Schwarz, E., Guest, P. C., Rahmoune, H., Kahn, R. S., et al. (2014). Cytokine alterations in first-episode schizophrenia patients before and after antipsychotic treatment. Schizophr. Res. 154, 23-29. doi: 10.1016/j.schres.2014.02.005

Diaz Heijtz, R., Wang, S., Anuar, F., Qian, Y., Bjorkholm, B., Samuelsson, A., et al. (2011). Normal gut microbiota modulates brain development and behavior. Proc. Natl. Acad. Sci. U.S.A. 108, 3047-3052. doi: 10.1073/pnas.1010529108

Dickerson, F. B., Stallings, C., Origoni, A., Katsafanas, E., Savage, C. L., Schweinfurth, L. A., et al. (2014). Effect of probiotic supplementation on schizophrenia symptoms and association with gastrointestinal functioning: a randomized, placebo-controlled trial. Prim. Care Companion CNS Disord. 16:13m01579. doi: 10.4088/PCC. $13 \mathrm{~m} 01579$

Dinan, T. G., Borre, Y. E., and Cryan, J. F. (2014). Genomics of schizophrenia: time to consider the gut microbiome? Mol. Psychiatry 19, 1252-1257. doi: $10.1038 / \mathrm{mp} .2014 .93$

Dinan, T. G., and Cryan, J. F. (2017). Gut instincts: microbiota as a key regulator of brain development, ageing and neurodegeneration. J. Physiol. 595, 489-503. doi: 10.1113/JP273106

Dinan, T. G., Stanton, C., and Cryan, J. F. (2013). Psychobiotics: a novel class of psychotropic. Biol. Psychiatry 74, 720-726. doi: 10.1016/j.biopsych.2013.05.001

Dinan, T. G., Stilling, R. M., Stanton, C., and Cryan, J. F. (2015). Collective unconscious: how gut microbes shape human behavior. J. Psychiatr. Res. 63, 1-9. doi: 10.1016/j.jpsychires.2015.02.021

Di Nicola, M., Cattaneo, A., Hepgul, N., Di Forti, M., Aitchison, K. J., Janiri, L., et al. (2013). Serum and gene expression profile of cytokines in first-episode psychosis. Brain Behav. Immun. 31, 90-95. doi: 10.1016/j.bbi.2012.06.010

Douglas, A. E., and Werren, J. H. (2016). Holes in the hologenome: why host-microbe symbioses are not holobionts. MBio 7:e02099. doi: $10.1128 / \mathrm{mBio} .02099-15$

Dowlati, Y., Herrmann, N., Swardfager, W., Liu, H., Sham, L., Reim, E. K., et al. (2010). A meta-analysis of cytokines in major depression. Biol. Psychiatry 67, 446-457. doi: 10.1016/j.biopsych.2009.09.033

Dunbar, R. I. (2012). The social brain meets neuroimaging. Trends Cogn. Sci. 16, 101-102. doi: 10.1016/j.tics.2011.11.013

Durkin, M. S., Maenner, M. J., Newschaffer, C. J., Lee, L. C., Cunniff, C. M., Daniels, J. L., et al. (2008). Advanced parental age and the risk of autism spectrum disorder. Am. J. Epidemiol. 168, 1268-1276. doi: 10.1093/aje/kwn250

Eckburg, P. B., Bik, E. M., Bernstein, C. N., Purdom, E., Dethlefsen, L., Sargent, M., et al. (2005). Diversity of the human intestinal microbial flora. Science 308, 1635-1638. doi: 10.1126/science.1110591

El Aidy, S., Derrien, M., Aardema, R., Hooiveld, G., Richards, S. E., Dane, A., et al. (2014). Transient inflammatory-like state and microbial dysbiosis are pivotal in establishment of mucosal homeostasis during colonisation of germ-free mice. Benef. Microbes 5, 67-77. doi: 10.3920/BM2013.0018

El Aidy, S., Kunze, W., Bienenstock, J., and Kleerebezem, M. (2012). The microbiota and the gut-brain axis: insights from the temporal and spatial mucosal alterations during colonisation of the germfree mouse intestine. Benef. Microbes 3, 251-259. doi: 10.3920/BM2012.0042

Elizabeth Cantor-Graae and Jean-Paul Selten (2005). Schizophrenia and Migration: a meta-analysis and review. Am. J. Psychiatry 162, 12-24. doi: 10.1176/appi.ajp.162.1.12

Erhardt, S., Blennow, K., Nordin, C., Skogh, E., Lindstrom, L. H., and Engberg, G. (2001). Kynurenic acid levels are elevated in the cerebrospinal fluid of patients with schizophrenia. Neurosci. Lett. 313, 96-98. doi: 10.1016/S0304-3940(01)02242-X

Erhardt, S., Pocivavsek, A., Repici, M., Liu, X.-C., Imbeault, S., Maddison, D. C., et al. (in press). Adaptive and behavioral changes in kynurenine 3-monooxygenase knockout mice: relevance to psychotic disorders. Biol. Psychiatry. doi: 10.1016/j.biopsych.2016.12.011

Erny, D., Hrabe de Angelis, A. L., Jaitin, D., Wieghofer, P., Staszewski, O., David, E., et al. (2015). Host microbiota constantly control maturation and function of microglia in the CNS. Nat. Neurosci. 18, 965-977. doi: 10.1038/ nn. 4030 
Evans, S. J., Bassis, C. M., Hein, R., Assari, S., Flowers, S. A., Kelly, M. B., et al. (2017). The gut microbiome composition associates with bipolar disorder and illness severity. J. Psychiatr. Res. 87, 23-29. doi: 10.1016/j.jpsychires.2016.12.007

Facci, L., Barbierato, M., Marinelli, C., Argentini, C., Skaper, S. D., and Giusti, P. (2014). Toll-like receptors $2,-3$ and -4 prime microglia but not astrocytes across central nervous system regions for ATP-dependent interleukin-1beta release. Sci. Rep. 4:6824. doi: 10.1038/srep06824

Falony, G., Joossens, M., Vieira-Silva, S., Wang, J., Darzi, Y., Faust, K., et al. (2016). Population-level analysis of gut microbiome variation. Science 352, 560-564. doi: $10.1126 /$ science.aad3503

Faludi, G., and Mirnics, K. (2011). Synaptic changes in the brain of subjects with schizophrenia. Int. J. Dev. Neurosci. 29, 305-309. doi: 10.1016/j.ijdevneu.2011.02.013

Feigenson, K. A., Kusnecov, A. W., and Silverstein, S. M. (2014). Inflammation and the two-hit hypothesis of Schizophrenia. Neurosci. Biobehav. Rev. 38, 72-93. doi: 10.1016/j.neubiorev.2013.11.006

Felger, J. C., and Miller, A. H. (2012). Cytokine effects on the basal ganglia and dopamine function: the subcortical source of inflammatory malaise. Front. Neuroendocrinol. 33, 315-327. doi: 10.1016/j.yfrne.2012.09.003

Felger, J. C., Mun, J., Kimmel, H. L., Nye, J. A., Drake, D. F., Hernandez, C. R., et al. (2013). Chronic interferon-alpha decreases dopamine 2 receptor binding and striatal dopamine release in association with anhedonia-like behavior in nonhuman primates. Neuropsychopharmacology 38, 2179-2187. doi: $10.1038 /$ npp.2013.115

Fenn, A. M., Gensel, J. C., Huang, Y., Popovich, P. G., Lifshitz, J., and Godbout, J. P. (2014). Immune activation promotes depression 1 month after diffuse brain injury: a role for primed microglia. Biol. Psychiatry 76, 575-584. doi: 10.1016/j.biopsych.2013.10.014

Fernandez-Real, J. M., Serino, M., Blasco, G., Puig, J., Daunis-i-Estadella, J., Ricart, W., et al. (2015). Gut microbiota interacts with brain microstructure and function. j. Clin. Endocrinol. Metab. 100, 4505-4513. doi: 10.1210/jc.2015-3076

Feustel, S. M., Meissner, M., and Liesenfeld, O. (2012). Toxoplasma gondii and the blood-brain barrier. Virulence 3, 182-192. doi: 10.4161/viru.19004

Filiano, A. J., Gadani, S. P., and Kipnis, J. (2017). How and why do T cells and their derived cytokines affect the injured and healthy brain? Nat. Rev. Neurosci. 18, 375-384. doi: 10.1038/nrn.2017.39

Finegold, S. M., Dowd, S. E., Gontcharova, V., Liu, C., Henley, K. E., and Wolcott, R. D. (2010). Pyrosequencing study of fecal microflora of autistic and control children. Anaerobe 16, 444-453. doi: 10.1016/j.anaerobe.2010.06.008

Finegold, S. M., Molitoris, D., Song, Y., Liu, C., Vaisanen, M. L., Bolte, E., et al. (2002). Gastrointestinal microflora studies in late-onset autism. Clin. Infect. Dis. 35, S6-S16. doi: 10.1086/341914

Fontainhas, A. M., Wang, M., Liang, K. J., Chen, S., Mettu, P., Damani, M., et al. (2011). Microglial morphology and dynamic behavior is regulated by ionotropic glutamatergic and GABAergic neurotransmission. PLoS ONE 6:e15973. doi: 10.1371/journal.pone.0015973

Forrest, C. M., Khalil, O. S., Pisar, M., McNair, K., Kornisiuk, E., Snitcofsky, M., et al. (2013). Changes in synaptic transmission and protein expression in the brains of adult offspring after prenatal inhibition of the kynurenine pathway. Neuroscience 254, 241-259. doi: 10.1016/j.neuroscience.2013.09.034

Forrest, C. M., McNair, K., Pisar, M., Khalil, O. S., Darlington, L. G., and Stone, T. W. (2015). Altered hippocampal plasticity by prenatal kynurenine administration, kynurenine-3-monoxygenase (KMO) deletion or galantamine. Neuroscience 310, 91-105. doi: 10.1016/j.neuroscience.2015.09.022

Foster, J. A. (2016). Gut Microbiome and behavior: focus on neuroimmune interactions. Int. Rev. Neurobiol. 131, 49-65. doi: 10.1016/bs.irn.2016.07.005

Francino, M. P. (2014). Early development of the gut microbiota and immune health. Pathogens 3, 769-790. doi: 10.3390/pathogens3030769

Frank, M. G., Baratta, M. V., Sprunger, D. B., Watkins, L. R., and Maier, S. F. (2007). Microglia serve as a neuroimmune substrate for stress-induced potentiation of CNS pro-inflammatory cytokine responses. Brain Behav. Immun. 21, 47-59. doi: 10.1016/j.bbi.2006.03.005

Franzosa, E. A., Morgan, X. C., Segata, N., Waldron, L., Reyes, J., Earl, A. M., et al. (2014). Relating the metatranscriptome and metagenome of the human gut. Proc. Natl. Acad. Sci. U.S.A. 111, E2329-E2338. doi: 10.1073/pnas.1319284111

Freytag, V., Carrillo-Roa, T., and Milnik, A. (2017). A peripheral epigenetic signature of immune system genes is linked to neocortical thickness and Memory 8:15193. doi: 10.1038/ncomms15193
Frohlich, E. E., Farzi, A., Mayerhofer, R., Reichmann, F., Jacan, A., Wagner, B., et al. (2016). Cognitive impairment by antibiotic-induced gut dysbiosis: analysis of gut microbiota-brain communication. Brain Behav. Immun. 56, 140-155. doi: 10.1016/j.bbi.2016.02.020

Frost, G., Sleeth, M. L., Sahuri-Arisoylu, M., Lizarbe, B., Cerdan, S., Brody, L., et al. (2014). The short-chain fatty acid acetate reduces appetite via a central homeostatic mechanism. Nat. Commun. 5:3611. doi: 10.1038/ncomms4611

Frye, R. E., Rose, S., Chacko, J., Wynne, R., Bennuri, S. C., Slattery, J. C., et al. (2016). Modulation of mitochondrial function by the microbiome metabolite propionic acid in autism and control cell lines. Transl. Psychiatry 6:e927. doi: 10.1038/tp.2016.189

Fujimura, K. E., Sitarik, A. R., Havstad, S., Lin, D. L., Levan, S., Fadrosh, D., et al. (2016). Neonatal gut microbiota associates with childhood multisensitized atopy and T cell differentiation. Nat. Med. 22, 1187-1191. doi: 10.1038/nm. 4176

Fusar-Poli, P., Tantardini, M., De Simone, S., Ramella-Cravaro, V., Oliver, D., Kingdon, J., et al. (2017). Deconstructing vulnerability for psychosis: metaanalysis of environmental risk factors for psychosis in subjects at ultra high-risk. Eur. Psychiatry 40, 65-75. doi: 10.1016/j.eurpsy.2016.09.003

Galley, J. D., Nelson, M. C., Yu, Z., Dowd, S. E., Walter, J., Kumar, P. S., et al. (2014a). Exposure to a social stressor disrupts the community structure of the colonic mucosa-associated microbiota. BMC Microbiol. 14:189. doi: 10.1186/1471-2180-14-189

Galley, J. D., Yu, Z., Kumar, P., Dowd, S. E., Lyte, M., and Bailey, M. T. (2014b). The structures of the colonic mucosa-associated and luminal microbial communities are distinct and differentially affected by a prolonged murine stressor. Gut Microbes 5, 748-760. doi: 10.4161/19490976.2014.972241

García-Bueno, B., Gass,ó, P., MacDowell, K. S., Callado, L. F., Mas, S., Bernardo, M., et al. (2016). Evidence of activation of the Toll-like receptor4 proinflammatory pathway in patients with schizophrenia. J. Psychiatry Neurosci. 41, E46-E55. doi: 10.1503/jpn.150195

Gareau, M. G., Wine, E., Rodrigues, D. M., Cho, J. H., Whary, M. T., Philpott, D. J., et al. (2011). Bacterial infection causes stress-induced memory dysfunction in mice. Gut 60, 307-317. doi: 10.1136/gut.2009.202515

George, B., and Klijn, A. (2013). A modern name for schizophrenia (PSS) would diminish self-stigma. Psychol. Med. 43, 1555-1557. doi: $10.1017 /$ S0033291713000895

Ghaziuddin, M., Ghaziuddin, N., and Greden, J. (2002). Depression in persons with autism: implications for research and clinical care. J. Autism Dev. Disord. 32, 299-306. doi: 10.1023/A:1016330802348

Giovanoli, S., Engler, H., Engler, A., Richetto, J., Voget, M., Willi, R., et al. (2013). Stress in puberty unmasks latent neuropathological consequences of prenatal immune activation in mice. Science 339, 1095-1099. doi: $10.1126 /$ science. 1228261

Giovanoli, S., Notter, T., Richetto, J., Labouesse, M. A., Vuillermot, S., Riva, M. A., et al. (2015). Late prenatal immune activation causes hippocampal deficits in the absence of persistent inflammation across aging. J. Neuroinflammation 12:221. doi: 10.1186/s12974-015-0437-y

Goines, P. E., Croen, L. A., Braunschweig, D., Yoshida, C. K., Grether, J., Hansen, R., et al. (2011). Increased midgestational IFN- $\gamma$, IL-4 and IL-5 in women bearing a child with autism: a case-control study. Mol. Autism 2:13. doi: 10.1186/2040-2392-2-13

Golubeva, A. V., Crampton, S., Desbonnet, L., Edge, D., O’Sullivan, O., Lomasney, K. W., et al. (2015). Prenatal stress-induced alterations in major physiological systems correlate with gut microbiota composition in adulthood. Psychoneuroendocrinology 60, 58-74. doi: 10.1016/j.psyneuen.2015. 06.002

Gondalia, S. V., Palombo, E. A., Knowles, S. R., Cox, S. B., Meyer, D., and Austin, D. W. (2012). Molecular characterisation of gastrointestinal microbiota of children with autism (with and without gastrointestinal dysfunction) and their neurotypical siblings. Autism Res. 5, 419-427. doi: 10.1002/aur.1253

Gonzalez-Burgos, G., and Lewis, D. A. (2012). NMDA receptor hypofunction, parvalbumin-positive neurons, and cortical gamma oscillations in schizophrenia. Schizophr. Bull. 38, 950-957. doi: 10.1093/schbul/sbs010

Grabrucker, S., Jannetti, L., Eckert, M., Gaub, S., Chhabra, R., Pfaender, S., et al. (2014). Zinc deficiency dysregulates the synaptic ProSAP/Shank scaffold and might contribute to autism spectrum disorders. Brain 137, 137-152. doi: $10.1093 /$ brain/awt303 
Graeber, M. B., and Streit, W. J. (2010). Microglia: biology and pathology. Acta Neuropathol. 119, 89-105. doi: 10.1007/s00401-009-0622-0

Graham, A. M., Rasmussen, J. M., Rudolph, M. D., Heim, C. M., Gilmore, J. H., Styner, M., et al. (in press). Maternal Systemic interleukin-6 during pregnancy is associated with newborn amygdala phenotypes and subsequent behavior at 2 years of age. Biol. Psychiatry. doi: 10.1016/j.biopsych.2017.05.027

Gramsbergen, J. B., Hodgkins, P. S., Rassoulpour, A., Turski, W. A., Guidetti, P., and Schwarcz, R. (1997). Brain-specific modulation of kynurenic acid synthesis in the rat. J. Neurochem. 69, 290-298. doi: 10.1046/j.1471-4159.1997.69010290.x

Green, M. J., Matheson, S. L., Shepherd, A., Weickert, C. S., and Carr, V. J. (2011). Brain-derived neurotrophic factor levels in schizophrenia: a systematic review with meta-analysis. Mol. Psychiatry 16, 960-972. doi: 10.1038/mp.2010.88

Grosse Wiesmann, C., Schreiber, J., Singer, T., Steinbeis, N., and Friederici, A. D. (2017). White matter maturation is associated with the emergence of Theory of Mind in early childhood. Nat. Commun. 8:14692. doi: 10.1038/ncomms 14692

Guarner, F., Bourdet-Sicard, R., Brandtzaeg, P., Gill, H. S., McGuirk, P., and van Eden, W. (2006). Mechanisms of disease: the hygiene hypothesis revisited. Nat. Clin. Pract. Gastroenterol. Hepatol. 3, 275-284. doi: 10.1038/ncpgasthep0471

Guidetti, P., Hoffman, G. E., Melendez-Ferro, M., Albuquerque, E. X., and Schwarcz, R. (2007). Astrocytic localization of kynurenine aminotransferase II in the rat brain visualized by immunocytochemistry. Glia $55,78-92$. doi: $10.1002 /$ glia.20432

Habela, C. W., Song, H., and Ming, G. L. (2016). Modeling synaptogenesis in schizophrenia and autism using human iPSC derived neurons. Mol. Cell. Neurosci. 73, 52-62. doi: 10.1016/j.mcn.2015.12.002

Haddad, L., Schäfer, A., Streit, F., Lederbogen, F., Grimm, O., Wüst, S., et al. (2015). Brain structure correlates of urban upbringing, an environmental risk factor for Schizophrenia. Schizophr. Bull. 41, 115-122. doi: 10.1093/schbul/ sbu072

Hanage, W. P. (2014). Microbiology: microbiome science needs a healthy dose of scepticism. Nature 512, 247-248. doi: 10.1038/512247a

Haroon, E., Raison, C. L., and Miller, A. H. (2012). Psychoneuroimmunology meets neuropsychopharmacology: translational implications of the impact of inflammation on behavior. Neuropsychopharmacology 37, 137-162. doi: 10.1038/npp.2011.205

Harrison, N. A., Brydon, L., Walker, C., Gray, M. A., Steptoe, A., and Critchley, H. D. (2009). Inflammation causes mood changes through alterations in subgenual cingulate activity and mesolimbic connectivity. Biol. Psychiatry 66, 407-414. doi: 10.1016/j.biopsych.2009.03.015

Havlicek, J., Gasova, Z. G., Smith, A. P., Zvara, K., and Flegr, J. (2001). Decrease of psychomotor performance in subjects with latent 'asymptomatic' toxoplasmosis. Parasitology 122, 515-520. doi: 10.1017/S00311820010 07624

Hazlett, H. C., Gu, H., Munsell, B. C., Kim, S. H., Styner, M., Wolff, J. J., et al. (2017). Early brain development in infants at high risk for autism spectrum disorder. Nature 542, 348-351. doi: 10.1038/nature21369

Hibberd, M. C., Wu, M., Rodionov, D. A., Li, X., Cheng, J., Griffin, N. W., et al. (2017). The effects of micronutrient deficiencies on bacterial species from the human gut microbiota. Sci. Transl. Med. 9:eaal4069. doi: 10.1126/scitranslmed.aal4069

Hidaka, B. H. (2012). Depression as a disease of modernity: explanations for increasing prevalence. J. Affect. Disord. 140, 205-214. doi: 10.1016/j.jad.2011.12.036

Hinwood, M., Morandini, J., Day, T. A., and Walker, F. R. (2011). Evidence that microglia mediate the neurobiological effects of chronic psychological stress on the medial prefrontal cortex. Cereb. Cortex 22, 1442-1454. doi: 10.1093/cercor/bhr229

Hinwood, M., Tynan, R. J., Charnley, J. L., Beynon, S. B., Day, T. A., and Walker, F. R. (2012). Chronic stress induced remodeling of the prefrontal cortex: structural re-organization of microglia and the inhibitory effect of minocycline. Cereb. Cortex 23, 1784-1797. doi: 10.1093/cercor/ bhs151

Hoban, A. E., Moloney, R. D., Golubeva, A. V., McVey Neufeld, K. A., O'Sullivan, O., Patterson, E., et al. (2016a). Behavioural and neurochemical consequences of chronic gut microbiota depletion during adulthood in the rat. Neuroscience 339, 463-477. doi: 10.1016/j.neuroscience.2016.10.003
Hoban, A. E., Stilling, R. M., Moloney, G., Shanahan, F., Dinan, T. G., Clarke, G., et al. (2017). The microbiome regulates amygdala-dependent fear recall. Mol. Psychiatry. doi: 10.1038/mp.2017.100. [Epub ahead of print].

Hoban, A. E., Stilling, R. M., Ryan, F. J., Shanahan, F., Dinan, T. G., Claesson, M. J., et al. (2016b). Regulation of prefrontal cortex myelination by the microbiota. Transl. Psychiatry 6:e774. doi: 10.1038/tp.2016.42

Hodes, G. E., Kana, V., and Menard, C. (2015). Neuroimmune mechanisms of Depression 18, 1386-1393. doi: 10.1038/nn.4113

Holmes, S. E., Hinz, R., Drake, R. J., Gregory, C. J., Conen, S., Matthews, J. C., et al. (2016). In vivo imaging of brain microglial activity in antipsychotic-free and medicated schizophrenia: a [11C](R)-PK11195 positron emission tomography study. Mol. Psychiatry 21, 1672-1679. doi: 10.1038/mp.2016.180

Hommer, R. E., and Swedo, S. E. (2015). Schizophrenia and autism-related disorders. Schizophr. Bull. 41, 313-314. doi: 10.1093/schbul/sbu188

Hor, K., and Taylor, M. (2010). Suicide and schizophrenia: a systematic review of rates and risk factors. J. Psychopharmacol. 24, 81-90. doi: $10.1177 / 1359786810385490$

Hsiao, E. Y., McBride, S. W., Hsien, S., Sharon, G., Hyde, E. R., McCue, T., et al. (2013). Microbiota modulate behavioral and physiological abnormalities associated with neurodevelopment disorders. Cell 155, 1451-1463. doi: 10.1016/j.cell.2013.11.024

Hu, W., MacDonald, M. L., Elswick, D. E., and Sweet, R. A. (2015). The glutamate hypothesis of schizophrenia: evidence from human brain tissue studies. Ann. N.Y. Acad. Sci. 1338, 38-57. doi: 10.1111/nyas. 12547

Hueston, C. M., Cryan, J. F., and Nolan, Y. M. (2017). Stress and adolescent hippocampal neurogenesis: diet and exercise as cognitive modulators. Transl. Psychiatry 7:e1081. doi: 10.1038/tp.2017.48

Insel, T., Cuthbert, B., Garvey, M., Heinssen, R., Pine, D. S., Quinn, K., et al. (2010). Research domain criteria (RDoC): toward a new classification framework for research on mental disorders. Am. J. Psychiatry 167, 748-751. doi: 10.1176/appi.ajp.2010.09091379

Jacka, F. N. (2017). Nutritional psychiatry: where to next? EBioMedicine 17, 24-29. doi: 10.1016/j.ebiom.2017.02.020

Jacka, F. N., O’Neil, A., Opie, R., Itsiopoulos, C., Cotton, S., Mohebbi, M., et al. (2017). A randomised controlled trial of dietary improvement for adults with major depression (the 'SMILES' trial). BMC Med. 15:23. doi: 10.1186/s12916-017-0791-y

Jacka, F. N., Pasco, J. A., Mykletun, A., Williams, L. J., Hodge, A. M., O'Reilly, S. L., et al. (2010). Association of Western and traditional diets with depression and anxiety in women. Am. J. Psychiatry 167, 305-311. doi: 10.1176/appi.ajp.2009.09060881

Jacob, J., Vanessa, R., Steve, M., Sean, C., David, W., and James, B. (2013). A chemical-genetics approach to study the molecular pathology of central serotonin abnormalities in fetal valproate syndrome. J. Neurol. Neurosurg. Psychiatr. 84:e2. doi: 10.1136/jnnp-2013-306573.34

Janak, P. H., and Tye, K. M. (2015). From circuits to behaviour in the amygdala. Nature 517, 284-292. doi: 10.1038/nature14188

Janik, R., Thomason, L. A. M., Stanisz, A. M., Forsythe, P., Bienenstock, J., and Stanisz, G. J. (2016). Magnetic resonance spectroscopy reveals oral Lactobacillus promotion of increases in brain GABA, N-acetyl aspartate and glutamate. Neuroimage 125, 988-995. doi: 10.1016/j.neuroimage.2015.11.018

Jasarevic, E., Howerton, C. L., Howard, C. D., and Bale, T. L. (2015). Alterations in the Vaginal Microbiome by maternal stress are associated with metabolic reprogramming of the offspring gut and brain. Endocrinology 156, 3265-3276. doi: 10.1210/en.2015-1177

Jhamnani, K., Shivakumar, V., Kalmady, S., Rao, N. P., and Venkatasubramanian, G. (2013). Successful use of add-on minocycline for treatment of persistent negative symptoms in schizophrenia. J. Neuropsychiatry Clin. Neurosci. 25, E06-E07. doi: 10.1176/appi.neuropsych.11120376

Jiang, H., Ling, Z., Zhang, Y., Mao, H., Ma, Z., Yin, Y., et al. (2015). Altered fecal microbiota composition in patients with major depressive disorder. Brain Behav. Immun. 48, 186-194. doi: 10.1016/j.bbi.2015.03.016

Jiang, H. Y., Xu, L. L., Shao, L., Xia, R. M., Yu, Z. H., Ling, Z. X., et al. (2016). Maternal infection during pregnancy and risk of autism spectrum disorders: a systematic review and meta-analysis. Brain Behav. Immun. 58, 165-172. doi: 10.1016/j.bbi.2016.06.005

Jirtle, R. L., and Skinner, M. K. (2007). Environmental epigenomics and disease susceptibility. Nat. Rev. Genet. 8, 253-262. doi: 10.1038/nrg2045 
Jones, C. A., Watson, D. J. G., and Fone, K. C. F. (2011). Animal models of schizophrenia. Br. J. Pharmacol. 164, 1162-1194. doi: 10.1111/j.1476-5381.2011.01386.x

Jones, K. L., Croen, L. A., Yoshida, C. K., Heuer, L., Hansen, R., Zerbo, O., et al. (2017). Autism with intellectual disability is associated with increased levels of maternal cytokines and chemokines during gestation. Mol. Psychiatry 22, 273-279. doi: 10.1038/mp.2016.77

Joyce, D. W., Kehagia, A. A., Tracy, D. K., Proctor, J., and Shergill, S. S. (2017). Realising stratified psychiatry using multidimensional signatures and trajectories. J. Transl. Med. 15:15. doi: 10.1186/s12967-016-1116-1

Kahn, R. S., and Keefe, R. S. (2013). Schizophrenia is a cognitive illness: time for a change in focus. JAMA Psychiatry 70, 1107-1112. doi: 10.1001/jamapsychiatry.2013.155

Kaiser, T., and Feng, G. (2015). Modeling psychiatric disorders for developing effective treatments. Nat. Med. 21, 979-988. doi: 10.1038/nm.3935

Kang, D.-W., Adams, J. B., Gregory, A. C., Borody, T., Chittick, L., Fasano, A., et al. (2017). Microbiota Transfer Therapy alters gut ecosystem and improves gastrointestinal and autism symptoms: an open-label study. Microbiome 5:10. doi: $10.1186 / \mathrm{s} 40168-016-0225-7$

Kang, D. W., Park, J. G., Ilhan, Z. E., Wallstrom, G., Labaer, J., Adams, J. B., et al. (2013). Reduced incidence of Prevotella and other fermenters in intestinal microflora of autistic children. PLoS ONE 8:e68322. doi: 10.1371 /journal.pone.0068322

Kau, A. L., Ahern, P. P., Griffin, N. W., Goodman, A. L., and Gordon, J. I. (2011). Human nutrition, the gut microbiome and the immune system. Nature 474, 327-336. doi: 10.1038/nature10213

Kelly, J. R. (2016). The Gut Microbiota in Depression. Ph.D., thesis, University College Cork.

Kelly, J. R., Allen, A. P., Temko, A., Hutch, W., Kennedy, P. J., Farid, N., et al. (2017a). Lost in translation? The potential psychobiotic Lactobacillus rhamnosus (JB-1) fails to modulate stress or cognitive performance in healthy male subjects. Brain Behav. Immun. 61, 50-59. doi: 10.1016/j.bbi.2016.11.018

Kelly, J. R., Borre, Y., C, O. B., Patterson, E., El Aidy, S., Deane, J., et al. (2016a). Transferring the blues: depression-associated gut microbiota induces neurobehavioural changes in the rat. J. Psychiatr. Res. 82, 109-118. doi: 10.1016/j.jpsychires.2016.07.019

Kelly, J. R., Clarke, G., Cryan, J. F., and Dinan, T. G. (2016b). Brain-gut-microbiota axis: challenges for translation in psychiatry. Ann. Epidemiol. 26, 366-372. doi: 10.1016/j.annepidem.2016.02.008

Kelly, J. R., Clarke, G., Cryan, J. F., and Dinan, T. G. (2017b). Dimensional thinking in psychiatry in the era of the Research Domain Criteria (RDoC). Irish J. Psychol. Med. doi: 10.1017/ipm.2017.7. [Epub ahead of print].

Kelly, J. R., Kennedy, P. J., Cryan, J. F., Dinan, T. G., Clarke, G., and Hyland, N. P. (2015). Breaking down the barriers: the gut microbiome, intestinal permeability and stress-related psychiatric disorders. Front. Cell. Neurosci. 9:392. doi: 10.3389/fncel.2015.00392

Kennedy, P. J., Cryan, J. F., Dinan, T. G., and Clarke, G. (2017). Kynurenine pathway metabolism and the microbiota-gut-brain axis. Neuropharmacology 112, 399-412. doi: 10.1016/j.neuropharm.2016.07.002

Kéri, S., Szab,ó, C., and Kelemen, O. (2017). Antipsychotics influence Toll-like receptor (TLR) expression and its relationship with cognitive functions in schizophrenia. Brain Behav. Immun. 62, 256-264. doi: 10.1016/j.bbi.2016.12.011

Khalil, O. S., Pisar, M., Forrest, C. M., Vincenten, M. C., Darlington, L. G., and Stone, T. W. (2014). Prenatal inhibition of the kynurenine pathway leads to structural changes in the hippocampus of adult rat offspring. Eur. J. Neurosci. 39, 1558-1571. doi: 10.1111/ejn.12535

Khan, N. A., Raine, L. B., Drollette, E. S., Scudder, M. R., Kramer, A. F., and Hillman, C. H. (2015). Dietary fiber is positively associated with cognitive control among prepubertal children. J. Nutr. 145, 143-149. doi: $10.3945 /$ in. 114.198457

Khandaker, G. M., Pearson, R. M., Zammit, S., Lewis, G., and Jones, P. B. (2014). Association of serum interleukin 6 and c-reactive protein in childhood with depression and psychosis in young adult life: a population-based longitudinal study. JAMA Psychiatry 71, 1121-1128. doi: 10.1001/jamapsychiatry.2014.1332

Khodaie-Ardakani, M. R., Mirshafiee, O., Farokhnia, M., Tajdini, M., Hosseini, S. M., Modabbernia, A., et al. (2014). Minocycline add-on to risperidone for treatment of negative symptoms in patients with stable schizophrenia: randomized double-blind placebo-controlled study. Psychiatry Res. 215, 540-546. doi: 10.1016/j.psychres.2013.12.051

Kielian, T. (2006). Toll-like receptors in central nervous system glial inflammation and homeostasis. J. Neurosci. Res. 83, 711-730. doi: 10.1002/jnr.20767

Kirsch, P., Esslinger, C., Chen, Q., Mier, D., Lis, S., Siddhanti, S., et al. (2005). Oxytocin modulates neural circuitry for social cognition and fear in humans. J. Neurosci. 25, 11489-11493. doi: 10.1523/JNEUROSCI.398405.2005

Klerman, G. L., and Weissman, M. M. (1989). INcreasing rates of depression. JAMA 261, 2229-2235. doi: 10.1001/jama.1989.03420150079041

Knuesel, I., Chicha, L., Britschgi, M., Schobel, S. A., Bodmer, M., Hellings, J. A., et al. (2014). Maternal immune activation and abnormal brain development across CNS disorders. Nat. Rev. Neurol. 10, 643-660. doi: 10.1038/nrneurol.2014.187

Kohler, O., Petersen, L., Mors, O., Mortensen, P. B., Yolken, R. H., Gasse, C., et al. (2017). Infections and exposure to anti-infective agents and the risk of severe mental disorders: a nationwide study. Acta Psychiatr. Scand. 135, 97-105. doi: $10.1111 /$ acps. 12671

Kohman, R. A., and Rhodes, J. S. (2013). Neurogenesis, inflammation and behavior. Brain Behav. Immun. 27, 22-32. doi: 10.1016/j.bbi.2012.09.003

Kolb, B., Mychasiuk, R., Muhammad, A., Li, Y., Frost, D. O., and Gibb, R. (2012). Experience and the developing prefrontal cortex. Proc. Natl. Acad. Sci. U.S.A. 109, 17186-17193. doi: 10.1073/pnas.1121251109

Kosmicki, J. A., Samocha, K. E., Howrigan, D. P., and Sanders, S. J. (2017). Refining the role of de novo protein-truncating variants in neurodevelopmental disorders by using population reference samples. Nat. Genet. 49, 504-510. doi: $10.1038 /$ ng. 3789

Kostic, A. D., Gevers, D., Siljander, H., Vatanen, T., Hyotylainen, T., Hamalainen, A. M., et al. (2015). The dynamics of the human infant gut microbiome in development and in progression toward type 1 diabetes. Cell Host Microbe 17, 260-273. doi: 10.1016/j.chom.2015.01.001

Krabbendam, L., and van Os, J. (2005). Schizophrenia and urbanicity: a major environmental influence-conditional on genetic risk. Schizophr. Bull. 31, 795-799. doi: 10.1093/schbul/sbi060

Labus, J. S., Hollister, E. B., Jacobs, J., Kirbach, K., Oezguen, N., Gupta, A., et al. (2017). Differences in gut microbial composition correlate with regional brain volumes in irritable bowel syndrome. Microbiome 5:49. doi: $10.1186 / \mathrm{s} 40168-017-0260-\mathrm{z}$

Landry, S. H., and Loveland, K. A. (1988). Communication behaviors in autism and developmental language delay. J. Child Psychol. Psychiatry 29, 621-634. doi: 10.1111/j.1469-7610.1988.tb01884.x

Lankelma, J. M., Nieuwdorp, M., de Vos, W. M., and Wiersinga, W. J. (2015). The gut microbiota in internal medicine: implications for health and disease. Neth. J. Med. 73, 61-68.

Lartseva, A., Dijkstra, T., and Buitelaar, J. K. (2014). Emotional language processing in autism spectrum disorders: a systematic review. Front. Hum. Neurosci. 8:991. doi: 10.3389/fnhum.2014.00991

Lasalvia, A., Penta, E., Sartorius, N., and Henderson, S. (2015). Should the label "schizophrenia" be abandoned? Schizophr. Res. 162, 276-284. doi: 10.1016/j.schres.2015.01.031

Laursen, T. M., Nordentoft, M., and Mortensen, P. B. (2014). Excess early mortality in schizophrenia. Annu. Rev. Clin. Psychol. 10, 425-448. doi: 10.1146/annurev-clinpsy-032813-153657

Leclercq, S., Mian, F. M., Stanisz, A. M., Bindels, L. B., Cambier, E., Ben-Amram, H., et al. (2017). Low-dose penicillin in early life induces long-term changes in murine gut microbiota, brain cytokines and behavior. Nat. Commun. 8:15062. doi: 10.1038/ncomms15062

Lederbogen, F., Kirsch, P., Haddad, L., Streit, F., Tost, H., Schuch, P., et al. (2011). City living and urban upbringing affect neural social stress processing in humans. Nature 474, 498-501. doi: 10.1038/nature10190

Levkovitz, Y., Mendlovich, S., Riwkes, S., Braw, Y., Levkovitch-Verbin, H., Gal, G., et al. (2010). A double-blind, randomized study of minocycline for the treatment of negative and cognitive symptoms in early-phase schizophrenia. J. Clin. Psychiatry 71, 138-149. doi: 10.4088/JCP.08m 04666yel

Levone, B. R., Cryan, J. F., and O'Leary, O. F. (2015). Role of adult hippocampal neurogenesis in stress resilience. Neurobiol. Stress 1, 147-155. doi: 10.1016/j.ynstr.2014.11.003 
Ley, R. E., Lozupone, C. A., Hamady, M., Knight, R., and Gordon, J. I. (2008). Worlds within worlds: evolution of the vertebrate gut microbiota. Nat. Rev. Microbiol. 6, 776-788. doi: 10.1038/nrmicro1978

Li, S.-O., Wang, J.-L., Bjørklund, G., Zhao, W.-N., and Yin, C.-H. (2014). Serum copper and zinc levels in individuals with autism spectrum disorders. Neuroreport 25, 1216-1220. doi: 10.1097/WNR.0000000000000251

Lim, S.-M., Jang, H.-M., Jeong, J.-J., Han, M. J., and Kim, D.-H. (2017). Lactobacillus johnsonii CJLJ103 attenuates colitis and memory impairment in mice by inhibiting gut microbiota lipopolysaccharide production and NF- $\kappa$ B activation. J. Funct. Foods 34, 359-368. doi: 10.1016/j.jff.2017.05.016

Liu, Y., Zhang, L., Wang, X., Wang, Z., Zhang, J., Jiang, R., et al. (2016). Similar fecal microbiota signatures in patients with diarrhea-predominant irritable bowel syndrome and patients with depression. Clin. Gastroenterol. Hepatol. 14, 1602-1611.e5. doi: 10.1016/j.cgh.2016.05.033

Lombardo, M. V., Moon, H. M., Su, J., Palmer, T. D., Courchesne, E., and Pramparo, T. (2017). Maternal immune activation dysregulation of the fetal brain transcriptome and relevance to the pathophysiology of autism spectrum disorder. Mol. Psychiatry. doi: 10.1038/mp.2017.15. [Epub ahead of print].

Louveau, A., Smirnov, I., Keyes, T. J., Eccles, J. D., Rouhani, S. J., Peske, J. D., et al. (2015). Structural and functional features of central nervous system lymphatic vessels. Nature 523, 337-341. doi: 10.1038/nature14432

Lucki, I. (1998). The spectrum of behaviors influenced by serotonin. Biol. Psychiatry 44, 151-162. doi: 10.1016/S0006-3223(98)00139-5

Luczynski, P., Whelan, S. O., O’Sullivan, C., Clarke, G., Shanahan, F., Dinan, T. G., et al. (2016). Adult microbiota-deficient mice have distinct dendritic morphological changes: differential effects in the amygdala and hippocampus. Eur. J. Neurosci. 44, 2654-2666. doi: 10.1111/ejn.13291

Lurie, I., Yang, Y. X., Haynes, K., Mamtani, R., and Boursi, B. (2015). Antibiotic exposure and the risk for depression, anxiety, or psychosis: a nested casecontrol study. J. Clin. Psychiatry 76, 1522-1528. doi: 10.4088/JCP.15m09961

Lyte, M. (2011). Probiotics function mechanistically as delivery vehicles for neuroactive compounds: microbial endocrinology in the design and use of probiotics. Bioessays 33, 574-581. doi: 10.1002/bies.201100024

Lyte, M. (2013). Microbial endocrinology in the microbiome-gut-brain axis: how bacterial production and utilization of neurochemicals influence behavior. PLoS Pathog. 9:e1003726. doi: 10.1371/journal.ppat.1003726

Macfabe, D. F. (2012). Short-chain fatty acid fermentation products of the gut microbiome: implications in autism spectrum disorders. Microb. Ecol. Health Dis. 23:19260. doi: 10.3402/mehd.v23i0.19260

MacFabe, D. F., Cain, D. P., Rodriguez-Capote, K., Franklin, A. E., Hoffman, J. E., Boon, F., et al. (2007). Neurobiological effects of intraventricular propionic acid in rats: possible role of short chain fatty acids on the pathogenesis and characteristics of autism spectrum disorders. Behav. Brain Res. 176, 149-169. doi: 10.1016/j.bbr.2006.07.025

Macfarlane, G. T., and Macfarlane, S. (2012). Bacteria, colonic fermentation, and gastrointestinal health. J. AOAC Int. 95, 50-60. doi: 10.5740/ jaoacint.SGE_Macfarlane

Magnuson, K. M., and Constantino, J. N. (2011). Characterization of depression in children with autism spectrum disorders. J. Dev. Behav. Pediatrics 32, 332-340. doi: 10.1097/DBP.0b013e318213f56c

Magnusson, K. R., Hauck, L., Jeffrey, B. M., Elias, V., Humphrey, A., Nath, R., et al. (2015). Relationships between diet-related changes in the gut microbiome and cognitive flexibility. Neuroscience 300, 128-140. doi: 10.1016/j.neuroscience.2015.05.016

Mancabelli, L., Milani, C., Lugli, G. A., Turroni, F., Ferrario, C., van Sinderen, D., et al. (2017). Meta-analysis of the human gut microbiome from urbanized and pre-agricultural populations. Environ. Microbiol. 19, 1379-1390. doi: 10.1111/1462-2920.13692

Marin, I. A., Goertz, J. E., Ren, T., Rich, S. S., Onengut-Gumuscu, S., Farber, E., et al. (2017). Microbiota alteration is associated with the development of stress-induced despair behavior. Sci. Rep. 7:43859. doi: 10.1038/srep43859

Marteau, P., and Shanahan, F. (2003). Basic aspects and pharmacology of probiotics: an overview of pharmacokinetics, mechanisms of action and side-effects. Best Pract. Res. Clin. Gastroenterol. 17, 725-740. doi: 10.1016/S1521-6918(03)00055-6

Martin, W. F., Garg, S., and Zimorski, V. (2015). Endosymbiotic theories for eukaryote origin. Philos. Trans. R. Soc. Biol. Sci. 370:20140330. doi: $10.1098 /$ rstb.2014.0330
Mawe, G. M., and Hoffman, J. M. (2013). Serotonin signalling in the gut-functions, dysfunctions and therapeutic targets. Nat. Rev. Gastroenterol. Hepatol. 10, 473-486. doi: 10.1038/nrgastro.2013.105

Mayer, E. A., Knight, R., Mazmanian, S. K., and Cryan, J. F. (2014a). Gut microbes and the brain: paradigm shift in Neuroscience. J. Neurosci. 34, 15490-15496. doi: 10.1523/JNEUROSCI.3299-14.2014

Mayer, E. A., Padua, D., and Tillisch, K. (2014b). Altered brain-gut axis in autism: comorbidity or causative mechanisms? Bioessays 36, 933-939. doi: 10.1002/bies.201400075

McCusker, R. H., and Kelley, K. W. (2013). Immune-neural connections: how the immune system's response to infectious agents influences behavior. J. Exp. Biol. 216, 84-98. doi: 10.1242/jeb.073411

McEwen, B. S. (2017). Allostasis and the epigenetics of brain and body health over the life course: the brain on stress. JAMA Psychiatry 74, 551-552. doi: 10.1001/jamapsychiatry.2017.0270

McEwen, B. S., Nasca, C., and Gray, J. D. (2016). Stress effects on neuronal structure: hippocampus, amygdala, and prefrontal cortex. Neuropsychopharmacology 41, 3-23. doi: 10.1038/npp.2015.171

McFall-Ngai, M., Hadfield, M. G., Bosch, T. C., Carey, H. V., Domazet-Loso, T., Douglas, A. E., et al. (2013). Animals in a bacterial world, a new imperative for the life sciences. Proc. Natl. Acad. Sci. U.S.A. 110, 3229-3236. doi: $10.1073 /$ pnas. 1218525110

McGlashan, T. H., and Hoffman, R. E. (2000). Schizophrenia as a disorder of developmentally reduced synaptic connectivity. Arch. Gen. Psychiatry 57, 637-648. doi: 10.1001/archpsyc.57.7.637

McKernan, D. P., Dennison, U., Gaszner, G., Cryan, J. F., and Dinan, T. G. (2011). Enhanced peripheral toll-like receptor responses in psychosis: further evidence of a pro-inflammatory phenotype. Transl. Psychiatry 1:e36. doi: 10.1038/tp.2011.37

Meehan, C., Harms, L., Frost, J. D., Barreto, R., Todd, J., Schall, U., et al. (2016). Effects of immune activation during early or late gestation on schizophreniarelated behaviour in adult rat offspring. Brain Behav. Immun. 63, 8-20. doi: 10.1016/j.bbi.2016.07.144

Messaoudi, M., Lalonde, R., Violle, N., Javelot, H., Desor, D., Nejdi, A., et al. (2011). Assessment of psychotropic-like properties of a probiotic formulation (Lactobacillus helveticus R0052 and Bifidobacterium longum R0175) in rats and human subjects. Br. J. Nutr. 105, 755-764. doi: 10.1017/S0007114510004319

Messias, E., Chen, C.-Y., and Eaton, W. W. (2007). Epidemiology of Schizophrenia: review of Findings and Myths. Psychiatr. Clin. North Am. 30, 323-338. doi: 10.1016/j.psc.2007.04.007

Meyer, U. (2014). Prenatal poly(i:C) exposure and other developmental immune activation models in rodent systems. Biol. Psychiatry 75, 307-315. doi: 10.1016/j.biopsych.2013.07.011

Meyer, U., Feldon, J., and Yee, B. K. (2009). A review of the fetal brain cytokine imbalance hypothesis of schizophrenia. Schizophr. Bull. 35, 959-972. doi: $10.1093 /$ schbul/sbn022

Meyer, U., Nyffeler, M., Engler, A., Urwyler, A., Schedlowski, M., Knuesel, I., et al. (2006). The time of prenatal immune challenge determines the specificity of inflammation-mediated brain and behavioral pathology. J. Neurosci. 26, 4752-4762. doi: 10.1523/JNEUROSCI.009906.2006

Miller, A. H., Haroon, E., Raison, C. L., and Felger, J. C. (2013). Cytokine targets in the brain: impact on neurotransmitters and neurocircuits. Depress. Anxiety 30, 297-306. doi: 10.1002/da.22084

Miller, B. J., Buckley, P., Seabolt, W., Mellor, A., and Kirkpatrick, B. (2011). Meta-analysis of cytokine alterations in schizophrenia: clinical status and antipsychotic effects. Biol. Psychiatry 70, 663-671. doi: 10.1016/j.biopsych.2011.04.013

Miyaoka, T., Yasukawa, R., Yasuda, H., Hayashida, M., Inagaki, T., and Horiguchi, J. (2008). Minocycline as adjunctive therapy for schizophrenia: an open-label study. Clin. Neuropharmacol. 31, 287-292. doi: 10.1097/WNF.0b013e3181593d45

Mohammadi, A. A., Jazayeri, S., Khosravi-Darani, K., Solati, Z., Mohammadpour, N., Asemi, Z., et al. (2015). Effects of probiotics on biomarkers of oxidative stress and inflammatory factors in petrochemical workers: a randomized, double-blind, placebo-controlled trial. Int. J. Prev. Med. 6:82. doi: $10.4103 / 2008-7802.164146$ 
Mohle, L., Mattei, D., Heimesaat, M. M., Bereswill, S., Fischer, A., Alutis, M., et al. (2016). Ly6C(hi) monocytes provide a link between antibiotic-induced changes in gut microbiota and adult hippocampal neurogenesis. Cell Rep. 15, 1945-1956. doi: 10.1016/j.celrep.2016.04.074

Molloy, C. A., and Manning-Courtney, P. (2003). Prevalence of chronic gastrointestinal symptoms in children with autism and autistic spectrum disorders. Autism 7, 165-171. doi: 10.1177/1362361303007002004

Molloy, M. J., Grainger, J. R., Bouladoux, N., Hand, T. W., Koo, L. Y., Naik, S., et al. (2013). Intraluminal containment of commensal outgrowth in the gut during infection-induced dysbiosis. Cell Host Microbe 14, 318-328. doi: 10.1016/j.chom.2013.08.003

Moloney, R. D., Desbonnet, L., Clarke, G., Dinan, T. G., and Cryan, J. F. (2014). The microbiome: stress, health and disease. Mamm. Genome 25, 49-74. doi: 10.1007/s00335-013-9488-5

Monk, C. S., Weng, S.-J., Wiggins, J. L., Kurapati, N., Louro, H. M. C., Carrasco, M., et al. (2010). Neural circuitry of emotional face processing in autism spectrum disorders. J. Psychiatry Neurosci. 35, 105-114. doi: 10.1503/jpn.090085

Monroe, J. M., Buckley, P. F., and Miller, B. J. (2015). Meta-analysis of antiToxoplasma gondii IgM antibodies in acute psychosis. Schizophr. Bull. 41, 989-998. doi: 10.1093/schbul/sbu159

Monteggia, L. M., Barrot, M., Powell, C. M., Berton, O., Galanis, V., Gemelli, T., et al. (2004). Essential role of brain-derived neurotrophic factor in adult hippocampal function. Proc. Natl. Acad. Sci. U.S.A. 101, 10827-10832. doi: 10.1073/pnas.0402141101

Montiel, C., Augusto, J., Baez, Y., Mario, G., and Pacheco-Lopez, G. (2014). Social neuroeconomics: the influence of microbiota in partner-choice and sociality. Curr. Pharm. Des. 20, 4774-4783. doi: 10.2174/1381612820666140130210631

Morgan, C. J., Coleman, M. J., Ulgen, A., Boling, L., Cole, J. O., Johnson, F. V., et al. (2017). Thought disorder in schizophrenia and bipolar disorder probands, their relatives, and nonpsychiatric controls. Schizophr. Bull. 43, 523-535. doi: 10.1093/schbul/sbx016

Moya-Pérez, A., Perez-Villalba, A., Benítez-Páez, A., Campillo, I., and Sanz, Y. (2017). Bifidobacterium CECT 7765 modulates early stress-induced immune, neuroendocrine and behavioral alterations in mice. Brain Behav. Immun. 65, 43-56. doi: 10.1016/j.bbi.2017.05.011

Mudd, A. T., Berding, K., Wang, M., Donovan, S. M., and Dilger, R. N. (2017). Serum cortisol mediates the relationship between fecal Ruminococcus and brain N-acetylaspartate in the young pig. Gut. Microbes. doi: 10.1080/19490976.2017.1353849. [Epub ahead of print].

Muller, N. (2014). Immunology of schizophrenia. Neuroimmunomodulation 21, 109-116. doi: 10.1159/000356538

Myint, A. M., and Kim, Y. K. (2014). Network beyond IDO in psychiatric disorders: revisiting neurodegeneration hypothesis. Prog. Neuropsychopharmacol. Biol. Psychiatry 48, 304-313. doi: 10.1016/j.pnpbp.2013.08.008

Narendran, R., and Frankle, W. G. (2016). Comment on Analyses and conclusions of "microglial activity in people at ultra high risk of psychosis and in schizophrenia: an [(11)C]PBR28 PET brain imaging study.” Am. J. Psychiatry 173, 536-537. doi: 10.1176/appi.ajp.2016.15111417

Naseribafrouei, A., Hestad, K., Avershina, E., Sekelja, M., Linlokken, A., Wilson, R., et al. (2014). Correlation between the human fecal microbiota and depression. Neurogastroenterol. Motil. 26, 1155-1162. doi: 10.1111/nmo.12378

Neufeld, K. M., Kang, N., Bienenstock, J., and Foster, J. A. (2011). Reduced anxiety-like behavior and central neurochemical change in germ-free mice. Neurogastroenterol. Motil. 23:255-e119. doi: 10.1111/j.1365-2982.2010. 01620.x

Neuhaus, E., Jones, E. J., Barnes, K., Sterling, L., Estes, A., Munson, J., et al. (2016). The relationship between early neural responses to emotional faces at age 3 and later autism and anxiety symptoms in adolescents with autism. J. Autism Dev. Disord. 46, 2450-2463. doi: 10.1007/s10803-016-2780-y

Newbury, J., Arseneault, L., Caspi, A., Moffitt, T. E., Odgers, C. L., and Fisher, H. L. (2016). Why are children in urban neighborhoods at increased risk for psychotic symptoms? Findings from a UK longitudinal cohort study. Schizophr. Bull. 42, 1372-1383. doi: 10.1093/schbul/sbw052

Nieto, R., Kukuljan, M., and Silva, H. (2013). BDNF and schizophrenia: from neurodevelopment to neuronal plasticity, learning, and memory. Front. Psychiatry 4:45. doi: 10.3389/fpsyt.2013.00045

Nilsson, L. K., Linderholm, K. R., Engberg, G., Paulson, L., Blennow, K., Lindstrom, L. H., et al. (2005). Elevated levels of kynurenic acid in the cerebrospinal fluid of male patients with schizophrenia. Schizophr. Res. 80, 315-322. doi: 10.1016/j.schres.2005.07.013

Nishino, R., Mikami, K., Takahashi, H., Tomonaga, S., Furuse, M., Hiramoto, T., et al. (2013). Commensal microbiota modulate murine behaviors in a strictly contamination-free environment confirmed by culture-based methods. Neurogastroenterol. Motil. 25, 521-528. doi: 10.1111/nmo. 12110

Notarangelo, F. M., and Pocivavsek, A. (2017). Elevated kynurenine pathway metabolism during neurodevelopment: implications for brain and behavior. Neuropharmacology 112, 275-285. doi: 10.1016/j.neuropharm.2016.03.001

Notarangelo, F. M., and Schwarcz, R. (2017). Restraint stress during pregnancy rapidly raises kynurenic acid levels in mouse placenta and fetal brain. Dev. Neurosci. 38, 458-468. doi: 10.1159/000455228

Notter, T., and Meyer, U. (2017). Microglia and schizophrenia: where next? Mol. Psychiatry 22, 788-789. doi: 10.1038/mp.2017.67

O’Tuathaigh, C. M. P., Fumagalli, F., Desbonnet, L., Perez-Branguli, F., Moloney G., Loftus, S., et al. (2017). Epistatic and independent effects on schizophreniarelated phenotypes following co-disruption of the risk factors neuregulin-1 $\times$ DISC1. Schizophr. Bull. 43, 214-225. doi: 10.1093/schbul/sbw120

O'Connor, J. C., Lawson, M. A., Andre, C., Moreau, M., Lestage, J., Castanon, N., et al. (2009). Lipopolysaccharide-induced depressive-like behavior is mediated by indoleamine 2,3-dioxygenase activation in mice. Mol. Psychiatry 14, 511-522. doi: 10.1038/sj.mp.4002148

Ogbonnaya, E. S., Clarke, G., Shanahan, F., Dinan, T. G., Cryan, J. F., and O'Leary, O. F. (2015). Adult hippocampal neurogenesis is regulated by the microbiome. Biol. Psychiatry 78, e7-e9. doi: 10.1016/j.biopsych.2014.12.023

O'Hara, A. M., and Shanahan, F. (2006). The gut flora as a forgotten organ. EMBO Rep. 7, 688-693. doi: 10.1038/sj.embor.7400731

Olszak, T., An, D., Zeissig, S., Vera, M. P., Richter, J., Franke, A., et al. (2012). Microbial exposure during early life has persistent effects on natural killer T cell function. Science 336, 489-493. doi: 10.1126/science.1219328

O'Mahony, S. M., Clarke, G., Borre, Y. E., Dinan, T. G., and Cryan, J. F. (2015). Serotonin, tryptophan metabolism and the brain-gut-microbiome axis. Behav. Brain Res. 277, 32-48. doi: 10.1016/j.bbr.2014.07.027

O’Mahony, S. M., Clarke, G., Dinan, T. G., and Cryan, J. F. (2017). Early-life adversity and brain development: is the microbiome a missing piece of the puzzle? Neuroscience 342, 37-54. doi: 10.1016/j.neuroscience.2015.09.068

O’Mahony, S. M., Marchesi, J. R., Scully, P., Codling, C., Ceolho, A. M., Quigley, E. M., et al. (2009). Early life stress alters behavior, immunity, and microbiota in rats: implications for irritable bowel syndrome and psychiatric illnesses. Biol. Psychiatry 65, 263-267. doi: 10.1016/j.biopsych.2008.06.026

O’Neill, S. M., Curran, E. A., Dalman, C., Kenny, L. C., Kearney, P. M., Clarke, G., et al. (2015). Birth by caesarean section and the risk of adult psychosis: a population-based cohort study. Schizophr Bull. 42, 633-641. doi: $10.1093 /$ schbul/sbv152

Öngür, D. (2017). Systems research in psychiatric neuroscience. JAMA Psychiatry 74, 553-554. doi: 10.1001/jamapsychiatry.2017.0513

Opie, R. S., Itsiopoulos, C., Parletta, N., Sanchez-Villegas, A., Akbaraly, T. N., Ruusunen, A., et al. (2017). Dietary recommendations for the prevention of depression. Nutr. Neurosci. 20, 161-171. doi: 10.1179/1476830515Y.0000000043

Parikshak, N. N., Swarup, V., Belgard, T. G., Irimia, M., Ramaswami, G., Gandal, M. J., et al. (2016). Genome-wide changes in lncRNA, splicing, and regional gene expression patterns in autism. Nature 540, 423-427. doi: 10.1038/nature20612

Park, S. J., Lee, J. Y., Kim, S. J., Choi, S. Y., Yune, T. Y., and Ryu, J. H. (2015). Toll-like receptor-2 deficiency induces schizophrenia-like behaviors in mice. Sci. Rep. 5:8502. doi: 10.1038/srep08502

Parracho, H. M., Bingham, M. O., Gibson, G. R., and McCartney, A. L. (2005) Differences between the gut microflora of children with autistic spectrum disorders and that of healthy children. J. Med. Microbiol. 54, 987-991. doi: 10.1099/jmm.0.46101-0

Patel, S., and Gruchalla, R. (2017). Can we be too clean for our own good? The hygiene hypothesis reviewed. Tex. Med. 113, 54-59.

Patterson, P. H. (2011). Modeling autistic features in animals. Pediatr. Res. 69, 34R-40R. doi: 10.1203/PDR.0b013e318212b80f

Pedersen, C. B., and Mortensen, P. B. (2001). Evidence of a dose-response relationship between urbanicity during upbringing and schizophrenia 
risk. Arch. Gen. Psychiatry 58, 1039-1046. doi: 10.1001/archpsyc.58. 11.1039

Peen, J., Schoevers, R. A., Beekman, A. T., and Dekker, J. (2010). The current status of urban-rural differences in psychiatric disorders. Acta Psychiatr. Scand. 121, 84-93. doi: 10.1111/j.1600-0447.2009.01438.x

Penders, J., Thijs, C., van den Brandt, P. A., Kummeling, I., Snijders, B., Stelma, F., et al. (2007). Gut microbiota composition and development of atopic manifestations in infancy: the KOALA Birth Cohort Study. Gut 56, 661-667. doi: 10.1136/gut.2006.100164

Pendyala, G., Chou, S., Jung, Y., Coiro, P., Spartz, E., Padmashri, R., et al. (2017). Maternal immune activation causes behavioral impairments and altered cerebellar cytokine and synaptic protein expression. Neuropsychopharmacology 42, 1435-1446. doi: 10.1038/npp.2017.7

Pequegnat, B., Sagermann, M., Valliani, M., Toh, M., Chow, H., AllenVercoe, E., et al. (2013). A vaccine and diagnostic target for Clostridium bolteae, an autism-associated bacterium. Vaccine 31, 2787-2790. doi: 10.1016/j.vaccine.2013.04.018

Perala, J., Suvisaari, J., Saarni, S. I., Kuoppasalmi, K., Isometsa, E., Pirkola, S., et al. (2007). Lifetime prevalence of psychotic and bipolar I disorders in a general population. Arch. Gen. Psychiatry 64, 19-28. doi: 10.1001/archpsyc.64.1.19

Perry, V. H., and Holmes, C. (2014). Microglial priming in neurodegenerative disease. Nat. Rev. Neurol. 10, 217-224. doi: 10.1038/nrneurol.2014.38

Pershing, M. L., Bortz, D. M., Pocivavsek, A., Fredericks, P. J., Jorgensen, C. V., Vunck, S. A., et al. (2015). Elevated levels of kynurenic acid during gestation produce neurochemical, morphological, and cognitive deficits in adulthood: implications for schizophrenia. Neuropharmacology 90, 33-41. doi: 10.1016/j.neuropharm.2014.10.017

Pershing, M. L., Phenis, D., Valentini, V., Pocivavsek, A., Lindquist, D. H., Schwarcz, R., et al. (2016). Prenatal kynurenine exposure in rats: age-dependent changes in NMDA receptor expression and conditioned fear responding. Psychopharmacology 233, 3725-3735. doi: 10.1007/s00213-016-4404-9

Pinto-Sanchez, M. I., Hall, G. B., Ghajar, K., Nardelli, A., Bolino, C., Lau, J. T., et al. (2017). Probiotic Bifidobacterium longum NCC3001 reduces depression scores and alters brain activity: a pilot study in patients with irritable bowel syndrome. Gastroenterology 153, 448-459.e8. doi: 10.1053/j.gastro.2017.05.003

Pisar, M., Forrest, C. M., Khalil, O. S., McNair, K., Vincenten, M. C., Qasem, S., et al. (2014). Modified neocortical and cerebellar protein expression and morphology in adult rats following prenatal inhibition of the kynurenine pathway. Brain Res. 1576, 1-17. doi: 10.1016/j.brainres.2014.06.016

Plitman, E., Iwata, Y., Caravaggio, F., Nakajima, S., Chung, J. K., Gerretsen, P., et al. (2017). Kynurenic acid in schizophrenia: a systematic review and meta-analysis. Schizophr. Bull. 43, 764-777. doi: 10.1093/schbul/sbw221

Pocivavsek, A., Thomas, M. A., Elmer, G. I., Bruno, J. P., and Schwarcz, R. (2014). Continuous kynurenine administration during the prenatal period, but not during adolescence, causes learning and memory deficits in adult rats. Psychopharmacology 231, 2799-2809. doi: 10.1007/s00213-0143452-2

Pollak, T. A., Drndarski, S., Stone, J. M., David, A. S., McGuire, P., and Abbott, N. J. (2017). The blood-brain barrier in psychosis. Lancet Psychiatry. doi: 10.1016/S2215-0366(17)30293-6. [Epub ahead of print].

Prandovszky, E., Gaskell, E., Martin, H., Dubey, J. P., Webster, J. P., and McConkey, G. A. (2011). The neurotropic parasite Toxoplasma gondii increases dopamine metabolism. PLOS ONE 6:e23866. doi: 10.1371/journal.pone.00 23866

Preissler, M. A., and Carey, S. (2005). The role of inferences about referential intent in word learning: evidence from autism. Cognition 97, B13-B23. doi: 10.1016/j.cognition.2005.01.008

Prinz, M., Tay, T. L., Wolf, Y., and Jung, S. (2014). Microglia: unique and common features with other tissue macrophages. Acta Neuropathol. 128, 319-331. doi: 10.1007/s00401-014-1267-1

Pyndt Jorgensen, B., Krych, L., Pedersen, T. B., Plath, N., Redrobe, J. P., Hansen, A. K., et al. (2015). Investigating the long-term effect of subchronic phencyclidinetreatment on novel object recognition and the association between the gut microbiota and behavior in the animal model of schizophrenia. Physiol. Behav. 141, 32-39. doi: 10.1016/j.physbeh.2014.12.042

Qin, J., Li, R., Raes, J., Arumugam, M., Burgdorf, K. S., and Manichanh, C. (2010). A human gut microbial gene catalogue established by metagenomic sequencing. Nature 464, 59-65. doi: 10.1038/nature08821
Qin, X., Feng, J., Cao, C., Wu, H., Loh, Y., and Cheng, Y. (2016). Association of peripheral blood levels of brain-derived neurotrophic factor with autism spectrum disorder in children: a systematic review and meta-analysis. JAMA Pediatr. 170, 1079-1086. doi: 10.1001/jamapediatrics.2016.1626

Quigley, E. M. M. (2017). Gut microbiome as a clinical tool in gastrointestinal disease management: are we there yet? Nat. Rev. Gastroenterol. Hepatol. 14, 315-320. doi: 10.1038/nrgastro.2017.29

Rasetti, R., Mattay, V. S., Wiedholz, L. M., Kolachana, B. S., Hariri, A. R., Callicott, J. H., et al. (2009). Evidence that altered amygdala activity in schizophrenia is related to clinical state and not genetic risk. Am. J. Psychiatry 166, 216-225. doi: 10.1176/appi.ajp.2008.08020261

Rea, K., Dinan, T. G., and Cryan, J. F. (2016). The microbiome: a key regulator of stress and neuroinflammation. Neurobiol Stress 4, 23-33. doi: 10.1016/j.ynstr.2016.03.001

Reber, S. O., Siebler, P. H., Donner, N. C., Morton, J. T., Smith, D. G., Kopelman, J. M., et al. (2016). Immunization with a heat-killed preparation of the environmental bacterium Mycobacterium vaccae promotes stress resilience in mice. Proc. Natl. Acad.f Sci. U.S.A. 113, E3130-E3139. doi: $10.1073 /$ pnas. 1600324113

Reed, S., Neuman, H., Moscovich, S., Glahn, R. P., Koren, O., and Tako, E. (2015). Chronic zinc deficiency alters chick gut microbiota composition and function. Nutrients 7, 9768-9784. doi: 10.3390/nu7125497

Reigstad, C. S., Salmonson, C. E., Rainey, J. F. III., Szurszewski, J. H., Linden, D. R., Sonnenburg, J. L., et al. (2015). Gut microbes promote colonic serotonin production through an effect of short-chain fatty acids on enterochromaffin cells. FASEB J. 29, 1395-1403. doi: 10.1096/fj.14-259598

Reininghaus, U., Bohnke, J. R., Hosang, G., Farmer, A., Burns, T., McGuffin, P., et al. (2016a). Evaluation of the validity and utility of a transdiagnostic psychosis dimension encompassing schizophrenia and bipolar disorder. Br. J. Psychiatry 209, 107-113. doi: 10.1192/bjp.bp.115.167882

Reininghaus, U., Kempton, M. J., Valmaggia, L., Craig, T. K., Garety, P., Onyejiaka, A., et al. (2016b). Stress sensitivity, aberrant salience, and threat anticipation in early psychosis: an experience sampling study. Schizophr. Bull. 42, 712-722. doi: 10.1093/schbul/sbv190

Relman, D. A. (2012). The human microbiome: ecosystem resilience and health. Nutr. Rev. 70(Suppl. 1), S2-S9. doi: 10.1111/j.1753-4887.2012.00489.x

Roche, E., Segurado, R., Renwick, L., McClenaghan, A., Sexton, S., Frawley, T., et al. (2016). Language disturbance and functioning in first episode psychosis. Psychiatry Res. 235, 29-37. doi: 10.1016/j.psychres.2015.12.008

Rogier, R., Koenders, M. I., and Abdollahi-Roodsaz, S. (2015). Toll-like receptor mediated modulation of $\mathrm{T}$ cell response by commensal intestinal microbiota as a trigger for autoimmune Arthritis 2015:527696. doi: 10.1155/2015/527696

Rojas, D. C. (2014). The role of glutamate and its receptors in autism and the use of glutamate receptor antagonists in treatment. J. Neural Transm. 121, 891-905. doi: 10.1007/s00702-014-1216-0

Romijn, A. R., and Rucklidge, J. J. (2015). Systematic review of evidence to support the theory of psychobiotics. Nutr. Rev. 73, 675-693. doi: 10.1093/nutrit/nuv025

Romijn, A. R., Rucklidge, J. J., Kuijer, R. G., and Frampton, C. (2017). A double-blind, randomized, placebo-controlled trial of Lactobacillus helveticus and Bifidobacterium longum for the symptoms of depression. Aust. N. Z. J. Psychiatry 51, 810-821. doi: 10.1177/0004867416686694

Rook, G. A., and Lowry, C. A. (2008). The hygiene hypothesis and psychiatric disorders. Trends Immunol. 29, 150-158. doi: 10.1016/j.it.2008.01.002

Rook, G. A., Lowry, C. A., and Raison, C. L. (2013). Microbial 'Old Friends', immunoregulation and stress resilience. Evol. Med. Public Health 2013, 46-64. doi: 10.1093/emph/eot004

Rook, G. A., Martinelli, R., and Brunet, L. R. (2003). Innate immune responses to mycobacteria and the downregulation of atopic responses. Curr. Opin. Allergy Clin. Immunol. 3, 337-342. doi: 10.1097/00130832-200310000-00003

Rook, G. A., Raison, C. L., and Lowry, C. A. (2014). Microbiota, immunoregulatory old friends and psychiatric disorders. Adv. Exp. Med. Biol. 817, 319-356. doi: 10.1007/978-1-4939-0897-4_15

Rosenberg, E., Koren, O., Reshef, L., Efrony, R., and Zilber-Rosenberg, I. (2007). The role of microorganisms in coral health, disease and evolution. Nat. Rev. Microbiol. 5, 355-362. doi: 10.1038/nrmicro1635

Round, J. L., and Mazmanian, S. K. (2009). The gut microbiota shapes intestinal immune responses during health and disease. Nat. Rev. Immunol. 9, 313-323. doi: $10.1038 /$ nri2515 
Ruddick, J. P., Evans, A. K., Nutt, D. J., Lightman, S. L., Rook, G. A., and Lowry, C. A. (2006). Tryptophan metabolism in the central nervous system: medical implications. Expert Rev. Mol. Med. 8, 1-27. doi: 10.1017/\$1462399406000068

Saghazadeh, A., and Rezaei, N. (2017). Brain-derived neurotrophic factor levels in autism: a systematic review and meta-analysis. J. Autism Dev. Disord. 47, 1018-1029. doi: 10.1007/s10803-016-3024-x

Sandin, S., Schendel, D., Magnusson, P., Hultman, C., Suren, P., Susser, E., et al. (2016). Autism risk associated with parental age and with increasing difference in age between the parents. Mol. Psychiatry 21, 693-700. doi: $10.1038 / \mathrm{mp} .2015 .70$

Sandler, R. H., Finegold, S. M., Bolte, E. R., Buchanan, C. P., Maxwell, A. P., Vaisanen, M. L., et al. (2000). Short-term benefit from oral vancomycin treatment of regressive-onset autism. J. Child Neurol. 15, 429-435. doi: $10.1177 / 088307380001500701$

Sarkar, A., Lehto, S. M., Harty, S., Dinan, T. G., Cryan, J. F., and Burnet, P. W. J. (2016). Psychobiotics and the manipulation of bacteriagut-brain signals. Trends Neurosci. 39, 763-781. doi: 10.1016/j.tins.2016. 09.002

Savignac, H. M., Corona, G., Mills, H., Chen, L., Spencer, J. P., Tzortzis, G., et al. (2013). Prebiotic feeding elevates central brain derived neurotrophic factor, $\mathrm{N}$-methyl-D-aspartate receptor subunits and D-serine. Neurochem. Int. 63, 756-764. doi: 10.1016/j.neuint.2013.10.006

Savignac, H. M., Tramullas, M., Kiely, B., Dinan, T. G., and Cryan, J. F. (2015). Bifidobacteria modulate cognitive processes in an anxious mouse strain. Behav. Brain Res. 287, 59-72. doi: 10.1016/j.bbr.2015.02.044

Schaefer, J., Giangrande, E., Weinberger, D. R., and Dickinson, D. (2013). The global cognitive impairment in schizophrenia: consistent over decades and around the world. Schizophr. Res. 150, 42-50. doi: 10.1016/j.schres.2013. 07.009

Schendel, D., and Bhasin, T. K. (2008). Birth weight and gestational age characteristics of children with autism, including a comparison with other developmental disabilities. Pediatrics 121, 1155-1164. doi: $10.1542 /$ peds.2007-1049

Schenkel, L. S., and Silverstein, S. M. (2004). Dimensions of premorbid functioning in schizophrenia: a review of neuromotor, cognitive, social, and behavioral domains. Genet. Soc. Gen. Psychol. Monogr. 130, 241-270. doi: 10.3200/MONO.130.3.241-272

Schizophrenia Working Group of the Psychiatric Genomics Consortium. (2014). Biological insights from 108 schizophrenia-associated genetic loci. Nature 511, 421-427. doi: 10.1038/nature13595

Schmidt, K., Cowen, P. J., Harmer, C. J., Tzortzis, G., Errington, S., and Burnet, P. W. (2015). Prebiotic intake reduces the waking cortisol response and alters emotional bias in healthy volunteers. Psychopharmacology 232, 1793-1801. doi: 10.1007/s00213-014-3810-0

Schmidt, M. J., and Mirnics, K. (2015). Neurodevelopment, GABA system dysfunction, and schizophrenia. Neuropsychopharmacology 40, 190-206. doi: $10.1038 /$ npp. 2014.95

Schoenbaum, M., Sutherland, J. M., Chappel, A., Azrin, S., Goldstein, A. B., Rupp, A., et al. (2017). Twelve-month health care use and mortality in commercially insured young people with incident psychosis in the United States. Schizophr. Bull. doi: 10.1093/schbul/sbx009. [Epub ahead of print].

Schwarcz, R., Bruno, J. P., Muchowski, P. J., and Wu, H. Q. (2012). Kynurenines in the mammalian brain: when physiology meets pathology. Nat. Rev. Neurosci. 13, 465-477. doi: 10.1038/nrn3257

Schwarz, E., Maukonen, J., Hyytiainen, T., Kieseppa, T., Orešič, M., Sabunciyan, S., et al. (in press). Analysis of microbiota in first episode psychosis identifies preliminary associations with symptom severity and treatment response. Schizophr. Res. doi: 10.1016/j.schres.2017.04.017

Sekar, A., Bialas, A. R., de Rivera, H., Davis, A., Hammond, T. R., Kamitaki, N., et al. (2016). Schizophrenia risk from complex variation of complement component 4. Nature 530, 177-183. doi: 10.1038/nature 16549

Selten, J. P., and Cantor-Graae, E. (2005). Social defeat: risk factor for schizophrenia? Br. J. Psychiatry 187, 101-102. doi: 10.1192/bjp.187.2.101

Selvaraj, S., Arnone, D., Cappai, A., and Howes, O. (2014). Alterations in the serotonin system in schizophrenia: a systematic review and meta-analysis of postmortem and molecular imaging studies. Neurosci. Biobehav. Rev. 45, 233-245. doi: 10.1016/j.neubiorev.2014.06.005
Semple, B. D., Blomgren, K., Gimlin, K., Ferriero, D. M., and Noble-Haeusslein, L. J. (2013). Brain development in rodents and humans: identifying benchmarks of maturation and vulnerability to injury across species. Prog. Neurobiol. 106-107, 1-16. doi: 10.1016/j.pneurobio.2013.04.001

Sender, R., and Fuchs, S. (2016). Revised estimates for the number of human and bacteria cells in the body. PLoS Biol. 14:e1002533. doi: 10.1371/journal.pbio.1002533

Setiawan, E., Wilson, A. A., Mizrahi, R., Rusjan, P. M., Miler, L., Rajkowska, G., et al. (2015). Role of translocator protein density, a marker of neuroinflammation, in the brain during major depressive episodes. JAMA Psychiatry 72, 268-275. doi: 10.1001/jamapsychiatry.2014.2427

Severance, E. G., Gressitt, K. L., Stallings, C. R., Katsafanas, E., Schweinfurth, L. A., Savage, C. L., et al. (2016a). Candida albicans exposures, sex specificity and cognitive deficits in schizophrenia and bipolar disorder. NPJ Schizophr. 2:16018. doi: $10.1038 / n$ pjschz.2016.18

Severance, E. G., Gressitt, K. L., Stallings, C. R., Katsafanas, E., Schweinfurth, L. A., Savage, C. L., et al. (2017). Probiotic normalization of Candida albicans in schizophrenia: a randomized, placebo-controlled, longitudinal pilot study. Brain Behav. Immun. 62, 41-45. doi: 10.1016/j.bbi.2016.11.019

Severance, E. G., Gressitt, K. L., Stallings, C. R., Origoni, A. E., Khushalani, S., Leweke, F. M., et al. (2013). Discordant patterns of bacterial translocation markers and implications for innate immune imbalances in schizophrenia. Schizophr. Res. 148, 130-137. doi: 10.1016/j.schres.2013.05.018

Severance, E. G., Xiao, J., Jones-Brando, L., Sabunciyan, S., Li, Y., Pletnikov, M., et al. (2016b). "Chapter seven - Toxoplasma gondii-a gastrointestinal pathogen associated with human brain diseases," in International Review of Neurobiology, eds J. F. Cryan and G. Clarke (Academic Press), 143-163.

Severance, E. G., Yolken, R. H., and Eaton, W. W. (2016c). Autoimmune diseases, gastrointestinal disorders and the microbiome in schizophrenia: more than a gut feeling. Schizophr. Res. 176, 23-35. doi: 10.1016/j.schres.2014. 06.027

Shen, M. D., Kim, S. H., McKinstry, R. C., Gu, H., Hazlett, H. C., Nordahl, C. W., et al. (2017). Increased extra-axial cerebrospinal fluid in high-risk infants who later develop autism. Biol. Psychiatry 82, 186-193. doi: 10.1016/j.biopsych.2017.02.1095

Sherwin, E., Dinan, T. G., and Cryan, J. F. (2017). Recent developments in understanding the role of the gut microbiota in brain health and disease. Ann. N. Y. Acad. Sci. doi: 10.1111/nyas.13416. [Epub ahead of print].

Silbersweig, D., and Loscalzo, J. (2017). Precision psychiatry meets network medicine: network psychiatry. JAMA Psychiatry 74, 665-666. doi: 10.1001/jamapsychiatry.2017.0580

Slavich, G. M., Way, B. M., Eisenberger, N. I., and Taylor, S. E. (2010). Neural sensitivity to social rejection is associated with inflammatory responses to social stress. Proc. Natl. Acad. Sci. U.S.A. 107, 14817-14822. doi: 10.1073/pnas.1009164107

Sliwa, J., and Freiwald, W. A. (2017). A dedicated network for social interaction processing in the primate brain. Science 356, 745-749. doi: 10.1126/science.aam6383

Smith, S. E. P., Li, J., Garbett, K., Mirnics, K., and Patterson, P. H. (2007). Maternal immune activation alters fetal brain development through interleukin-6. J. Neurosci. 27, 10695-10702. doi: 10.1523/JNEUROSCI.2178-07.2007

Son, J. S., Zheng, L. J., Rowehl, L. M., Tian, X., Zhang, Y., Zhu, W., et al (2015). Comparison of fecal microbiota in children with autism spectrum disorders and neurotypical siblings in the simons simplex collection. PLoS ONE 10:e0137725. doi: 10.1371/journal.pone.0137725

Song, Y., Liu, C., and Finegold, S. M. (2004). Real-time PCR quantitation of clostridia in feces of autistic children. Appl. Environ. Microbiol. 70, 6459-6465. doi: 10.1128/AEM.70.11.6459-6465.2004

Spencer, S. J., and Meyer, U. (2017). Perinatal programming by inflammation. Brain Behav. Immun. 63, 1-7. doi: 10.1016/j.bbi.2017.02.007

Spooren, W., Lindemann, L., Ghosh, A., and Santarelli, L. (2012). Synapse dysfunction in autism: a molecular medicine approach to drug discovery in neurodevelopmental disorders. Trends Pharmacol. Sci. 33, 669-684. doi: 10.1016/j.tips.2012.09.004

Stamper, C. E., Hoisington, A. J., Gomez, O. M., Halweg-Edwards, A. L., Smith, D. G., Bates, K. L., et al. (2016). "Chapter fourteen - the microbiome of the built environment and human behavior: implications for emotional health 
and well-being in postmodern western societies," in International Review of Neurobiology, eds J. F. Cryan and G. Clarke (Academic Press), 289-323.

St Clair, D., Xu, M., Wang, P., Yu, Y., Fang, Y., Zhang, F., et al. (2005). Rates of adult schizophrenia following prenatal exposure to the Chinese famine of 1959-1961. JAMA 294, 557-562. doi: 10.1001/jama.294.5.557

Steele, R. D. (1986). Blood-brain barrier transport of the alpha-keto acid analogs of amino acids. Fed. Proc. 45, 2060-2064.

Steenbergen, L., Sellaro, R., van Hemert, S., Bosch, J. A., and Colzato, L. S. (2015). A randomized controlled trial to test the effect of multispecies probiotics on cognitive reactivity to sad mood. Brain Behav. Immun. 48, 258-264. doi: 10.1016/j.bbi.2015.04.003

Stein, M. M., Hrusch, C. L., Gozdz, J., Igartua, C., Pivniouk, V., Murray, S. E., et al. (2016). Innate immunity and asthma risk in amish and hutterite farm children. N. Engl. J. Med. 375, 411-421. doi: 10.1056/NEJMoa1508749

Stiles, J., and Jernigan, T. L. (2010). The basics of brain development. Neuropsychol. Rev. 20, 327-348. doi: 10.1007/s11065-010-9148-4

Stilling, R. M., Bordenstein, S. R., Dinan, T. G., and Cryan, J. F. (2014a). Friends with social benefits: host-microbe interactions as a driver of brain evolution and development? Front. Cell. Infect. Microbiol. 4:147. doi: $10.3389 /$ fcimb.2014.00147

Stilling, R. M., Dinan, T. G., and Cryan, J. F. (2014b). Microbial genes, brain and behaviour - epigenetic regulation of the gut-brain axis. Genes Brain Behav. 13, 69-86. doi: 10.1111/gbb.12109

Stilling, R. M., Ryan, F. J., Hoban, A. E., Shanahan, F., Clarke, G., Claesson, M. J., et al. (2015). Microbes and neurodevelopment-Absence of microbiota during early life increases activity-related transcriptional pathways in the amygdala. Brain Behav. Immun. 50, 209-220. doi: 10.1016/j.bbi.2015. 07.009

Strachan, D. P. (1989). Hay fever, hygiene, and household size. BMJ 299, 1259-1260. doi: 10.1136/bmj.299.6710.1259

Strang, J. F., Kenworthy, L., Daniolos, P., Case, L., Wills, M. C., Martin, A., et al. (2012). Depression and anxiety symptoms in children and adolescents with autism spectrum disorders without intellectual disability. Res. Autism Spectr. Disord. 6, 406-412. doi: 10.1016/j.rasd.2011.06.015

Strati, F., Cavalieri, D., Albanese, D., De Felice, C., Donati, C., Hayek, J., et al. (2017). New evidences on the altered gut microbiota in autism spectrum disorders. Microbiome 5:24. doi: 10.1186/s40168-017-0242-1

Sudo, N., Chida, Y., Aiba, Y., Sonoda, J., Oyama, N., Yu, X. N., et al. (2004). Postnatal microbial colonization programs the hypothalamic-pituitaryadrenal system for stress response in mice. J. Physiol. 558, 263-275. doi: 10.1113/jphysiol.2004.063388

Sugama, S., Takenouchi, T., Fujita, M., Kitani, H., and Hashimoto, M. (2011). Cold stress induced morphological microglial activation and increased IL1beta expression in astroglial cells in rat brain. J. Neuroimmunol. 233, 29-36. doi: 10.1016/j.jneuroim.2010.11.002

Suhr, M. J., and Hallen-Adams, H. E. (2015). The human gut mycobiome: pitfalls and potentials-a mycologist's perspective. Mycologia 107, 1057-1073. doi: 10.3852/15-147

Sullivan, P. F., Kendler, K. S., and Neale, M. C. (2003). Schizophrenia as a complex trait: evidence from a meta-analysis of twin studies. Arch. Gen. Psychiatry 60, 1187-1192. doi: 10.1001/archpsyc.60.12.1187

Susser, E. S., and Lin, S. P. (1992). Schizophrenia after prenatal exposure to the Dutch Hunger Winter of 1944-1945. Arch. Gen. Psychiatry 49, 983-988. doi: 10.1001/archpsyc.1992.01820120071010

Suzuki, K., Sugihara, G., Ouchi, Y., Nakamura, K., Futatsubashi, M., Takebayashi, K., et al. (2013). Microglial activation in young adults with autism spectrum disorder. JAMA Psychiatry 70, 49-58. doi: 10.1001/jamapsychiatry. 2013.272

Takeda, K., and Akira, S. (2005). Toll-like receptors in innate immunity. Int. Immunol. 17, 1-14. doi: 10.1093/intimm/dxh186

Tan, J., McKenzie, C., Potamitis, M., Thorburn, A. N., Mackay, C. R., and Macia, L. (2014). The role of short-chain fatty acids in health and disease. Adv. Immunol. 121, 91-119. doi: 10.1016/B978-0-12-800100-4.00003-9

Tay, T. L., Savage, J. C., Hui, C. W., Bisht, K., and Tremblay, M.-È. (2017). Microglia across the lifespan: from origin to function in brain development, plasticity and cognition. J. Physiol. 595, 1929-1945. doi: 10.1113/JP272134

Teng, B. L., Nonneman, R. J., Agster, K. L., Nikolova, V. D., Davis, T. T., Riddick, N. V., et al. (2013). Prosocial effects of oxytocin in two mouse models of autism spectrum disorders. Neuropharmacology 72, 187-196. doi: 10.1016/j.neuropharm.2013.04.038

Thaiss, C. A., Levy, M., Korem, T., Dohnalová,á, L., Shapiro, H., Jaitin, D. A., et al. (2016). microbiota diurnal rhythmicity programs host transcriptome oscillations. Cell 167, 1495-1510.e12. doi: 10.1016/j.cell.2016.11.003

Thomas, E. H. X., Bozaoglu, K., Rossell, S. L., and Gurvich, C. (2017). The influence of the glutamatergic system on cognition in schizophrenia: a systematic review. Neurosci. Biobehav. Rev. 77, 369-387. doi: 10.1016/j.neubiorev.2017. 04.005

Thomas, R. H., Meeking, M. M., Mepham, J. R., Tichenoff, L., Possmayer, F., Liu, S., et al. (2012). The enteric bacterial metabolite propionic acid alters brain and plasma phospholipid molecular species: further development of a rodent model of autism spectrum disorders. J. Neuroinflammation 9:153. doi: 10.1186/1742-2094-9-153

Tick, B., Bolton, P., Happe, F., Rutter, M., and Rijsdijk, F. (2016). Heritability of autism spectrum disorders: a meta-analysis of twin studies. J. Child Psychol. Psychiatry 57, 585-595. doi: 10.1111/jcpp.12499

Tillisch, K., Labus, J., Kilpatrick, L., Jiang, Z., Stains, J., Ebrat, B., et al. (2013). Consumption of fermented milk product with probiotic modulates brain activity. Gastroenterology 144, 1394-1401. doi: 10.1053/j.gastro.2013.02.043

Tomova, A., Husarova, V., Lakatosova, S., Bakos, J., Vlkova, B., Babinska, K., et al. (2015). Gastrointestinal microbiota in children with autism in Slovakia. Physiol. Behav. 138, 179-187. doi: 10.1016/j.physbeh.2014.10.033

Too, L. K., McGregor, I. S., Baxter, A. G., and Hunt, N. H. (2016). Altered behaviour and cognitive function following combined deletion of Toll-like receptors 2 and 4 in mice. Behav. Brain Res. 303, 1-8. doi: 10.1016/j.bbr.2016.01.024

Torrey, E. F., and Yolken, R. H. (2003). Toxoplasma gondii and schizophrenia. Emerging Infect. Dis. 9, 1375-1380. doi: 10.3201/eid0911.030143

Trudler, D., Farfara, D., and Frenkel, D. (2010). Toll-like receptors expression and signaling in glia cells in neuro-amyloidogenic diseases: towards future therapeutic application. Mediators Inflamm. 2010:497987. doi: 10.1155/2010/497987

Turnbaugh, P. J., Hamady, M., Yatsunenko, T., Cantarel, B. L., Duncan, A., Ley, R. E., et al. (2009). A core gut microbiome in obese and lean twins. Nature 457, 480-484. doi: 10.1038/nature07540

Tynan, R. J., Naicker, S., Hinwood, M., Nalivaiko, E., Buller, K. M., Pow, D. V., et al. (2010). Chronic stress alters the density and morphology of microglia in a subset of stress-responsive brain regions. Brain Behav. Immun. 24, 1058-1068. doi: 10.1016/j.bbi.2010.02.001

Udina, M., Castellvi, P., Moreno-Espana, J., Navines, R., Valdes, M., Forns, X., et al. (2012). Interferon-induced depression in chronic hepatitis C: a systematic review and meta-analysis. J. Clin. Psychiatry 73, 1128-1138. doi: 10.4088/JCP.12r07694

Upthegrove, R., Manzanares-Teson, N., and Barnes, N. M. (2014). Cytokine function in medication-naive first episode psychosis: a systematic review and meta-analysis. Schizophr. Res. 155, 101-108. doi: 10.1016/j.schres.2014.03.005

Valkanova, V., Ebmeier, K. P., and Allan, C. L. (2013). CRP, IL-6 and depression: a systematic review and meta-analysis of longitudinal studies. J. Affect. Disord. 150, 736-744. doi: 10.1016/j.jad.2013.06.004

van Berckel, B. N., Bossong, M. G., Boellaard, R., Kloet, R., Schuitemaker, A., Caspers, E., et al. (2008). Microglia activation in recent-onset schizophrenia: a quantitative (R)-[11C]PK11195 positron emission tomography study. Biol. Psychiatry 64, 820-822. doi: 10.1016/j.biopsych.2008.04.025

van Os, J. (2016). "Schizophrenia" does not exist. BMJ 352, i375. doi: 10.1136/bmj.i375

van Steensel, F. J. A., Bögels, S. M., and Perrin, S. (2011). Anxiety disorders in children and adolescents with autistic spectrum disorders: a meta-analysis. Clin. Child Fam. Psychol. Rev. 14:302. doi: 10.1007/s10567-011-0097-0

Varese, F., Smeets, F., Drukker, M., Lieverse, R., Lataster, T., Viechtbauer, W., et al. (2012). Childhood adversities increase the risk of psychosis: a meta-analysis of patient-control, prospective- and cross-sectional cohort studies. Schizophr. Bull. 38, 661-671. doi: 10.1093/schbul/sbs050

Vassos, E., Pedersen, C. B., Murray, R. M., Collier, D. A., and Lewis, C. M. (2012). Meta-Analysis of the Association of Urbanicity With Schizophrenia. Schizophr. Bull. 38, 1118-1123. doi: 10.1093/schbul/sbs096

Vela, G., Stark, P., Socha, M., Sauer, A. K., Hagmeyer, S., and Grabrucker, A. M. (2015). Zinc in gut-brain interaction in autism and neurological disorders. Neural Plast. 2015:15. doi: 10.1155/2015/972791 
Vijay, N., and Morris, M. E. (2014). Role of monocarboxylate transporters in drug delivery to the brain. Curr. Pharm. Des. 20, 1487-1498. doi: $10.2174 / 13816128113199990462$

Voreades, N., Kozil, A., and Weir, T. L. (2014). Diet and the development of the human intestinal microbiome. Front. Microbiol. 5:494. doi: $10.3389 /$ fmicb. 2014.00494

Vorstman, J. A. S., Parr, J. R., Moreno-De-Luca, D., Anney, R. J. L., Nurnberger, J. I. Jr., and Hallmayer, J. F. (2017). Autism genetics: opportunities and challenges for clinical translation. Nat. Rev. Genet. 18, 362-376. doi: 10.1038/nrg.2017.4

Vuong, H. E., and Hsiao, E. Y. (2017). Emerging roles for the gut microbiome in autism spectrum disorder. Biol Psychiatry 81, 411-423. doi: 10.1016/j.biopsych.2016.08.024

Wang, L., Christophersen, C. T., Sorich, M. J., Gerber, J. P., Angley, M. T., and Conlon, M. A. (2011). Low relative abundances of the mucolytic bacterium Akkermansia muciniphila and Bifidobacterium spp. in feces of children with autism. Appl. Environ. Microbiol. 77, 6718-6721. doi: 10.1128/AEM.05212-11

Wang, L., Christophersen, C. T., Sorich, M. J., Gerber, J. P., Angley, M. T., and Conlon, M. A. (2012). Elevated fecal short chain fatty acid and ammonia concentrations in children with autism spectrum disorder. Dig. Dis. Sci. 57, 2096-2102. doi: 10.1007/s10620-012-2167-7

Wang, L., Christophersen, C. T., Sorich, M. J., Gerber, J. P., Angley, M. T., and Conlon, M. A. (2013). Increased abundance of Sutterella spp. and Ruminococcus torques in feces of children with autism spectrum disorder. Mol. Autism. 4:42. doi: 10.1186/2040-2392-4-42

Wang, S., and Adolphs, R. (2017). Reduced specificity in emotion judgment in people with autism spectrum disorder. Neuropsychologia 99, 286-295. doi: 10.1016/j.neuropsychologia.2017.03.024

Wang, S. X., and Wu, W. C. (2005). Effects of psychological stress on small intestinal motility and bacteria and mucosa in mice. World J. Gastroenterol. 11, 2016-2021. doi: 10.3748/wjg.v11.i13.2016

Whitaker-Azmitia, P. M. (2001). Serotonin and brain development: role in human developmental diseases. Brain Res. Bull. 56, 479-485. doi: 10.1016/S0361-9230(01)00615-3

WHO (2015). Statement on caesarean section rates. Reprod. Health Matt. 23, 149-150. doi: 10.1016/j.rhm.2015.07.007

Wikoff, W. R., Anfora, A. T., Liu, J., Schultz, P. G., Lesley, S. A., Peters, E. C., et al. (2009). Metabolomics analysis reveals large effects of gut microflora on mammalian blood metabolites. Proc. Natl. Acad. Sci. U.S.A. 106, 3698-3703. doi: $10.1073 /$ pnas.0812874106

Williams, B. L., Hornig, M., Buie, T., Bauman, M. L., Cho Paik, M., Wick, I., et al. (2011). Impaired carbohydrate digestion and transport and mucosal dysbiosis in the intestines of children with autism and gastrointestinal disturbances. PLoS ONE 6:e24585. doi: 10.1371/journal.pone.0024585

Williamson, L. L., McKenney, E. A., Holzknecht, Z. E., Belliveau, C., Rawls, J. F., Poulton, S., et al. (2015). Got worms? Perinatal exposure to helminths prevents persistent immune sensitization and cognitive dysfunction induced by early-life infection. Brain Behav. Immun. 51, 14-28. doi: 10.1016/j.bbi.2015. 07.006

Willsey, A. J., Sanders, S. J., Li, M., Dong, S., Tebbenkamp, A. T., Muhle, R. A., et al. (2013). Coexpression networks implicate human midfetal deep cortical projection neurons in the pathogenesis of autism. Cell 155, 997-1007. doi: $10.1016 /$ j.cell.2013.10.020

Wong, M. L., Inserra, A., Lewis, M. D., Mastronardi, C. A., Leong, L., Choo, J., et al. (2016). Inflammasome signaling affects anxiety- and depressivelike behavior and gut microbiome composition. Mol. Psychiatry 21, 797-805. doi: 10.1038/mp.2016.46

Xiao, J., Li, Y., Gressitt, K. L., He, H., Kannan, G., Schultz, T. L., et al. (2016). Cerebral complement $\mathrm{Clq}$ activation in chronic Toxoplasma infection. Brain Behav. Immun. 58, 52-56. doi: 10.1016/j.bbi.2016 04.009

Xu, M.-Q., Sun, W.-S., Liu, B.-X., Feng, G.-Y., Yu, L., Yang, L., et al. (2009). Prenatal malnutrition and adult schizophrenia: further evidence from the 1959-1961 chinese famine. Schizophr. Bull. 35, 568-576. doi: 10.1093/schbul/sbn168

Yano, J. M., Yu, K., Donaldson, G. P., Shastri, G. G., Ann, P., Ma, L., et al. (2015). Indigenous bacteria from the gut microbiota regulate host serotonin biosynthesis. Cell 161, 264-276. doi: 10.1016/j.cell.2015.02.047

Yasuda, H., Yoshida, K., Yasuda, Y., and Tsutsui, T. (2011). Infantile zinc deficiency: association with autism spectrum disorders. Sci. Rep. 1:129. doi: 10.1038/srep00129

Yolken, R. H., Severance, E. G., Sabunciyan, S., Gressitt, K. L., Chen, O., Stallings, C., et al. (2015). Metagenomic sequencing indicates that the oropharyngeal phageome of individuals with schizophrenia differs from that of controls. Schizophr. Bull. 41, 1153-1161. doi: 10.1093/schbul/sbu197

Yolken, R. H., and Torrey, E. F. (2008). Are some cases of psychosis caused by microbial agents? A review of the evidence. Mol Psychiatry 13, 470-479. doi: $10.1038 / \mathrm{mp} .2008 .5$

Yorbik, Ö., Akay, C., Sayal, A., Cansever, A., Söhmen, T., and O. Çavdar, A. (2004). Zinc status in autistic children. J. Trace Elements Exp. Med. 17, 101-107. doi: 10.1002/jtra.20002

Yu, M., Jia, H., Zhou, C., Yang, Y., Zhao, Y., Yang, M., et al. (2017). Variations in gut microbiota and fecal metabolic phenotype associated with depression by $16 \mathrm{~S}$ rRNA gene sequencing and LC/MS-based metabolomics. J. Pharm. Biomed. Anal. 138, 231-239. doi: 10.1016/j.jpba.2017.02.008

Yuen, R. K. C., Merico, D., Bookman, M., Howe, J. L., Thiruvahindrapuram, B., Patel, R. V., et al. (2017). Whole genome sequencing resource identifies 18 new candidate genes for autism spectrum disorder. Nat. Neurosci. 20, 602-611. doi: $10.1038 / \mathrm{nn} .4524$

Zackular, J. P., Moore, J. L., Jordan, A. T., Juttukonda, L. J., Noto, M. J., Nicholson, M. R., et al. (2016). Dietary zinc alters the microbiota and decreases resistance to clostridium difficile infection. Nat. Med. 22, 1330-1334. doi: 10.1038/nm.4174

Zheng, P., Zeng, B., Zhou, C., Liu, M., Fang, Z., Xu, X., et al. (2016). Gut microbiome remodeling induces depressive-like behaviors through a pathway mediated by the host's metabolism. Mol. Psychiatry. 21, 786-796 doi: $10.1038 / \mathrm{mp} .2016 .44$

Zhernakova, A., Kurilshikov, A., Bonder, M. J., Tigchelaar, E. F., Schirmer, M., Vatanen, T., et al. (2016). Population-based metagenomics analysis reveals markers for gut microbiome composition and diversity. Science 352, 565-569. doi: 10.1126/science.aad3369

Zijlmans, M. A. C., Korpela, K., Riksen-Walraven, J. M., de Vos, W. M. and de Weerth, C. (2015). Maternal prenatal stress is associated with the infant intestinal microbiota. Psychoneuroendocrinology 53, 233-245. doi: 10.1016/j.psyneuen.2015.01.006

Zilber-Rosenberg, I., and Rosenberg, E. (2008). Role of microorganisms in the evolution of animals and plants: the hologenome theory of evolution. FEMS Microbiol. Rev. 32, 723-735. doi: 10.1111/j.1574-6976.2008.00123.x

Conflict of Interest Statement: The authors declare that the research was conducted in the absence of any commercial or financial relationships that could be construed as a potential conflict of interest.

Copyright (c) 2017 Kelly, Minuto, Cryan, Clarke and Dinan. This is an open-access article distributed under the terms of the Creative Commons Attribution License (CC $B Y)$. The use, distribution or reproduction in other forums is permitted, provided the original author(s) or licensor are credited and that the original publication in this journal is cited, in accordance with accepted academic practice. No use, distribution or reproduction is permitted which does not comply with these terms. 